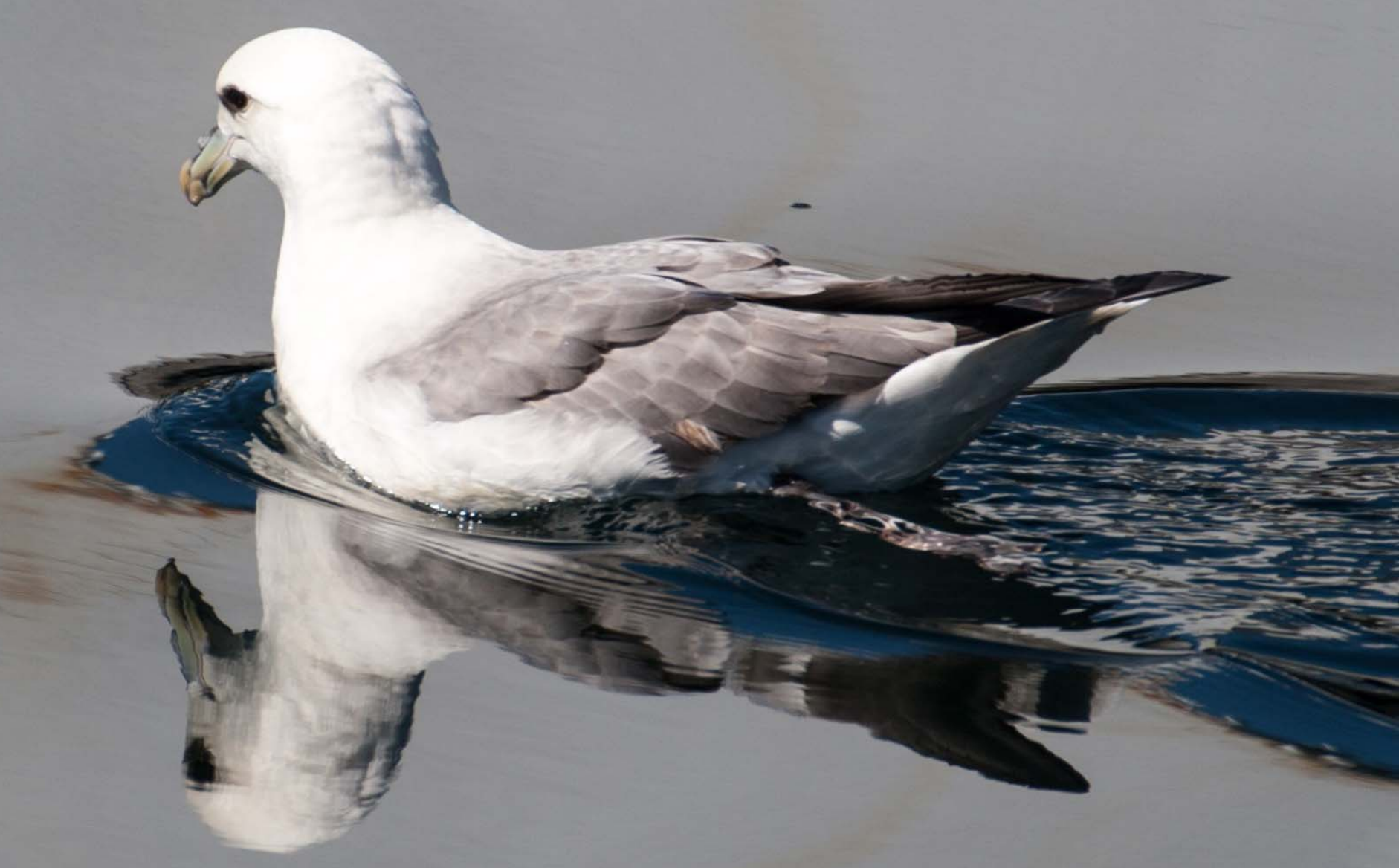

\title{
Fulmar Litter EcoQO monitoring in the Netherlands - Update 2016
}

Den Helder, September 2017 


\title{
Citation:
}

Van Franeker, J.A., Kühn, S. \& Meijboom, A. (2017)

Fulmar Litter EcoQO monitoring in the Netherlands - Update 2016.

Wageningen Marine Research report c053/17 \& RWS Centrale Informatievoorziening BM 17.23

\section{Keywords:}

OSPAR-ECoQO; MSFD-GES; KRM-GMT; Fulmarus glacialis; monitoring; marine litter; plastic ingestion

\author{
Wageningen Offerte $\mathrm{nr} \quad$ 15.43.128 \\ Marine Research project nr: 4312100031 \\ references: $\quad$ project name: Fulmar-EcoQO-NL2015-19 \\ contact: Dr. Jan Andries van Franeker, \\ Wageningen Marine Research \\ Ankerpark 27, 1781 AG Den Helder, The Netherlands \\ E: jan.vanfraneker@wur.nl T: +31 317487085
}

Client: $\quad$ Ministry of Infrastructure and the Environment (I\&M)

RWS Water, Traffic and Living Environment (RWS-WVL)

RWS-CIV, PO Box 556, 3000 AN Rotterdam, The Netherlands

contact: Dhr. Mervyn Roos 06-12218134 mervyn.roos@rws.nl

RWS bestelnr $\quad 4500246263$

RWS zaaknr 31113529

Opdrachtbrief RWS-2016/1093 dated 12 Jan 2016

Title at RWS: $\quad$ "Monitoring plastics in magen van Noordse stormvogels van de Nederlandse Noordzeekust update 2015 t/m 2019"

This report can be downloaded for free from https:// doi.org/10.18174/423968

Wageningen Marine Research provides no printed copies of reports

Wageningen Marine Research is ISO 9001: 2008 certified.

Photo cover: Northern Fulmar searching for food (Faroe Islands)

photo by Jan van Franeker (all photos in this report by the first author)

\section{(C) 2017 Wageningen Marine Research Wageningen UR}

Wageningen Marine Research institute of Stichting Wageningen Research is registered in the Dutch traderecord nr. 09098104, BTW nr. NL 806511618
The Management of Wageningen Marine Research is not responsible for resulting damage, as well as for damage resulting from the application of results or research obtained by Wageningen Marine Research, its clients or any claims related to the application of information found within its research. This report has been made on the request of the client and is wholly the client's property. This report may not be reproduced and/or published partially or in its entirety without the express written consent of the client. 


\section{Contents}

$\begin{array}{ll}\text { Summary Report } & \mathbf{5}\end{array}$

$\begin{array}{llr}1 & \text { Introduction } & 13\end{array}$

$2 \quad$ Marine litter and policy measures $\quad 15$

$3 \quad$ The Fulmar as an ecological monitor of marine litter $\quad 17$

$4 \quad$ Materials and Methods $\quad 21$

$5 \quad$ Results \& Discussion $\quad 29$

5.1 The year $2016 \quad 29$

$\begin{array}{lll}5.2 & \text { Current levels for the Netherlands (2012-2016) } & 30\end{array}$

$\begin{array}{lll}5.3 \text { Trends } & 36\end{array}$

5.3.1 long-term trends $\quad 36$

5.3.2 Recent trends $\quad 36$

$\begin{array}{lll}5.4 & \text { Dutch data in terms of the OSPAR EcoQO metric } & 39\end{array}$

$\begin{array}{lll}5.5 & \text { Concluding remarks } & 40\end{array}$

$6 \quad$ Acknowledgements $\quad 42$

$\begin{array}{llr}7 & \text { References } & 43\end{array}$

$\begin{array}{lr}\text { Quality Assurance } & 51\end{array}$

$\begin{array}{lr}\text { J ustification } & 51\end{array}$ 


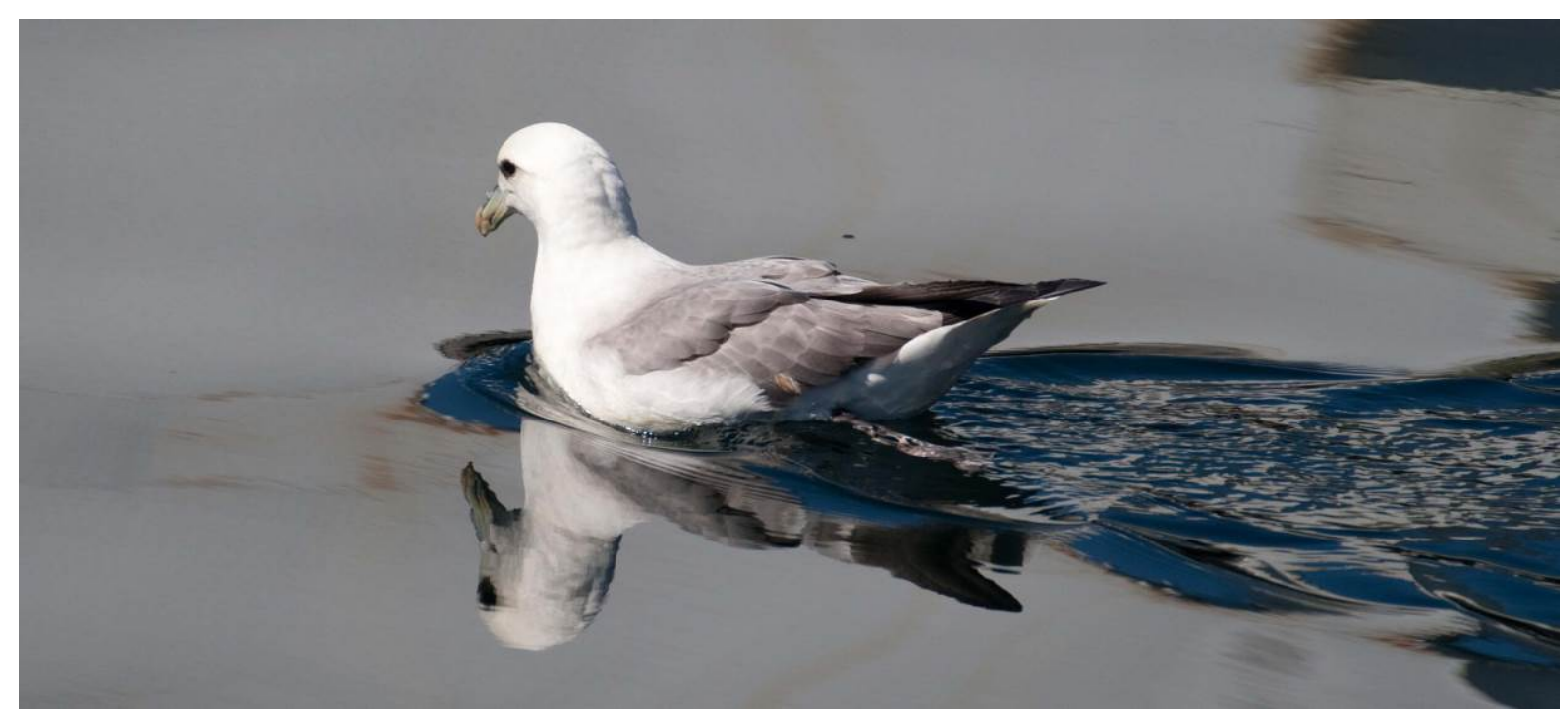

Photo Seabirds mirror the environmental conditions in their marine habitat. Plastics in stomach contents of Northern Fulmars reflect the levels of marine litter in their oceanic foraging areas. As such, they can be used as indicators of ecosystem quality in European policy. (front page photo: Fulmar searching for food at the Faroe Islands) 


\section{Summary Report}

\section{Fulmar Litter EcoQO monitoring in the Netherlands - Update 2016}

Marine debris has serious economic and ecological consequences. Economic impacts are most severe for coastal communities, tourism, shipping and fisheries. Marine wildlife suffers from entanglement and ingestion of debris, with microparticles potentially affecting marine food chains up to the level of human consumers. In the North Sea, marine litter problems were firmly recognized in 2002 when surrounding states assigned to OSPAR the task to include marine plastic litter in its system of Ecological Quality Objectives (EcoQOs) (North Sea Ministerial Conference 2002). At that time, in the Netherlands, marine litter was already monitored by the abundance of plastic debris in stomachs of a seabird species, the Northern Fulmar (Fulmarus glacialis).

Fulmars are purely offshore foragers that ingest all sorts of litter from the sea surface and do not regurgitate poorly degradable diet components like plastics. I nitial size of ingested debris is usually in the range of millimetres to centimetres, but may be considerably larger for flexible items as for instance threadlike or sheetlike materials. I tems must gradually wear down in the muscular stomach to a size small enough for passage to the intestines. During this process, plastics accumulate in the stomach to a level that integrates litter levels encountered in their foraging area for a period of probably up to a few weeks. The Dutch monitoring approach using beached fulmars was developed for international implementation by OSPAR as one of its EcoQOs for the North Sea (OSPAR 2008, 2009, 2010a,b; Van Franeker et al. 2011). This approach is now also implemented as an indicator for 'Good Environmental Status (GES)' in the Marine Strategy Framework Directive (MSFD) (EC 2008, 2010; Galgani et al. 2010; MSFD-TSML 2011, 2013). International guidelines on the monitoring methods and data presentation have been published (OSPAR 2015a,b) which were implemented in the recent 'Intermediate Assessment' (OSPAR 2017).

OSPAR has identified a long term (undated) target for acceptable ecological quality as:

“There should be less than $10 \%$ of Northern Fulmars (Fulmarus glacialis) having 0.1 gram or more plastic in the stomach in samples of 50-100 beached fulmars from each of 5 different areas of the North Sea over a period of at least 5 years".

The European MSFD aims for Good Environmental Status by the year 2020 and defines GES for marine litter as the situation in which

"properties and quantities of marine litter do not cause harm to the coastal and marine environment"

The concept of 'no harm' and setting related short term targets is a complicated issue (Rochman et al. 2016; Werner et al. 2017). Different countries may define a MSFD target for ingested plastics differently, but there is a tendency to adhere to the OSPAR long term target, with on the short term a requirement for change or significant change towards that target by 2020. For European marine areas where fulmars do not occur, other species are needed as ingestion indicators, for which methodology and targets are being developed (e.g. Matiddi et al. 2017).

The monitoring system uses fulmars found dead on beaches, or accidentally killed as e.g. fisheries bycatch. In a pilot study it has been shown that the amount of plastic in stomachs of slowly starved beached birds was not statistically different from that of healthy birds killed in instantaneous accidents in the same area. Standard procedures for dissection and stomach analyses have been documented in a manual, reports, scientific literature and condensed OSPAR guidelines. Different categories of plastic are recorded, with as major types the industrial plastics (the raw granular feedstock for producers) as opposed to user plastics (from all sorts of consumer waste).

Information on abundance of plastics in fulmars may be expressed in different ways, such as by:

$>$ Incidence or prevalence - The percentage of birds having plastic in the stomach (\% frequency of occurrence $=\% \mathrm{FO}$ ), irrespective of the quantity of plastic. 
> Average $\pm \mathbf{s e}$ - Averages refer to straightforward arithmetic averages, with standard errors, for either number of particles or mass of plastic for all birds in a sample, including the ones without any plastic ('population average').

$>$ Geometric mean - Geometric means of plastic mass are calculated using data transformation (natural logarithm) to reduce influence of extreme outliers and to facilitate comparison between smaller samples. To include zero values in the geometric means, the transformation includes addition of $1 \mathrm{mg}$ to each sample, later corrected for in back-calculation. In part of our data-tables and graphs we have added median values for comparison.

$>$ EcoQO performance - The percentage of birds having more than 0.1 gram of plastic in the stomach (again including zero values), allowing direct comparison to the long term OSPAR target, which aims at having less than $10 \%$ of such birds.

> State assessment data pooling - Data are frequently pooled over 5 year periods to have a focus on reliable averages and consistent trends rather than on incidental short term fluctuations. The 5 year data are not derived from annual averages or means, but are based on individual data from all birds sampled in these five years. Graphs often represent pooled data for 5 years, but shift one year by datapoint, i.e. running averages. Subsequent data points in the graph thus overlap for 4 years of data, and are only intended to visually illustrate trends over time or geographic patterns and have no statistical meaning.

$>$ Trend analysis statistics - Statistical analyses investigating time related trends or regional differences are based on the mass of plastic. Tests for significance of trends over time are based on linear regressions of log-transformed data for the mass of plastics in individual birds against year of collection. A distinction is made between the 'long-term trend' over all years in the dataset (now 1979-2016 for the Netherlands) and the 'recent trend', which is defined as the trend over the past 10 years (now 2007-2016).

\section{The $\mathbf{2 0 1 6}$ update of monitoring data for the Netherlands}

This report adds new data for year 2016 to earlier updates (Van Franeker et al. 2016). The sample size of 30 stomachs of Dutch beached fulmar corpses was an improvement to two earlier years, but was still below the desired annual sample. Our program aims for an annual sample size of \pm 40 birds or more. A smaller annual sample is not a problem for the monitoring system, as the 'current' situation is calculated from 5 years of data ( 169 birds) and trend analyses use a minimum of 10 years of data (374 birds). Annual data and the most recent pooled 5-year details are summarized in Table i. In 2016, the within year results comply well with the longer 5-year pooled data. However, since this is not always the case, it is nevertheless recommended to use the 2012-2016 data to describe the current situation.

Table i Data summary for study year added to the existing monitoring series (the table presents year or period of sampling with sample size $(n)$, and for each of main plastic categories and total plastic: the incidence $(\%)$, the average number of particles $(n)$ and the associated average mass per bird in gram $(\mathrm{g})$. The final column gives EcoQO performance, that is the percentage of birds that exceeds $0.1 \mathrm{~g}$ of plastic mass in the stomach.

\begin{tabular}{cc} 
Year & $n$ \\
\hline $\begin{array}{c}\text { 2016 } \\
\text { period }\end{array}$ & 30 \\
\hline $2012-16$ & 169
\end{tabular}

\begin{tabular}{ccc}
\multicolumn{3}{c}{$\begin{array}{c}\text { INDUSTRIAL } \\
\text { PLASTICS }\end{array}$} \\
\hline$\%$ & $\mathrm{n}$ & $\mathbf{g}$ \\
\hline $47 \%$ & 2.0 & $\mathbf{0 . 0 4}$ \\
& & \\
\hline $57 \%$ & 1.8 & $\mathbf{0 . 0 4}$
\end{tabular}

\begin{tabular}{ccc}
\multicolumn{3}{c}{ USER } \\
\multicolumn{3}{c}{ PLASTICS } \\
\hline$\%$ & $\mathrm{n}$ & $\mathbf{g}$ \\
\hline $87 \%$ & 29.5 & $\mathbf{0 . 2 5}$ \\
\hline $90 \%$ & 20.5 & $\mathbf{0 . 2 4}$
\end{tabular}

\begin{tabular}{|c|c|c|c|}
\hline \multicolumn{3}{|c|}{$\begin{array}{l}\text { ALL PLASTICS } \\
\text { (ind+user) }\end{array}$} & \multirow[b]{2}{*}{ EcoQO } \\
\hline$\%$ & $\mathrm{n}$ & g & \\
\hline $87 \%$ & 31.5 & 0.30 & $50 \%$ \\
\hline $91 \%$ & 22.3 & 0.28 & $50 \%$ \\
\hline
\end{tabular}

\section{Current situation in plastic ingestion by fulmars in the Netherlands}

Current data for the Netherlands (years 2012 to 2016; 169 fulmars, Table i) are that 91\% of beached fulmars had plastic in the stomach. The average number of items per stomach was 22.3 particles with a mass of $0.28 \mathrm{gram}$. The critical EcoQO value of 0.1 gram plastic was exceeded by $50 \%$ of the birds. Although still far off the long term OSPAR target, these data are the best on record throughout the history of fulmar monitoring in the Netherlands. 


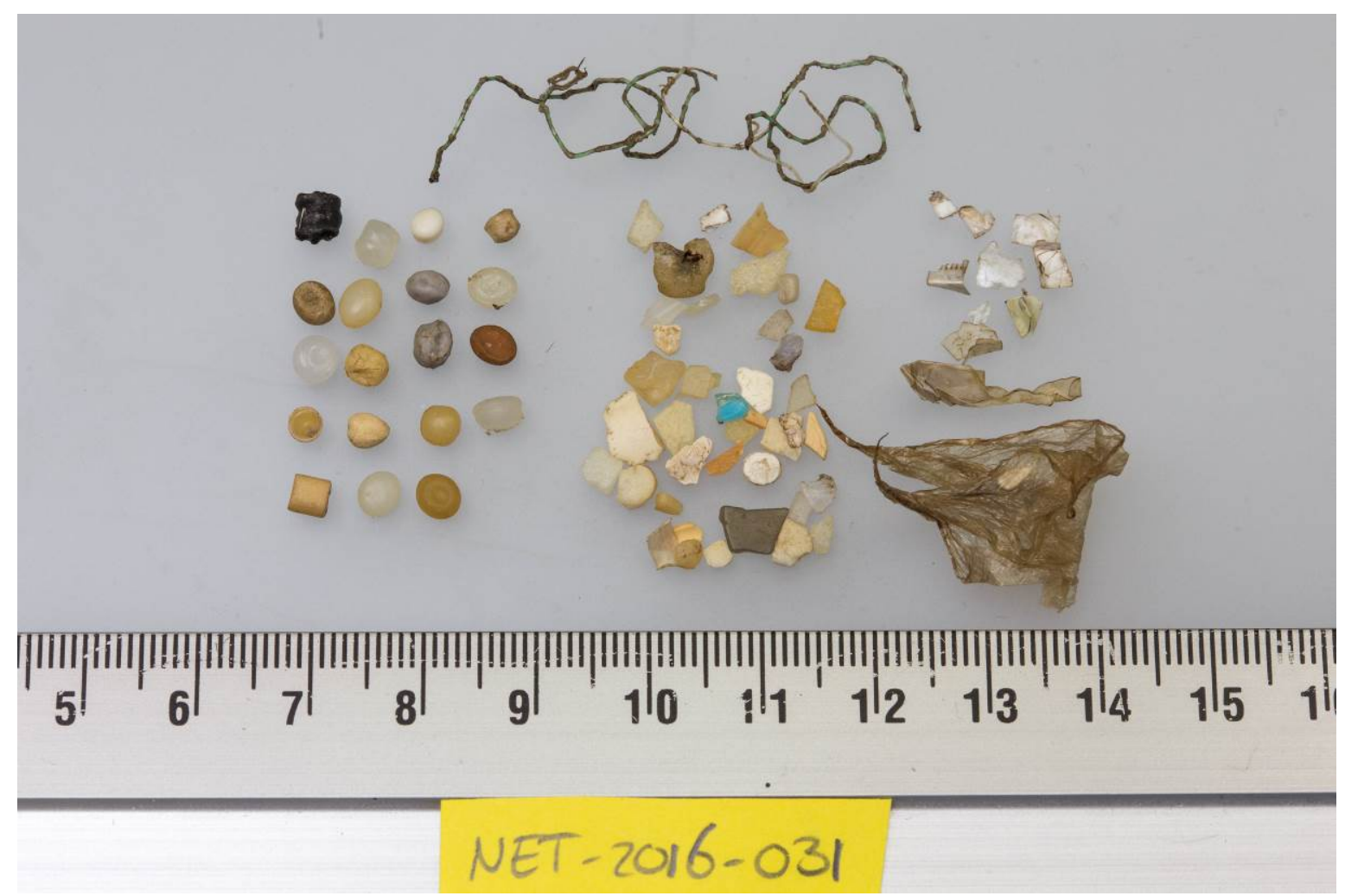

Photo: Fulmar stomach content NET-2016-031 On average, present day beached fulmars have only about 2 industrial plastic pellets in their stomach, and approximately five times as much mass of plastic consumer debris (Table i). Stomach contents are highly variable and the photo shows the stomach content of a fulmar that had ingested 19 pellets (left) and a broad range of threads (top), foams (right), sheets (lower right) and fragments (centre) of plastic. Mass of plastic in this sample was $0.7303 \mathrm{~g}$, roughly 2.5 times the recent 5 -year average.

\section{Long-term trend 1979-2016}

Long term trends for EcoQO performance in the Netherlands are visualized in Figure i and for average mass in Figure ii. Both graphs show data as running 5-year averages (periods with 10 or less birds in

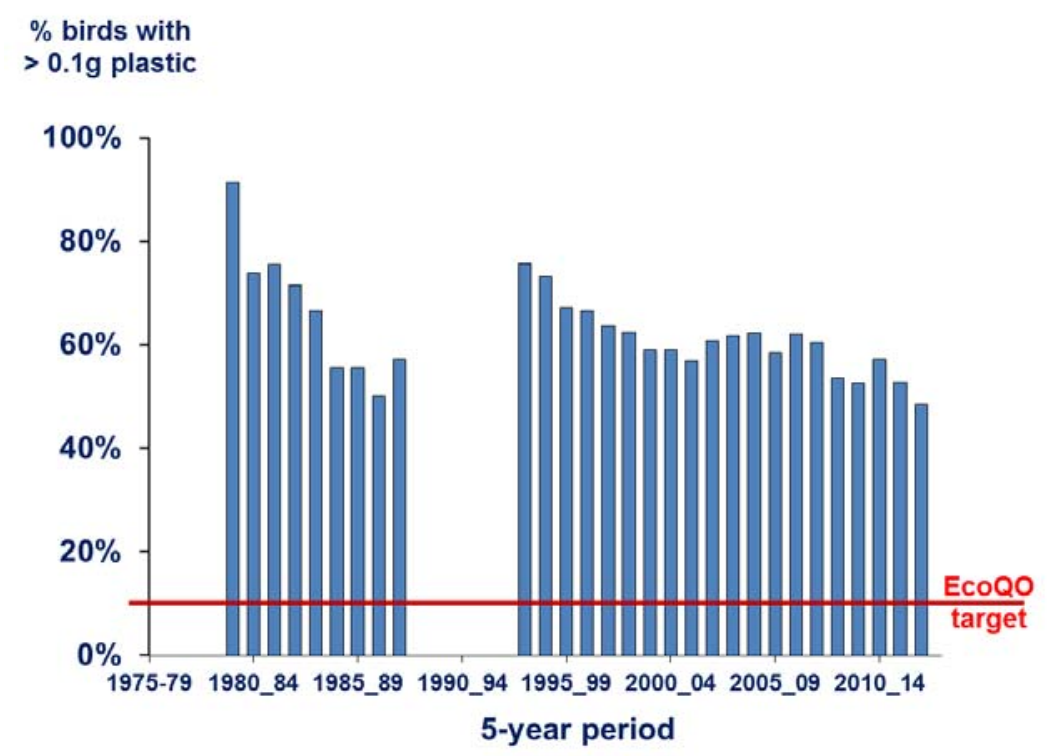

the sample are not shown).

The main message from the EcoQO graph is that throughout our period of observation, ecological quality has not been in compliance with the OSPAR EcoQO target. The EcoQO performance over 5-year periods has varied between $48 \%$ and $91 \%$, whereas the target is that it should go below $10 \%$. The most recent average of $48 \%$ of fulmars exceeding the 0.1 gram threshold is an improvement compared to the previous 5year periods and the best on the long term record.

Figure i EcoQO performance among fulmars from the Netherlands 1979-2016. Data are shown by annually updated 5 year performances (i.e. data points shift one year ahead at a time). Data for early 1990s are not included because of small sample size $(<=10)$. This graphic visualization does not represent a statistical trend analysis. 

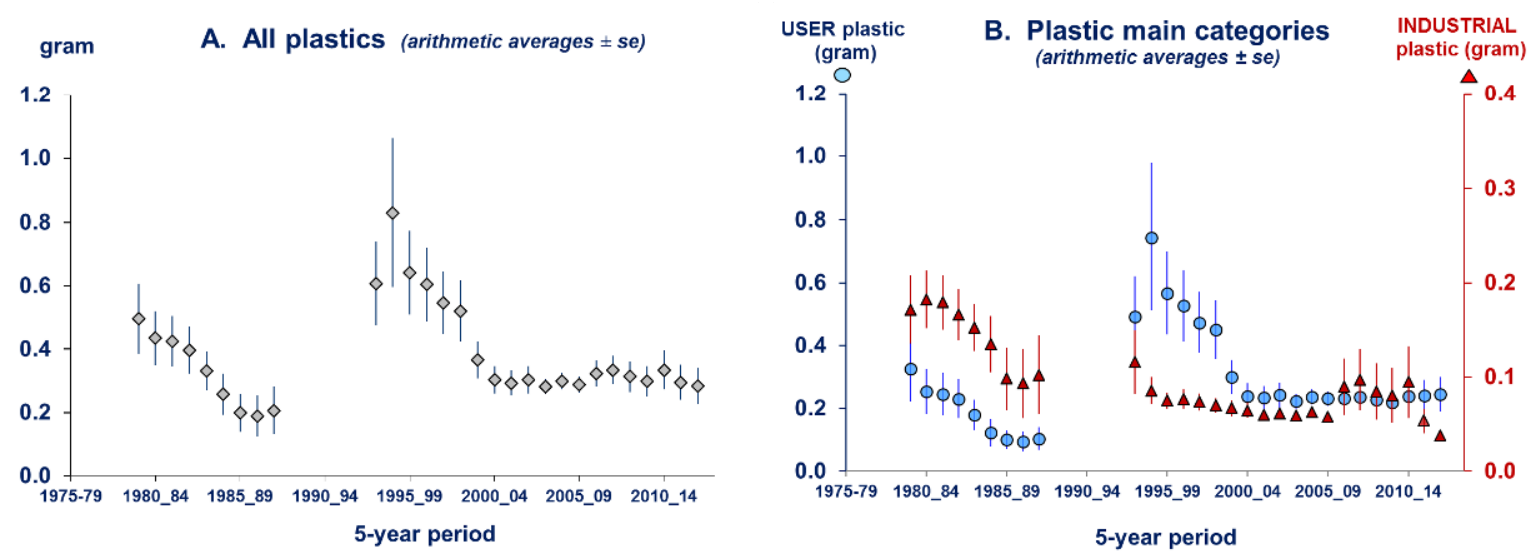

Figure ii Plastic mass in stomachs of fulmars from the Netherlands 1979-2016 A: all plastics combined (grey diamonds) and B: user plastic (blue circles, left y-axis) and industrial plastic (red triangles, right $y$-axis). Data are shown by arithmetic average \pm standard error for mass for running 5 year averages (i.e. data points shift one year ahead at a time) where sample size was over 10 birds. These graphic visualizations do not represent a statistical trend analysis.

The graphs on average mass of plastics (Figure ii) show some more detail of changes. During the 1980 s, there was a tendency for decreasing amounts of plastic (total plastic 1979-1989, n=70 $p=0.034$; similar trend in industrial and user plastic subcategories, but separately not significant). However, a sharp increase was seen towards the mid-1990s, which was completely due to increased user plastic debris. This peak for the mid-1990s was followed by a period of rapid reduction in ingested plastic mass until the early 2000s, but after that, the situation appeared more or less stable. The current level for all plastics combined (Figure ii A) is similar to the average situation in the 1980s, but (Figure ii B) shows that developments for industrial plastics have been very different than for consumer waste. User plastics were the main factor for the rise and fall seen in total plastics, but industrial granules approximately halved from the 1980s to mid-1990s and next tended to a very slow continued decrease except for slight aberrations caused by exceptional outliers (5-year data for average mass of industrial plastic around 2010 and 2011 were influenced by just 2 birds that had an exceptionally large number of industrial granules in the stomach).

In the EcoQO approach, statistical tests for trends only consider patterns of linear change in mass of ingested plastic. Over the long term, the rise and fall in overall plastics and user plastics before and after the mid-1990s in Figure ii is therefore not visible in trends illustrated in Figure iii A. and Table ii A. User plastics appear virtually stable over the long term linear analysis. Industrial plastics on the other hand have strongly decreased since the early 1980s, resulting in a persistent strongly significant long-term reduction $(\mathrm{p}<0.001)$. As a consequence of this mix of long-term trends, the composition of plastic litter has changed remarkably since the early 1980s, with nowadays a reduced proportion of industrial plastics (from about $50 \%$ to circa $20 \%$ of total plastic mass) and an increased proportional mass of user plastics. The decrease in industrial plastics in the North Sea has also been observed in the North Pacific and both North and South Atlantic oceans. Due to the long term decrease in industrial plastics, also the long term trend for total plastic is significantly downwards $(p=0.006)$.

\section{Recent 10-year trends 2007-2016}

Long term trends are less useful to evaluate the effects of more recent policies and public behaviour towards marine littering. The EcoQO approach therefor evaluates trends over the most recent 10 years in the dataset. The current 10 year change (Table ii B; Figure iii B) continues to be hopeful for an improving environmental situation. Following years of insignificant changes, the previous report (2006-2015) for the first time indicated a statistically significant reduction for mass of industrial- and user plastics. The current figure for industrial plastics indicates continued reduction, but is just not significant $(p=0.054)$. However, user plastics $(p=0.040)$ and the combination of industrial and user plastics (also $p=0.040$ ) all provide evidence for of continued slow but statistically significant improvement in environmental quality (Table ii B). The role of reduced abundance of user plastics in the recent trend represents a very important difference with the long term trend which was dominated by industrial plastics. 
Table ii Linear regression analysis of trends in plastic ingestion in Dutch fulmars for (A) longterm and (B) recent 10-year data series. Trends in plastic mass evaluated by In- transformed individual mass values against year. EcoQO performance by simple numerical score for above or below the 0.1 gram threshold level ( 0 below; 1 above).

A.

LONG TERM TRENDS 1979-2016

for plastics in Fulmar stomachs, the Netherlands

\begin{tabular}{lcrrrrrr} 
& $\boldsymbol{n}$ & constant & slope & s.e. & t & p & \\
\cline { 2 - 7 } Industrial plastics (InGIND) & 1064 & 88.0 & -0.0461 & 0.0092 & -4.99 & $<.001$ & $--\downarrow$ \\
User plastics (InGUSE) & 1064 & -0.4 & -0.0011 & 0.0080 & -0.14 & 0.889 & n.s. \\
All plastics combined (InGPLA) & 1064 & 41.2 & -0.0217 & 0.0078 & -2.78 & 0.006 & $--\downarrow$
\end{tabular}

B.

RECENT 10-YEAR TRENDS 2007-2016

for plastics in Fulmar stomachs, the Netherlands

\begin{tabular}{lcrrrrrr} 
& $\boldsymbol{n}$ & constant & slope & s.e. & t & p & \\
\hline Industrial plastics (InGIND) & 374 & 151.9 & -0.0778 & 0.0402 & -1.94 & 0.054 & n.s. $\downarrow$ \\
User plastics (InGUSE) & 374 & 144.6 & -0.0732 & 0.0355 & -2.06 & 0.040 & $-\downarrow$ \\
All plastics combined (InGPLA) & 374 & 144.1 & -0.0728 & 0.0353 & -2.07 & 0.040 & $-\downarrow$
\end{tabular}
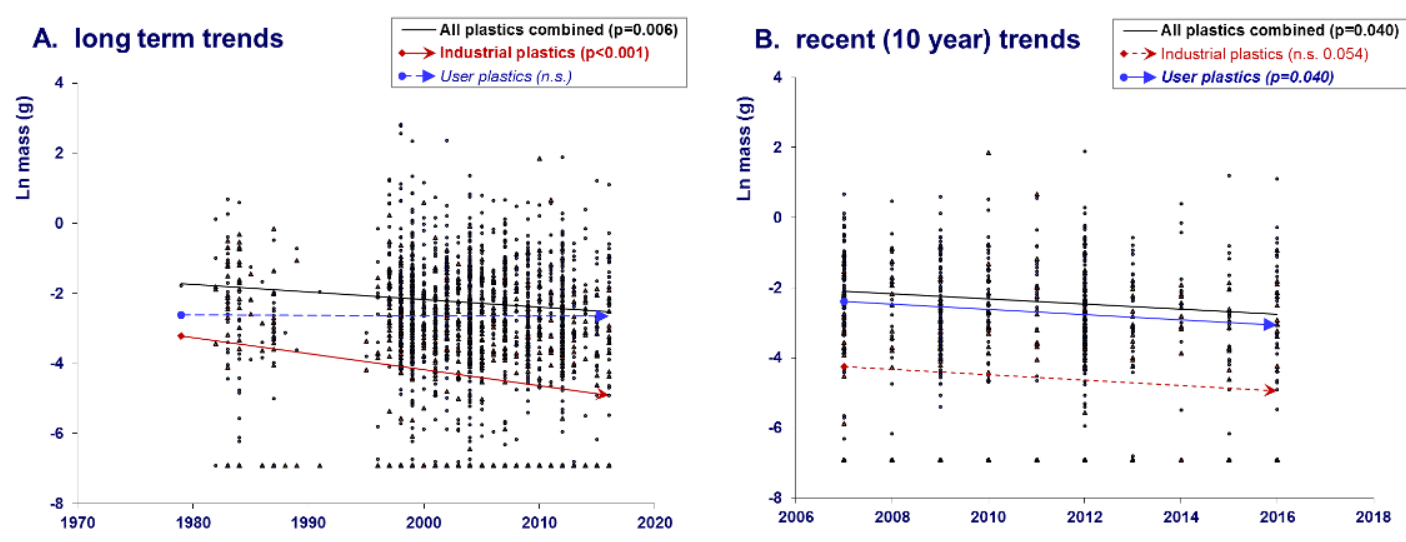

Figure iii Trends in plastic mass in stomachs of fulmars from the Netherlands 1979-2016 for (A) long-term and (B) recent 10-year data series. Graphs show In transformed mass data for industrial plastic and user plastic in stomachs of individual fulmars, plotted against year, and linear trendlines for industrial (lower, red line), user (middle blue line) and total plastics (top black line). n.s. means that the test result is not significant.

Trend analyses may be used to predict future developments in relation to e.g. a policy relevant estimate when average mass of plastic would be expected to go below a specific level, or when the EcoQO target may be reached.

It is difficult to pinpoint specific events that from the 1980s to the 1990s triggered the strong increase in consumer plastics and simultaneous decrease in industrial plastics, nor can we identify a clear background for the subsequent rapid decrease in user debris. In reports up to 2014 no further significant changes were observed in the fulmar monitoring approach since the early 2000s, but now for two subsequent reporting periods, statistically significant improvement can be demonstrated. High media attention raised for the 'Pacific garbage patch' and 'plastic soup' since the early 2000s has likely contributed to increased awareness, with associated policies and actions by authorities, industry and general public gradually taking effect. Developments are underway for implementation of the European Marine Strategy Directive (2008/56/EC) and its requirements towards Good Environmental Status (e.g. OSPAR 2014).

To evaluate the changes observed so far, the slow reduction in the ingested quantities of plastics in fulmar stomachs may be viewed in the light of strong and continuing increases in shipping traffic and the proportion of plastics in wastes. Figure iv visualizes increased shipping in the southern North Sea 
by annual freight handled in the Port of Rotterdam. About $40 \%$ of produced plastics are used for single use packaging, which means that global plastic production can be used to visualise increased proportion of plastics in waste-streams if improper handling of waste, i.e. loss to the environment, had remained unaltered. Other indicators for marine and landbased activities representing risks for plastic pollution of the North Sea, could be added. In that broader perspective, the observed slow reduction in quantities of plastics ingested by fulmars gains in significance.

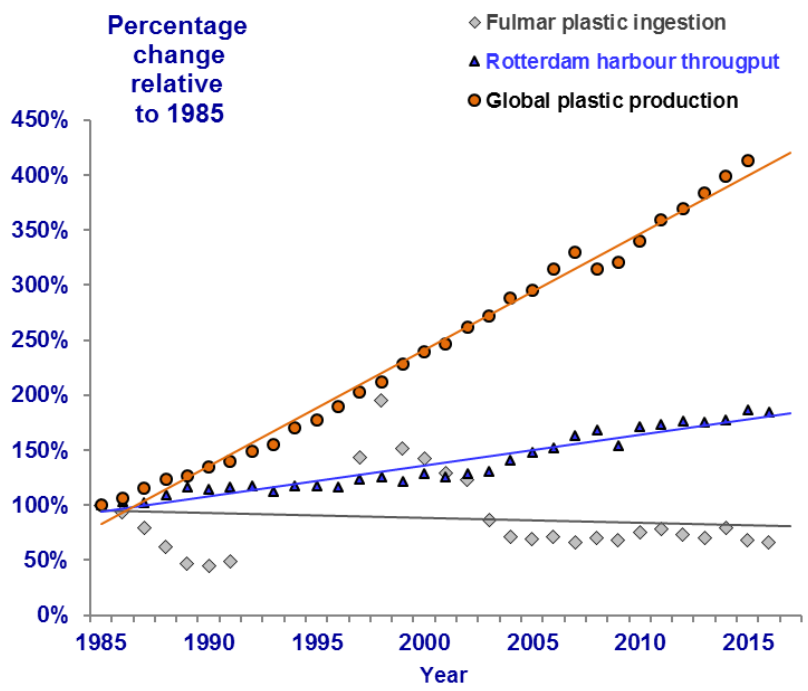

Figure iv Comparative trends in global plastic production, freight quantities handled by Port of Rotterdam, and mass quantities of plastics in stomachs of fulmars (5-year arithmetic averages). Shown are cumulative percentage changes from reference year 1985. (Sources: Port of Rotterdam, 2017; PlasticsEurope 2016; this report)

\section{CONCLUSIONS}

1. Over the period 2012-2016, among 169 fulmars beached in the Netherlands, $91 \%$ contained plastic, on average 22.3 particles per stomach, weighing 0.28 gram. In this sample, $50 \%$ of the birds had more than 0.1 gram plastic in the stomach whereas North Sea governments aim at a long term OSPAR Ecological Quality Objective (EcoQO) of less than $10 \%$ of such birds.

2. Trend analyses over the past ten years (2007-2016) confirm a modest, but statistically significant decrease in mass of ingested plastics in stomachs of fulmars beached in the Netherlands. Importantly, consumer debris significantly contributes to this trend.

3. It is not possible to pinpoint a single clear cause for the observed change. Increased awareness among all stake-holders may lead to gradually improved policy measures and implementation by marine industries and general public. 


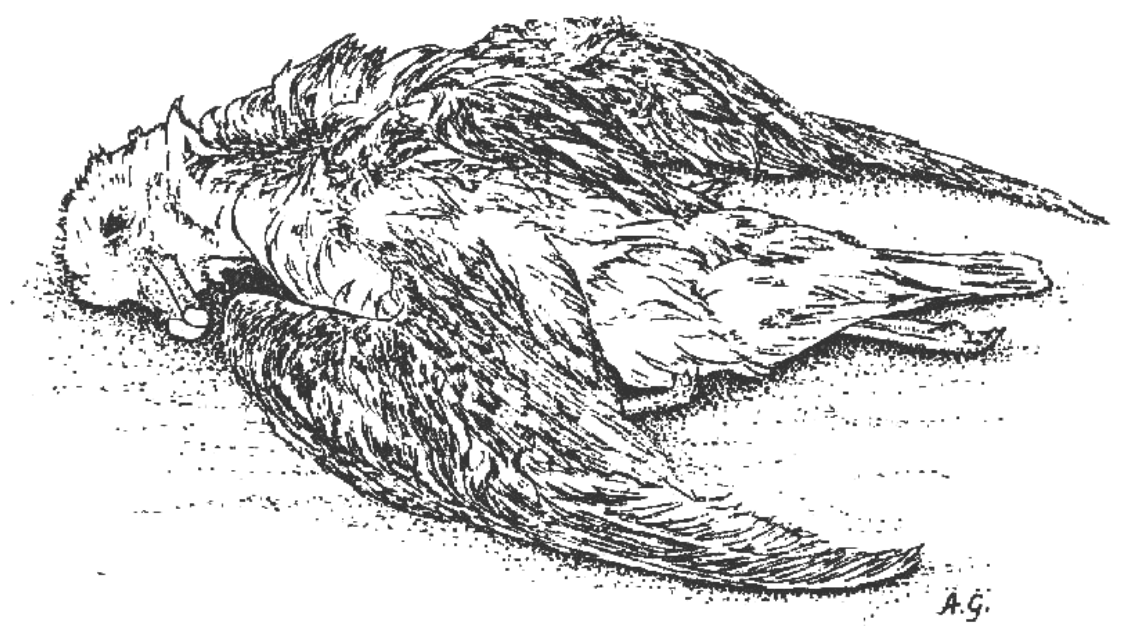

Beached fulmar (line-drawing by Arnold Gronert) 


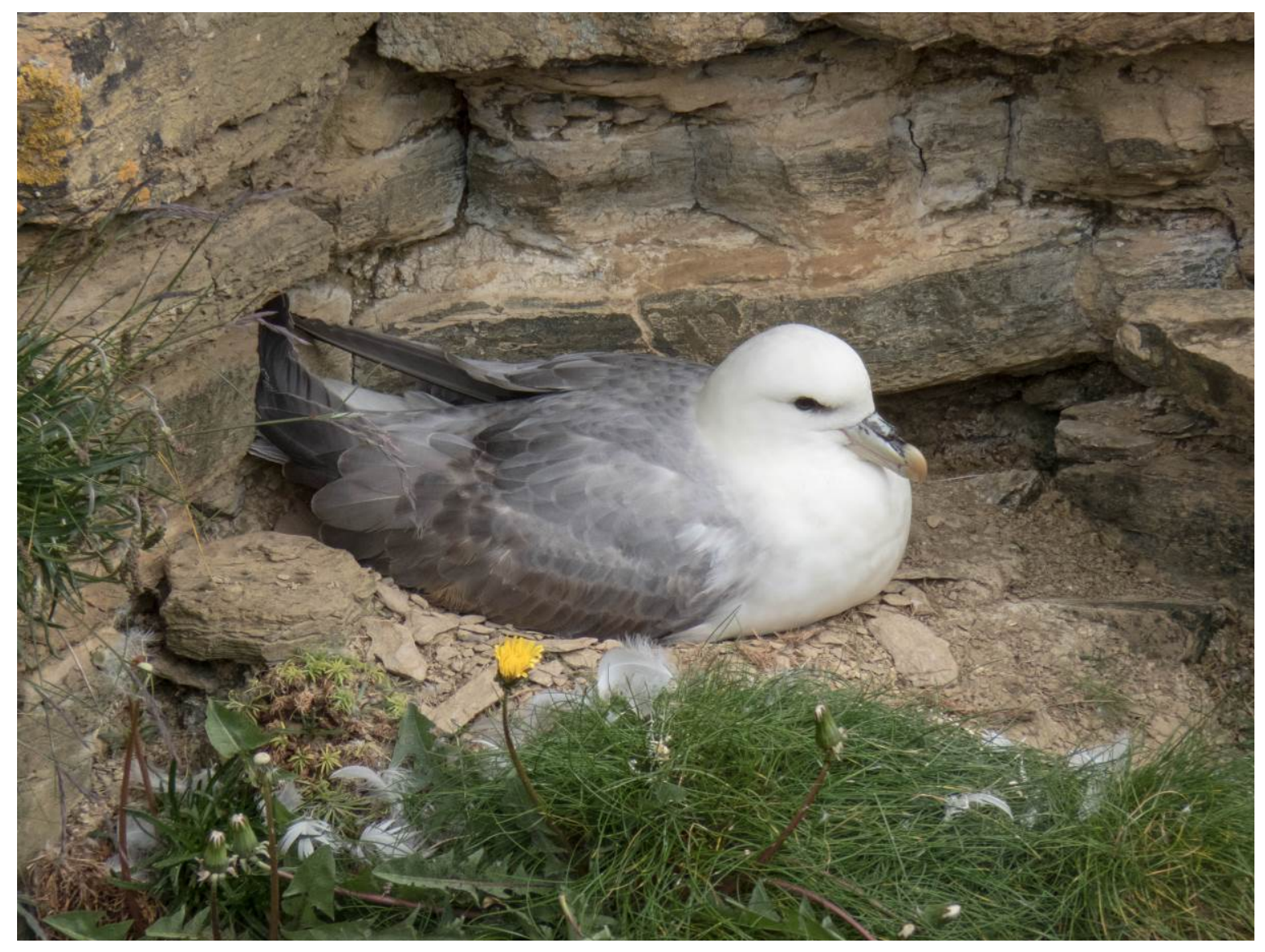

Photo: Northern Fulmar incubating its egg on cliffs of the Orkney I slands. In most situations, the impact from ingested plastics will not be directly lethal to individual fulmars. However, sublethal effects such as from potentially reduced fat reserves, or chemicals stored in fat may play a role in breeding success and survival in periods of high energy requirements, such as during multi-day incubation shifts. Since nearly every fulmar ingests plastics, such sublethal effects affect the whole population. 


\section{Introduction}

Marine litter, in particular plastic waste, represents an environmental problem in the North Sea and elsewhere, with considerable economic and ecological consequences. In 2005, a large study along the full $30 \mathrm{~km}$ coast length of the island of Texel revealed that each day, on each $\mathrm{km}$ of beach, 7 to $8 \mathrm{~kg}$ of debris washed ashore (Van Franeker 2005). Roughly half of the debris was wood, the other half was synthetic materials, with minor contributions from other materials such as glass and metals. On Texel, the main source of the debris, estimated at up to $90 \%$ of mass, was related to activities at sea, i.e. shipping, fisheries, aquaculture and offshore industries.

The economic consequences of marine litter affect many stakeholders. Coastal municipalities are confronted with excessive costs for beach clean-ups. Tourism suffers damage because visitors avoid polluted beaches especially when health-risks are involved. Fisheries are confronted with a substantial by-catch of marine litter which causes loss of time, damage to gear, and tainted catch. Shipping suffers financial damage and -more importantly- safety-risks from fouled propellers or blocked waterintakes. Marine litter blowing inland can even seriously affect farming practices. The overall economic damage from marine litter is difficult to estimate, but detailed study in the Shetlands with additional surveys elsewhere indicate that even local costs may run into millions of Euros (Hall 2000; Lozano \& Mouat 2009; Mouat et al. 2010; Newman et al. 2015).

The ecological consequences of marine litter are most obvious in the suffering and death of marine birds or mammals entangled in debris. Entangled whales are front page news and attract a lot of public attention. However, only a small proportion of entanglement mortality becomes visible among beached animals. Even less apparent are the consequences from the ingestion of plastics and other types of litter. Ingestion is extremely common among a wide range of marine species including many seabirds, marine mammals and sea-turtles (Laist 1987, 1997; Derraik 2002; Kühn et al. 2015). It can cause direct mortality but the major impact most likely occurs through reduced fitness of many individuals. Sub-lethal effects on animal populations remain largely invisible. In spite of spectacular examples of mortality caused by marine litter, the real impact on marine wildlife therefore remains difficult to estimate (Browne et al. 2015; Rochman et al. 2016; Werner et al. 2016). Plastics gradually break down to microscopically small particles, but these may pose an even more serious problem (Thompson et al. 2004; Bergmann et al. 2015). Although experimental results and model predictions are not all in agreement, concerns about microplastics are increasing as plastics can adsorb and concentrate organic pollutants from the surrounding water and, once ingested, might release chemicals into marine organisms with associated negative effects (Arthur et al. 2009; Browne et al. 2008, 2013; Endo et al. 2005, 2013; Gouin et al. 2011; Koelmans et al. 2013a,b, 2014, 2016; Moore 2008; Teuten et al. 2007, 2009; Chua et al. 2014; Rochman et al. 2013, 2014a, b; Tanaka et al. 2013; Thompson et al. 2009; Van Cauwenberghe \& Janssen 2014; Cole et al. 2015; Watts et al. 2015; CBD 2016; Beaman \& Bergeron 2016; Peda et al. 2016; Besseling et al. 2017; Heindler et al. 2017; Hermabessiere et al. 2017; Ribeiro et al. 2017). Thus, in addition to the toxic substances incorporated into plastics in the manufacturing process, plastics may concentrate pollutants from the environment and act as a pathway adding to their accumulation in marine organisms. Evidently, this same mechanism operates at all levels of organisms and sizes of ingested plastic material, from small zooplankton filter-feeders to large marine birds and mammals, but it is the microplastic issue and their ingestion by small filter-feeders that has emphasized the potential scale and urgency of the problem of marine plastic litter, as it may ultimately affect human food quality and safety as well (Hauser et al. 2015; Hunt et al. 2016). Concerns have also been expressed for the even smaller particles, those in the nano-size range, which might penetrate into tissues and cells with potential chemical and mechanical damage to e.g. DNA (Koelmans et al. 2015; Booth et al. 2016; Gigault et al. 2016; Liu et al. 2016; Jahnke et al. 2017). Accumulation of marine plastic litter, including a 'soup' of microplastics, in all major gyres of the oceans (Moore 2008; Law et al. 2010; Maximenko et al. 2012; Van Sebille et al. 2012, 2015) and in deep-sea sediments and polar sea-ice (e.g. Obbard et al. 2014; Fischer et al. 2015; Cózar et al. 2017; Munari et al. 2017; Tekman et al. 2017) have emphasized the global scale of this marine litter problem.

Recognizing the negative impacts from marine debris, a variety of international policy measures has attempted to reduce input of litter. Examples of these are the London Dumping Convention 1972; Bathing Water Directive 1976; MARPOL 73/78 Annex V 1988; Special Area status North Sea MARPOL Annex V 1991; and the OSPAR Convention 1992. In the absence of significant improvements, political measures have been intensified by for example the EU-Directive 2000/59/EC on Port Reception 
Facilities (EC 2000), the Declaration from the North Sea Ministerial Conference (2002) in Bergen, and recently in a revision of MARPOL Annex V (MEPC 2011) and the European Marine Strategy Framework Directive 2008/56/EC (EC 2008; EC 2010).

Policy initiatives have recognized the need to use quantifiable and measurable aims. Therefore, the North Sea Ministers in the 2002 Bergen Declaration decided to introduce a system of Ecological Quality Objectives for the North Sea (EcoQOs) (North Sea Ministerial Conference 2002). For example, the oil pollution situation in the North Sea is measured by the rate of oil-fouling among beached Guillemots (Uria aalge) with an EcoQO target of less than $10 \%$ of beached Guillemots having oil on the plumage (OSPAR 2005). Similarly, as proposed by ICES Working Group on Seabird Ecology (ICES-WGSE 2003), OSPAR decided to use the abundance of plastic in stomachs of seabirds, in casu the Northern Fulmar (Fulmarus glacialis) to measure quality objectives for marine litter (OSPAR 2008, 2009, 2010a, 2010b, $2015 a, b)$. The fulmar EcoQO monitoring has been included as an indicator for marine litter in the approach for Good Environmental Status in the European Marine Strategy Framework Directive (Galgani et al. 2010; EC 2010; MSFD GES Technical Subgroup on Marine Litter 2011).

Within the Netherlands, the Ministry of Infrastructure and the Environment (I\&M) has a coordinating role in governmental issues related to the North Sea environment. As such, I\&M is involved in the development of environmental monitoring systems ("graadmeters") for the Dutch continental shelf area. As a part of this activity, I\&M has commissioned several earlier projects by IMARES (Wageningen Marine Research) working towards a Fulmar-Litter-EcoQO. The first pilot project for the North Sea Directorate of I\&M considered stomach contents data of Dutch fulmars up to the year 2000 and made a detailed evaluation of their suitability for monitoring purposes (Van Franeker \& Meijboom 2002). A series of later reports commissioned by the Directorate-General for Civil Aviation and Maritime Affairs (DGLM) (see 'References') have provided annual updates on the Dutch time-series, paying special attention to shipping issues and EU Directive 2000/59/EC. As of 2010, updates of the fulmar monitoring reports have been commissioned by Rijkswaterstaat (RWS Water, Traffic and Living Environment RWS-WVL).

Internationally, as of 2002, the Dutch fulmar research was expanded to all countries around the North Sea as a project under the Save the North Sea (SNS) program. SNS was co-funded by EU Interreg IIIB over period 2002-2004 and aimed to reduce littering in the North Sea area by increasing stakeholder awareness. The fulmar acted as the symbol of the SNS campaign. The SNS fulmar study was published by Van Franeker et al. (2005). Findings strongly supported the important role of shipping (incl. fisheries) in the marine litter issue. For further publications of the SNS fulmar study see e.g. Save the North Sea (2004), Van Franeker (2004b,c), Edwards (2005), Guse et al. (2005), Olsen (2005). After completion of the European SNS project, the international work was continued through CSR awards from the NYK Group Europe Ltd and support from Chevron Upstream Europe. These funds contributed to further North Sea EcoQO wide updates in reports (Van Franeker \& the SNS Fulmar Study Group 2013), including peer reviewed scientific publications on the EcoQO methods with data up to 2007 (Van Franeker et al. 2011) and 2012 (Van Franeker \& Law 2015). These awards were used also to promote fulmar work in other areas of the world such as Ireland (Acampora et al. 2016), the Faroe I slands (Van Franeker 2012), Iceland (Kühn \& Van Franeker 2011), Svalbard (Trevail et al. 2015), Atlantic Canada (Bond et al. 2014), the Canadian Arctic (Mallory et al. 2006; Mallory 2008; Provencher et al. 2009) and the Pacific (Nevins et al. 2011; Avery-Gomm et al. 2012; Donnelly et al. 2014; Terepocki et al. 2017) and to explore the potential use of other marine species for ingestion monitoring as intended in the European Marine Strategy Directive (Bravo Rebolledo et al. 2013; Foekema et al. 2013; Matiddi et al. 2017). The most recent international overview of the monitoring of plastics in stomach contents of fulmars in the North Sea area includes data up to 2014 (OSPAR 2017). Currently there is no funding dedicated to international coordination and integrated data analysis and reporting.

The current assignment from I\&M, through its section Rijkswaterstaat Water, Traffic and Living Environment RWS-WVL included:

$>\quad$ Update of the Dutch time series on litter in stomachs of fulmars with the data of year 2016.

$>\quad$ Continued co-ordination of the beached fulmar sampling in the Netherlands.

It was further agreed to provide:

> Annual additions to the basic raw data on individual birds underlying analyses back to year 2000 for RWS CIV (Centrale Informatievoorziening, Lelystad) or via CIV to third parties like OSPAR. 


\section{Marine litter and policy measures}

Compared to the problems from dumping of oil or toxic wastes, the issue of disposal of 'garbage' into the marine environment has long been considered of minor importance. It might still be considered that way if not for plastics. Plastics, although known since the early 1900s, started their real development only after 1960 (Andrady \& Neal 2009). Since then, they have found their way into almost every application, replacing old materials in existing products, and creating a new and endless array of 'disposable' packaging products.

Unfortunately, the same factors that made plastics such a popular product have resulted in them becoming an environmental problem. Low production costs have promoted careless use and low degradability leads to accumulation in the environment. In 2015, the world production of raw plastic resins reached a new height of 322 million tons (PlasticsEurope 2016), and when fibre production is included 380 million tons (Geyer et al. 2017). Around $40 \%$ of the plastics is used for single use packaging. It is estimated that from 1950 to 2015 over 8 billion tons of plastics have been produced, of which over 6 billion tons has turned to waste, $79 \%$ of which has ended up in landfills or the environment (Geyer et al. 2017). Calculations on mismanaged waste have indicated that annually 4.8 to 12.7 million tonnes of plastics are lost from global land-based sources to the marine environment ( Jambeck et al. 2015). Plastic consumption continues to grow; annual growth rates of between 5 to $10 \%$ were interrupted by the economic crisis in 2008 , but this was a temporary interruption.

Litter in the marine environment originates from a variety of sources, including merchant shipping, fisheries, offshore industry, recreational boating, coastal tourism, influx from rivers, sewage outflows, or direct dumping of wastes at sea or along seashores (Veiga et al. 2016). Coastal dumping of debris was common practise in many areas of north-western Europe during the previous century. For example, in the 1950s the city of Den Helder in the Netherlands operated dedicated ships to dispose of municipal waste at sea. However, in western Europe most of such dumpings have stopped tens of years ago. Also sewage treatment systems and risk for overflow during periods of excessive rain have strongly improved in the western European region. The relative importance of various sources differs strongly in different parts of the world, and is almost impossible to quantify in detail. As for the Netherlands, Dutch Coastwatch studies (e.g. Stichting de Noordzee 2003) score litter into categories 'from sea' (shipping, fisheries, offshore); 'beach-tourism'; 'dumped from land'; and 'unknown'. In the Netherlands, the 'from sea' category consistently represents in the order of $40 \%$ of litter items recorded. The 'unknown' category scores a similar percentage. Considerable uncertainties are linked to this categorization. More specific information may come from the OSPAR initiative for monitoring litter on beaches in a somewhat more systematic approach. In a first German report (Fleet 2003), ten years of Coastwatch-like surveys, plus two years of the more detailed OSPAR pilot project, were evaluated. From both studies it is concluded that shipping, fisheries and offshore installations are the main sources of litter found on German North Sea beaches. The larger proportion of litter certainly originates from shipping, with a considerable proportion of this originating from the fisheries industry. In the Netherlands, data to this effect were collected in a large beach litter study on Texel (van Franeker 2005) suggesting that up to $90 \%$ of plastic litter originates from shipping and fisheries in the Dutch area. More recent analyses of OSPAR beach survey data have not yet ventured in new estimates of proportional roles of sources (Schulz et al. 2013, 2017; Dagevos et al. 2013). A lot of attention is being given to touristic sources of debris on beaches and consumer behaviour in general.

In spite of the uncertainties in details, there is little doubt that waste disposal by ships is one of the important remaining sources of marine litter around the North Sea and worldwide, a fact also recognized by the International Maritime Organization (IMO) in its stepwise strengthening of the specific 'garbage-annex' to the MARPOL Convention. The International Convention for the Prevention of Marine Pollution from Ships (MARPOL 73/78) entered into force on 2nd October 1983 for Annexes I (oily wastes) and II (bulk liquid chemicals), but its Annex V, covering garbage, only achieved sufficient ratifications to enter into force on 31st December 1988. MARPOL Annex $V$ contained the following main prohibitions for discharge of solid wastes:

$>\quad$ No discharge of plastics.

$>\quad$ No discharge of buoyant dunning, lining or packaging material within 25 nautical miles $(\mathrm{nm})$.

$>\quad$ No discharge of garbage within $12 \mathrm{~nm}$. Food waste may be discharged if ground to pieces smaller than one inch.

$>\quad$ No discharge of any solid waste, including food waste, within $3 \mathrm{~nm}$. 
Unfortunately, control of compliance with Annex $\mathrm{V}$ regulations on ships is difficult (OECD-MTC 2003; Trouwborst 2011; Rakestraw 2012).

In the European region, and especially the North Sea area, the sheer intensity of merchant shipping and fisheries makes them an undisputed source of marine litter. From that background, North Sea states promoted that the North Sea received the status of MARPOL Special Area for its annexes I (oil) and V (garbage). Amendments to that effect were made in 1989, and the Special Area status for the North Sea entered into force in February 1991. "Special Areas" under MARPOL Annex V have a more restrictive set of regulations for the discharge of garbage, with the main additions being:

$>\quad$ No discharge, not only of plastics, but also of any sort of metal, rags, packing material, paper or glass.

$>\quad$ Discharge of food wastes must occur as far as practicable from land, and never closer than 12 nm.

Finally, MARPOL Annex $V$ was recently revised by the Marine Environment Protection Committee (MEPC 2011). The important change is that the former approach of 'waste disposal at sea is allowed except .......' has been replace by an approach of 'waste disposal is forbidden except .... Under the new regulations, entering into force on 1 J anuary 2013, nearly all waste disposal is thus completely prohibited irrespective of distance to land. This now includes glass, metal and all packaging materials, so it is similar to the Special Area Status that was already longer in force (1991) in the North Sea. Only food-wastes and 'non-harmful' cargo residues plus cleaning agents used in hold or on decks may be discharged under certain conditions such as distance to land.

Within the European Union, progress under worldwide MARPOL regulations was considered insufficient. High costs of proper disposal in combination with low risk of being fined for violations are a clear cause. Poor functioning of available reception facilities definitely plays a role as well. Compliance with MARPOL regulations is hard to enforce at sea, especially when many ships fall under jurisdiction of cheap flag-states with little concern for environmental issues. Compliance can only be promoted by measures that can be enforced when ships visit the harbour. From this perspective, the European Commission and parliament have installed the EU-Directive on Port Reception Facilities for shipgenerated waste and cargo residues (Directive 2000/59/EC). Key elements of the Directive are:

$>\quad$ Obligatory disposal of all ship-generated waste to reception facilities before leaving port. Shipgenerated waste includes operational oily residues, sewage, household and cargo-associated waste, but not residues from holds or tanks.

$>\quad$ Indirect financing, to a 'significant' degree, of the delivery of ship-generated waste. Finances for such 'free' waste reception should be derived from a fee system on all ships visiting the port. Delivery of cargo residues remains to be paid fully by the ship.

> Ports need to develop and implement a 'harbour waste plan' that guarantees appropriate reception and handling of wastes.

The term 'Significant' was later identified as meaning 'in the order of at least $30 \%$ '. The implementation date for the Directive was December 2002, but unfortunately suffered some delay in several countries. In the Netherlands, the Directive became implemented in late 2004, operating at or above the minimum level of indirect financing depending on the harbour. On an annual basis, results are evaluated by the Minister of I\&M in which also the results of the Fulmar-Litter-EcoQO monitoring are being used. This tool complements surveys of quantities of litter delivered in ports, or beach surveys for quantities of waste washing onto beaches. These approaches have their specific merits but do not measure residual levels of litter in the marine environment itself. The Fulmar-Litter-EcoQO does look at this marine environment and at the same time places such information in the context of ecological effects.

The EU Marine Strategy Framework Directive (MSFD) (EC 2008, 2010; Galgani et al. 2010; MSFD GES Technical Subgroup on Marine Litter 2011) is a strongly developing instrument for initiation of new policies. The MSFD aims for 'Good Environmental Status (GES)' in which regionally important sources of debris need to be specifically addressed. A start was made in the OSPAR Regional Action Plan (OSPAR 2014) which does not yet specify a target for fulmar plastic ingestion by the year 2020 in relation to GES. There appears to be a tendency to agree with the long term OSPAR target, with a GES 2020 target of a significant reduction in plastic ingestion by fulmars. 


\section{The Fulmar as an ecological monitor of marine litter}

The interpretation of monitoring information presented in this report requires a summary of earlier findings as published in earlier reports and peer reviewed literature (Van Franeker et al. 2011; Van Franeker \& Law 2015).

Since the early days of plastic pollution of our oceans, the Northern Fulmar has been known as a species that readily ingests marine plastic debris (Bourne 1976; Baltz \& Morejohn 1976; Day et al. 1985; Furness 1985; Van Franeker 1985; Moser \& Lee 1992; Robards et al. 1995; Blight \& Burger 1997). But it took until the pilot study of Van Franeker \& Meijboom (2002) to properly investigate the feasibility of using stomach contents of Northern Fulmars to monitor changes in marine litter abundance in an ecological context. Samples of fulmars available for a feasibility study of monitoring in the Netherlands mainly originated from the periods 1982 to 1987 and 1996 to 2000, with smaller numbers of birds from the years in between.

Reasons for selection of the fulmar out of a list of potential seabird species for monitoring are of a practical nature:

> Fulmars are abundant in the North Sea area (and elsewhere) and are regularly found in beached bird surveys, which guarantee supply of an adequate number of bird corpses for research.

$>\quad$ Fulmars are known to consume a wide variety of marine litter items.

$>\quad$ Fulmars avoid inshore areas and forage exclusively at sea (never on land).

$>\quad$ Fulmars do not normally regurgitate indigestible items, but accumulate these in the stomach (digestive processes and mechanical grinding gradually wear down particles to sizes that are passed on to the gut and are excreted).

$>\quad$ Thus, stomach contents of fulmars are representative for the wider offshore environment, averaging pollution levels over a foraging space and time span that avoids bias from local pollution incidents.

$>\quad$ Historical data are available in the form of a Dutch data series since 1982 (one earlier 1979 specimen); and literature is available on other locations and related species worldwide (Van Franeker 1985; Van Franeker \& Bell 1988).

$>\quad$ Other North Sea species that ingest litter either do not accumulate plastics (they regurgitate indigestible remains); are coastal only and/or find part of their food on land (e.g. Larus gulls); ingest litter only incidentally (e.g. North Sea alcids) or are too infrequent in beached bird surveys for the required sample size or spatial coverage (e.g. other tubenoses or Kittiwake Rissa tridactyla).

Beached birds may have died for a variety of reasons. For some birds, plastic accumulation in the stomach is evidently the direct cause of death, e.g. by plastic sheets blocking food passage. But more often the effects of litter ingestion act at sub-lethal levels, except maybe in cases of ingestion of chemical substances. For other birds, fouling of the plumage with oil or other pollutants (Camphuysen 2017), collisions with ships or other structures, drowning in nets, extremely poor weather or foodshortage may have been direct or indirect causes of mortality.

At dissection of birds, their sex, age, origin, condition, likely cause of death and a range of other potentially relevant parameters are determined. Standardized dissection procedures for EcoQO monitoring have been described in detail in a manual (Van Franeker 2004b), subsequent peer reviewed publications (Van Franeker et al. 2011; Van Franeker \& Law 2015) and OSPAR Guidelines (OSPAR 2015a,b).

Stomach contents are sorted into main categories of plastics (industrial and user plastics), non-plastic rubbish, pollutants, natural food remains and natural non-food remains. Each of these categories has a number of subcategories of specific items. For each individual bird and litter category, data are recorded on presence or absence ("incidence"), the number of items, and the mass of subcategory (see methods). For efficiency/economy reasons, some of the details described in the manual and earlier reports were discontinued in the current research projects.

The pilot study undertook extensive analyses to check whether time-related changes in litter abundance were susceptible to errors caused by bias from variables such as sex, age, origin, 
condition, cause of death, or season of death. If any of these would substantially affect quantities of ingested litter, changes in sample composition over the years could hamper or bias the detection of time-related trends.

A very important finding of the pilot study was that no statistical difference was found in litter in the stomach between birds that had slowly starved to death and 'healthy' birds that had died instantly (e.g. because of collision or drowning). This means that our results, which are largely based on beached starved birds, are representative for the 'average' healthy fulmar living in the southern North Sea.

Only age was found to have an effect on average quantities of ingested litter, adults having less plastic in their stomach than younger birds. Possibly, adults loose some of the plastics accumulated in their stomach when they feed chicks or spit stomach-oil during defence of nest-sites. Another factor could be that foraging experience may increase with age. Understanding of the observed age difference in plastic accumulation is poor. In search of better understanding of such issues, Chevron Upstream Europe has funded a cooperative project with the Faroese Fisheries Laboratory. Using fulmars from the Faroe Islands, we investigate seasonal and age related variations in stomach contents. On the Faroe Islands, fulmars are hunted for consumption and large numbers of samples are easily obtained. Additional samples have been obtained from fisheries by-catch in the area. Stomach contents are analysed for both normal diet (Faroese component in the study; Danielsen et al. 2010) and for accumulated litter (Dutch contribution to the study). General results were published in Van Franeker (2012), but detailed analyses of samples obtained from all months of the year during several years continue to be analysed.

Although age has been shown to affect absolute quantities of litter in stomach contents, changes over time follow the same pattern in adults or non-adults. As long as no directional change in age composition of samples is observed, trends may be analysed for the combined age groups. However, background information for the presentation of results and their interpretations always requires insight in age composition of samples.

Significant long term trends from 1982 to 2000 were detected in incidence, number of items and mass of industrial plastics, user plastics and suspected chemical pollutants (often paraffin-like substances). Over the 1982-2000 period, only industrial plastics decreased while user plastics significantly increased. When comparing averages in the 1980s to those in the 1990s, industrial plastics approximately halved from 6.8 granules per bird (77\% incidence; $0.15 \mathrm{~g}$ per bird) to 3.6 granules $(64 \% ; 0.08 \mathrm{~g})$. User plastics almost tripled from 7.8 items per bird $(84 \% ; 0.19 \mathrm{~g})$ to 27.6 items $(97 \%$; $0.52 \mathrm{~g})$.

Analysis of variability in data and Power Analysis revealed that reliable figures for litter in stomachs in a particular region and specific time period are obtained at a sample size of about 40 birds and that reliable conclusions on change or stability in ingested litter quantities can be made after periods of 4 to 8 years, depending on the category of litter. Lower annual sample sizes are no problem, but will lengthen the periods needed to draw conclusions on regional levels and trends.

Mass of litter, rather than incidence or number of items, should be considered the most useful unit of measurement in the long term. Mass is also the most representative unit in terms of ecological impact on organisms. Frequency of occurrence loses its sensitivity as an indicator when virtually all birds are positive (as is the case in fulmars). In regional or time-related analyses, mass of plastics is a more consistent measure than number of items, because the latter appears to vary with changes in plastic characteristics.

The pilot study concluded that stomach content analysis of beached fulmars offers a reliable monitoring tool for (changes in) the abundance of marine litter off the Dutch coast. By its focus on small-sized litter in the offshore environment such monitoring has little overlap with, and high additional value to beach litter surveys of larger waste items. Furthermore, stomach contents of fulmars reflect the potential ecological consequences of litter ingestion on a wide range of marine organisms and create public awareness of the fact that environmental problems from marine litter persist even when larger items are broken down to sizes below the range of normal human perception. As indicated there is an increasing concern on the dangers from microplastics, but monitoring quantities and effects in these species is more difficult than that of intermediate sized plastics in seabirds. 
The pilot study recommended that Dutch fulmar litter monitoring should focus on mass of plastics (industrial plastic and user) and suspected chemical substance. Each of these represents different sources of pollution, and thus specific policy measures aimed at reduced inputs. Because no funding was obtained to work on suspected chemicals, this element has been dropped and plastics have become the main focus. However, data-recording procedures are such that the raw data-level, various sub-categories of plastics, other rubbish and suspected chemicals continue to be recorded by number and mass, and can be extracted from databases, should the need and funding arise.

After publication of the pilot study, the Dutch monitoring has continued annually and has resulted in a series of annual reports (Van Franeker et al. 2003 to 2016) that initially confirmed further decrease of industrial and but especially showed a drop in user plastics after the late 1990s. However, this was soon followed by a halt or at least serious slow-down of such trends. Only in the most recent report (Van Franeker et al. 2016), the analysis over the period 2006-2015 showed a continuing trend of slow but significant decrease.

Internationally, the fulmar litter monitoring was boosted by the 'Save the North Sea (SNS)' campaign 2002-2004, which was co-funded by EU Interreg IIIB and aimed at increasing awareness among stakeholders so as to reduce littering behaviour. Expanding the Dutch fulmar study to locations all around the North Sea was one of the project components. Co-operation was established with interested groups in all countries around the North Sea. The final project report (Van Franeker et al. 2005) showed that fulmars from the southern North Sea had almost two times more plastic in the stomach than fulmars from the Scottish Islands, and almost four times as much as that in a small sample from the Faroe I slands. Van Franeker et al (2011) confirmed these patterns with data up to 2007. Location differences and relative abundances of different types of litter suggested a major role of shipping, and showed that the bulk of the litter problem in the North Sea region is of local origin.

Also in 2002, North Sea Ministers in the Bergen Declaration, decided to start a system of 'Ecological Quality Objectives (EcoQOs) for the North Sea'. One of the EcoQOs to be developed was for the issue of marine litter pollution, using stomach contents of a seabird, the fulmar, to monitor developments, and to set a target for 'acceptable ecological quality'. OSPAR was requested to look after implementation of the ecological quality objectives. Since then, a number of steps have been taken, based on reports from the Dutch studies and the Save the North Sea project. The current wording of the EcoQO target level (OSPAR 2010b) is:

"There should be less than $10 \%$ of Northern Fulmars (Fulmarus glacialis) having more than 0.1 gram plastic particles in the stomach in samples of 50 to 100 beach-washed fulmars from each of 4 to 5 different areas of the North Sea over a period of at least 5 years".

As recommended from the Dutch studies, the mass of plastics forms the basis of the EcoQO monitoring system. But rather than using average plastic mass for the target definition, a combination is used of frequency of occurrence of plastic masses above a certain critical mass level $(10 \% ; 0.1 \mathrm{~g})$. The background of such approach is that a few exceptional outliers can have a strong influence on the calculated average. The wording of the target level basically excludes influence of exceptional outlying values. A similar effect can be obtained by calculating mean values from logarithmically transformed data (Geometric means). The OSPAR Fulmar EcoQO has been published in a background document (OSPAR 2008) and its implementation was included in the OSPAR Quality Status Report (OSPAR $2010 a, b)$. Formal guidelines and assessment methods have been published (OSPAR 2015a,b). Recently OSPAR (2017) published an analysis of data up to 2014 for all five North Sea areas, indicating continued although less pronounced latitudinal differences as compared to Van Franeker et al. 2005 and 2011, and the absence of significant trends.

As indicated in Chapter 1, the international work was continued and expanded after the SNS project. The EcoQO approach to marine litter is now an element for assessment of 'Good Environmental Status' in the European Marine Strategy Framework Directive (Galgani et al. 2010; EC 2010; MSFD GES Technical Subgroup on Marine Litter 2011). Quality of the methodology has been established by publications in peer reviewed scientific articles (Ryan et al. 2009; Van Franeker et al. 2011; Kühn \& Van Franeker 2012; Trevail et al. 2015; Van Franeker \& Law 2015) and is used by researchers in the Canadian Atlantic and arctic and in the Pacific (Mallory 2008; Provencher et al. 2009; Nevins et al. 2011; Avery-Gomm et al. 2012; Donnelly-Greenan et al. 2014; Bond et al. 2014; Terepocki et al. 2017). In principle this monitoring can be implemented throughout the fulmars Atlantic and Pacific breeding ranges (Hatch \& Nettleship 1998).

The results of fulmar studies were also used in the UNEP yearbook 2011 (UNEP, 2011), which devoted a chapter to the global problem of marine litter (Kershaw et al. 2011), ranking plastic pollution as one 
of the main global threats to the marine environment. The example of fulmar monitoring methods and its long term character were extensively used in the most recent UNEP report on the marine plastic issue (UNEP 2016).

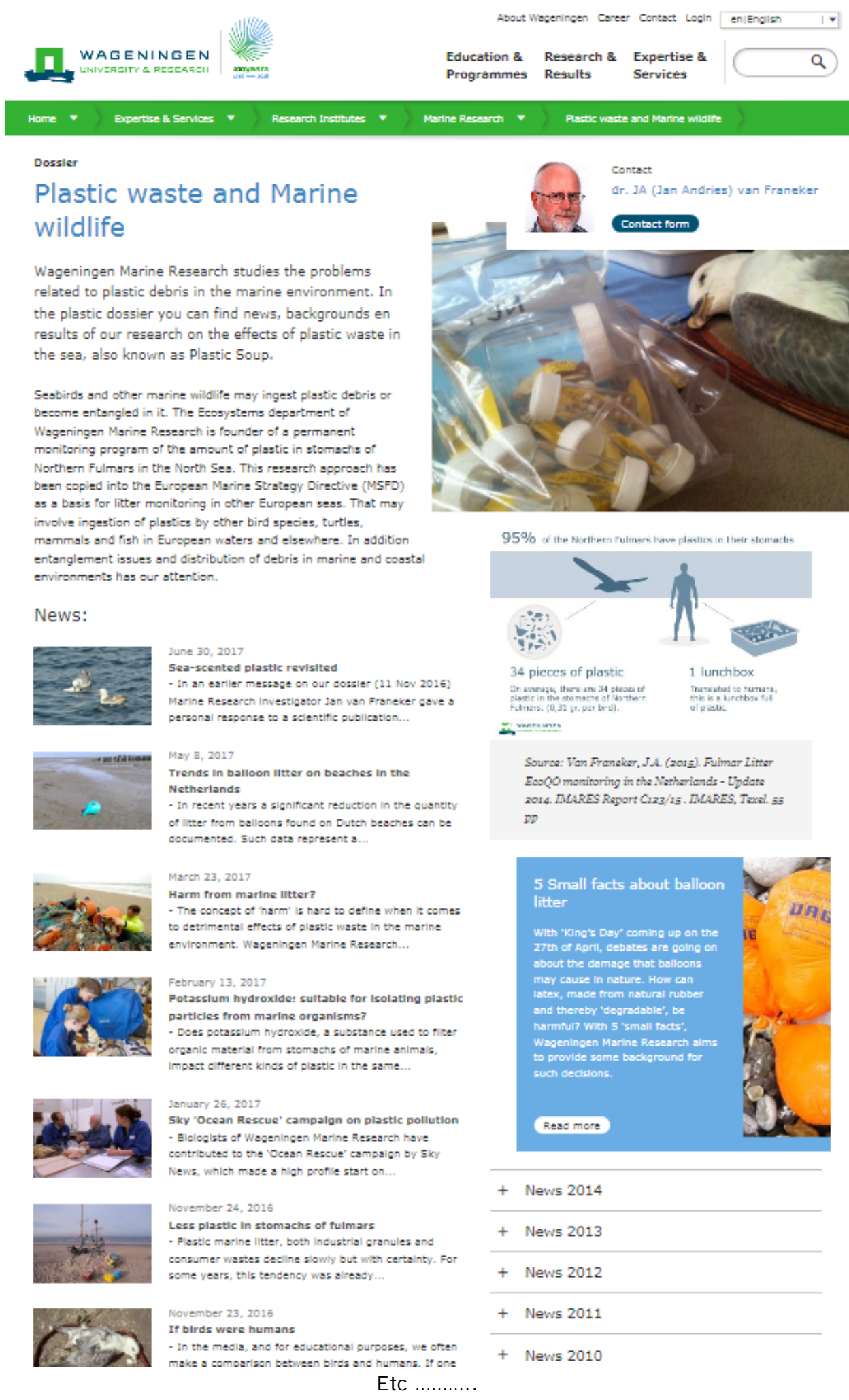

Photo: Outreach In the fulmar monitoring project, we aim to disseminate knowledge widely and promote participation. Through a webdossier www.wur.eu/ plastics-fulmars we inform general public, policy makers, scientific colleagues and volunteers involved in the program on our achievements and important developments. 


\section{Materials and Methods}

Wageningen Marine Research continues the collection of beached fulmars from Dutch beaches with the assistance of the Dutch Seabird Group (Nederlandse Zeevogelgroep - NZG) through its Working Group on Beached Bird Surveys (Nederlands Stookolieslachtofffer Onderzoek - NSO). Also several coastal bird rehabilitation centres support the collection program. Sampling effort for the Dutch fulmar study is spread over the full Dutch coastline, but hard to define in detail. In general, most fulmars in our study originate from the more northern part of the Netherlands, with next in line fulmars from the Zeeland area. The lower number of beached fulmars from the more central parts of the Dutch coast may be due to lower observer effort, but also to more rapid disappearance of corpses due to higher numbers of scavenging foxes or cleaning activities on the touristic beaches.

With the Save the North Sea project in 2002, IMARES, now Wageningen Marine Research, started co-ordinated similar sampling projects at a range of locations in all countries around the North Sea. Organizations involved in different countries differ widely, and range from volunteer bird groups to governmental beach cleaning projects. Fig. 1 shows all locations that were involved in the Save the North Sea monitoring program, and their regional grouping. Lack of funding has led to a stop of the international coordination, although separate countries, except Sweden, have committed to continued monitoring and submission of basic data to OSPAR, also as a part of their involvement in the European Marine Strategy Framework Directive.

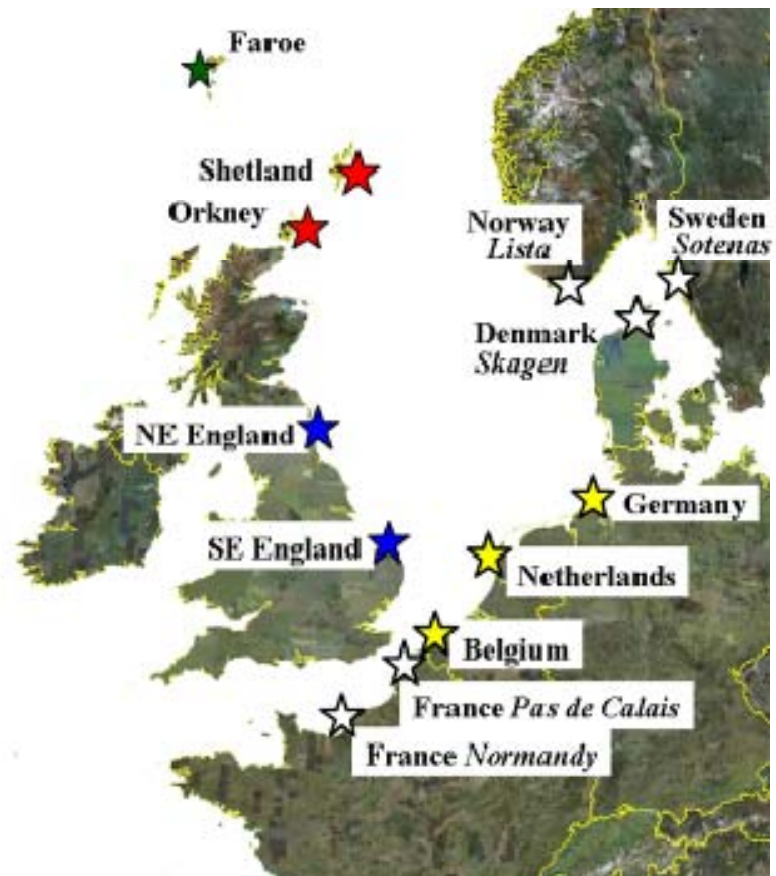

Figure 1. Fulmar-Litter study sites in the Save the North Sea Project (SNS). Colour of symbols indicates regional grouping into Scottish I slands (red), East England (blue), Channel area (white), Southeastern North Sea (yellow), and Skagerrak area (white). Not all locations are equally active. The Faroe Islands study area is considered as an external reference monitoring site for the North Sea. For further details see the online supplement of Van Franeker et al. (2011).

Bird corpses are stored frozen until analysis. Standardized dissection methods for fulmar corpses have been published in a dedicated manual (Van Franeker 2004b) and are internationally calibrated during annual workshops. Stomach content analyses and methods for data processing and presentation of results were described in full detail in Van Franeker \& Meijboom (2002), further developed in consultation with ICES and OSPAR by updates in later reports and OSPAR documents (OSPAR 2008, $2010 b)$. Scientific reliability of the methodology was established by its publication in the peer reviewed scientific literature (van Franeker et al. 2011; Van Franeker \& Law 2015) with condensed guidelines for future assessments recently published by OSPAR (OSPAR 2015a,b)

For convenience, some of the methodological information is repeated here in a condensed form. 


\section{Dissection}

At dissections, a full series of data is recorded that is of use to determine sex, age, breeding status, likely cause of death, origin, condition index and other issues. Age, the only variable found to influence litter quantities in stomach contents (Van Franeker \& Meijboom 2002), is largely determined on the basis of development of sexual organs (size and shape) and presence of Bursa of Fabricius (a gland-like organ positioned near the end of the gut which is involved in immunity systems of young birds; it is well developed in chicks, but disappears within the first year of life or shortly after). Further details are provided in Van Franeker (2004b). In the future, an updated version of the manual should be published to improve details and maximize efficiency of methods.

\section{Stomach procedure}

After dissection, stomachs of birds are opened for analysis. Stomachs of fulmars have two 'units': initially food is stored and starts to digest in a large glandular stomach (the proventriculus) after which it passes into a small muscular stomach (the gizzard) where harder prey remains can be processed through mechanical grinding. In early phases of the project, data for the two individual stomachs were recorded separately, but for the purpose of reduction in monitoring costs, the contents of proventriculus and gizzard are now combined.

Stomach, contents are carefully rinsed in a sieve with a $1 \mathrm{~mm}$ mesh and then transferred to a petri dish for sorting under a binocular microscope. The $1 \mathrm{~mm}$ mesh is used because smaller meshes become clogged with mucus from the stomach wall and with food-remains. Analyses using smaller meshes were found to be extremely time consuming and particles smaller than $1 \mathrm{~mm}$ seemed rare in the stomachs, and when present contribute little to plastic mass.

If oil or chemical types of pollutants are present, these may be sub-sampled and weighed before rinsing the remainder of stomach content. Although this was a standard component at the start of our studies, requirements for the Dutch "graadmeter" and international EcoQO have a focus on plastic or at best MARPOL Annex $V$ litter types. Thus, for financial efficiency, potential chemical pollutants in the stomachs are no longer part of the project. If sticky substances hamper further processing of the litter objects, hot water and detergents are used to rinse the material clean as needed for further sorting and counting under a binocular microscope.

\section{Categorization of debris in stomach contents}

The following categorization is ideally used for plastics and other rubbish found in the stomachs, with acronyms between parentheses. However, please note that for financial efficiency in OSPAR EcoQO monitoring, the required dataset has been restricted to just categories 1.1 (Industrial Plastics) and 1.2 (User Plastics) without further subcategories (OSPAR 2015a,b).

\section{PLASTI CS (PLA)}

1.1. I ndustrial plastic pellets (IND) These are small, often cylindrically-shaped granules of \pm 4 $\mathrm{mm}$ diameter, but also disc and rectangular shapes occur. Various names are used, such as pellets, beads or granules. They can be considered as "raw" plastic or a half-product in the form of which, plastics are usually first produced (mostly from mineral oil). The raw industrial plastics are then usually transported to manufacturers that melt the granules and mix them with a variety of additives (fillers, stabilizers, colorants, anti-oxidants, softeners, biocides, etc.) that depend on the user product to be made. For the time being, included in this category are a relatively small number of very small, usually transparent spherical granules, also considered to be a raw industrial product.

1.2. User plastics (USE) (all non-industrial remains of plastic objects) may be differentiated in the following subcategories:

1.2.1. sheetlike user plastics (she), as in plastic bags, foils etc., usually broken up in smaller pieces;

1.2.2. threadlike user plastics (thr) as in (remains of) ropes, nets, nylon line, packaging straps etc. Sometimes 'balls' of threads and fibres form in the gizzard;

1.2.3. foamed user plastics (foam), as in foamed polystyrene cups or packaging or foamed polyurethane in matrasses or construction foams;

1.2.4. fragments (frag) of more or less hard plastic items as used in a huge number of applications (bottles, boxes, toys, tools, equipment housing, toothbrushes, lighters etc.);

1.2.5. other (poth), for example cigarette filters, rubber, elastics etc., so items that are 'plastic-like' or do not fit into a clear category.

2. RUBBISH (RUB) other than plastic:

2.1. paper (pap) which besides normal paper includes silver paper, aluminium foil etc., so various types of non-plastic packaging material; 
2.2. kitchenfood (kit) for human food wastes such as fried meat, chips, vegetables, onions etc., probably mostly originating from ships' galley refuse;

2.3. various rubbish (rubvar) is used for e.g. pieces of timber (manufactured wood); paint chips, pieces of metals etc.;

2.4. fish hook (hook) from either sport-fishing or long-lining.

Further optional categories of stomach contents (not included in this study)

\section{POLLUTANTS (POL)}

3.1.1. For items indicating industrial or chemical waste remains such as slags (the remains of burning ovens, e.g. remains of coal or ore after melting out the metals); tar-lumps (remains of mineral oil); chemical (lumps or 'mud' of paraffin-like materials or sticky substances arbitrarily judged to be unnatural and of chemical origin) and featherlumps (indicating excessive preening by the bird of feathers sticky with oil or chemical pollutants).

\section{NATURAL FOOD REMAI NS (FOO)}

4.1.1. Numbers of specific items may be recorded in separate subcategories (fish otoliths, eye-lenses, squid-jaws, crustacean remains, jelly-type prey remains, scavenged tissues incl. feathers, insects, other).

\section{NATURAL NON-FOOD REMAI NS (NFO)}

5.1.1. Numbers of subcategories e.g. plant-remains, seaweed, pumice, stone and other may be recorded.

\section{Non-plastic or debris categories}

To be able to sort out items of categories 1 and 2, all other materials in the stomachs described in categories 3 to 5, have to be cleaned out. However in these latter categories, further identification, categorization, counting, weighing and data-processing is not essential for the EcoQO. Whether details are recorded depends of the interest of the participating research group and their reasons to collect beached fulmars.

\section{Acronyms}

In addition to the acronyms used for (sub) categories as above, further acronyms may be used to describe datasets. Logarithmic transformed data are initiated by 'In' (natural logarithm); mass data are characterized by capital G (gram) and numerical data by $\mathrm{N}$ (number). For example InGIND refers to the dataset that uses In-transformed data for the mass of industrial plastics in the stomachs; acronym NUSE refers to a dataset based on the number of items of user plastics.

\section{Particle counts and category weights}

For the main categories 1 (plastic) and 2 (rubbish) we record for each bird and each (sub) category:

$>$ The number of particles ( $\mathrm{N}=$ count of number of items in each (sub)category)

$>$ mass ( $\mathrm{W}=$ weight in grams) using Sartorius electronic weighing scale after at least a two day period of air drying at laboratory temperatures. For marine litter (categories 1 to 3 above), this is done separately for all subcategories. In the early fulmar study we also weighed the natural-food and natural-non-food categories as a whole, but this was discontinued in 2006 to reduce costs. Weights are recorded in grams accurate to the 4th decimal (= tenth of milligram).

On the basis of these records, data can be presented in different formats.

Incidence (\% FO)

The most simple form of data presentation is by presence or absence. Incidence, also known as prevalence, or as Frequency of Occurrence (\% FO) gives the percentage of all investigated stomachs that contained the category of debris discussed. The quantity of debris in a stomach is irrelevant in this respect.

\section{Arithmetic Average}

Data for numbers or mass are frequently shown as averages with standard errors calculated for a specific type of debris by location and specified time period. Averages are calculated over all available stomachs in a sample, so including the ones that contained no plastic ('population averages'). Usage of standard error (se) is preferred over standard deviation (sd) because se reflects the reliability of the calculated average by taking into account the sample size where sd mainly considers the spread in the data. Especially when sample sizes are smaller, arithmetic averages may be influenced by short term or local variations or extreme outliers. An option then is to pool data over a larger area or longer time period. An alternative to reduce influence of outliers is by logarithmic transformation of data. 

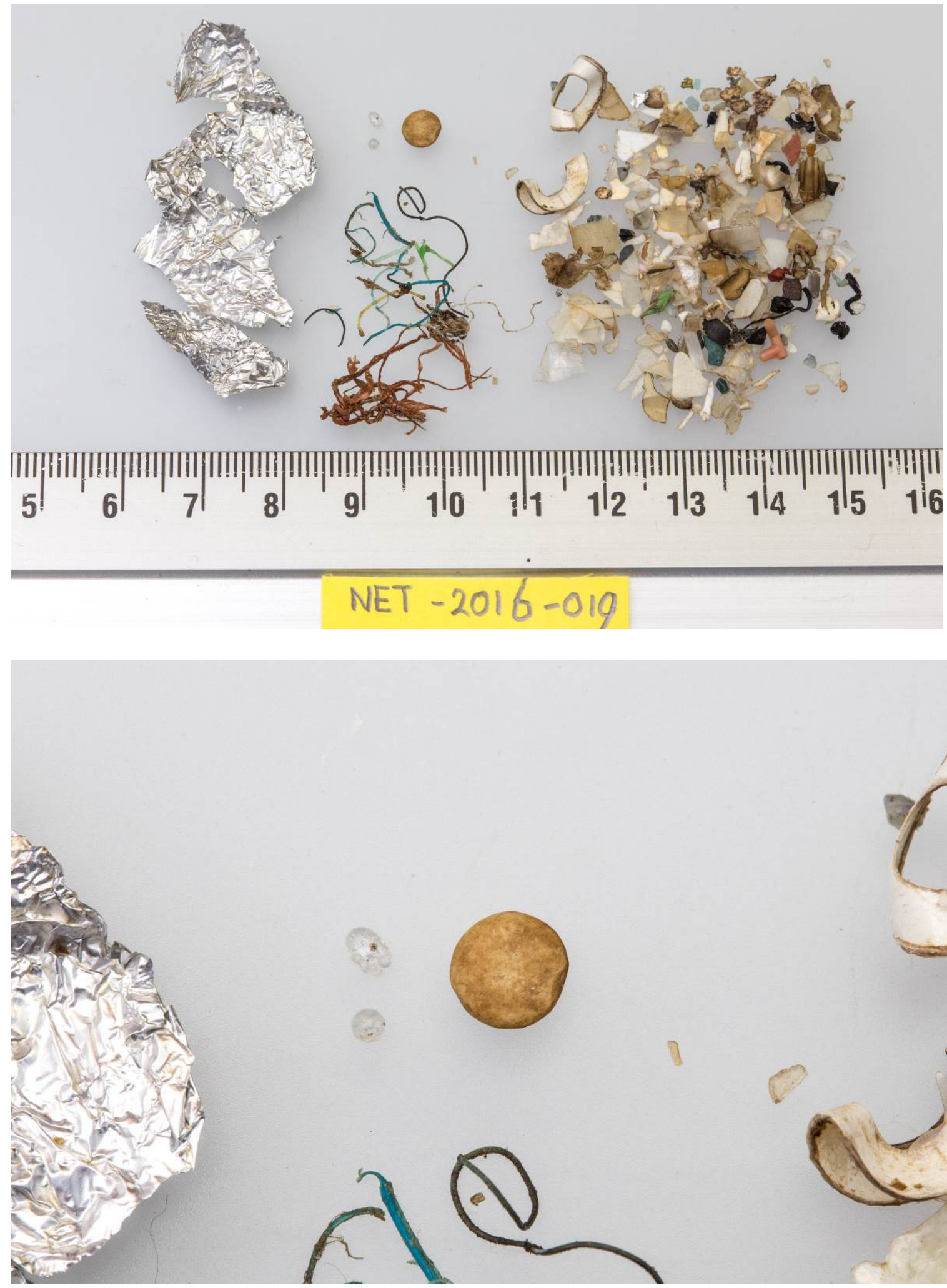

Photos Microbeads in the stomach content of Fulmar NET-2016-019. This stomach contained aluminium foil and a range of different forms of plastics (industrial granule, threads, sheets, fragments and foamy bits (upper photo). In fulmars we rarely find microbeads because normally, particles of that small size will quickly pass into the intestines and are excreted. This bird had two microbeads, small glassy spheres. The lower photo zooms in and shows these microspheres to the left of the industrial granule. Items like this are included as 'probably industrial' in the industrial category. 


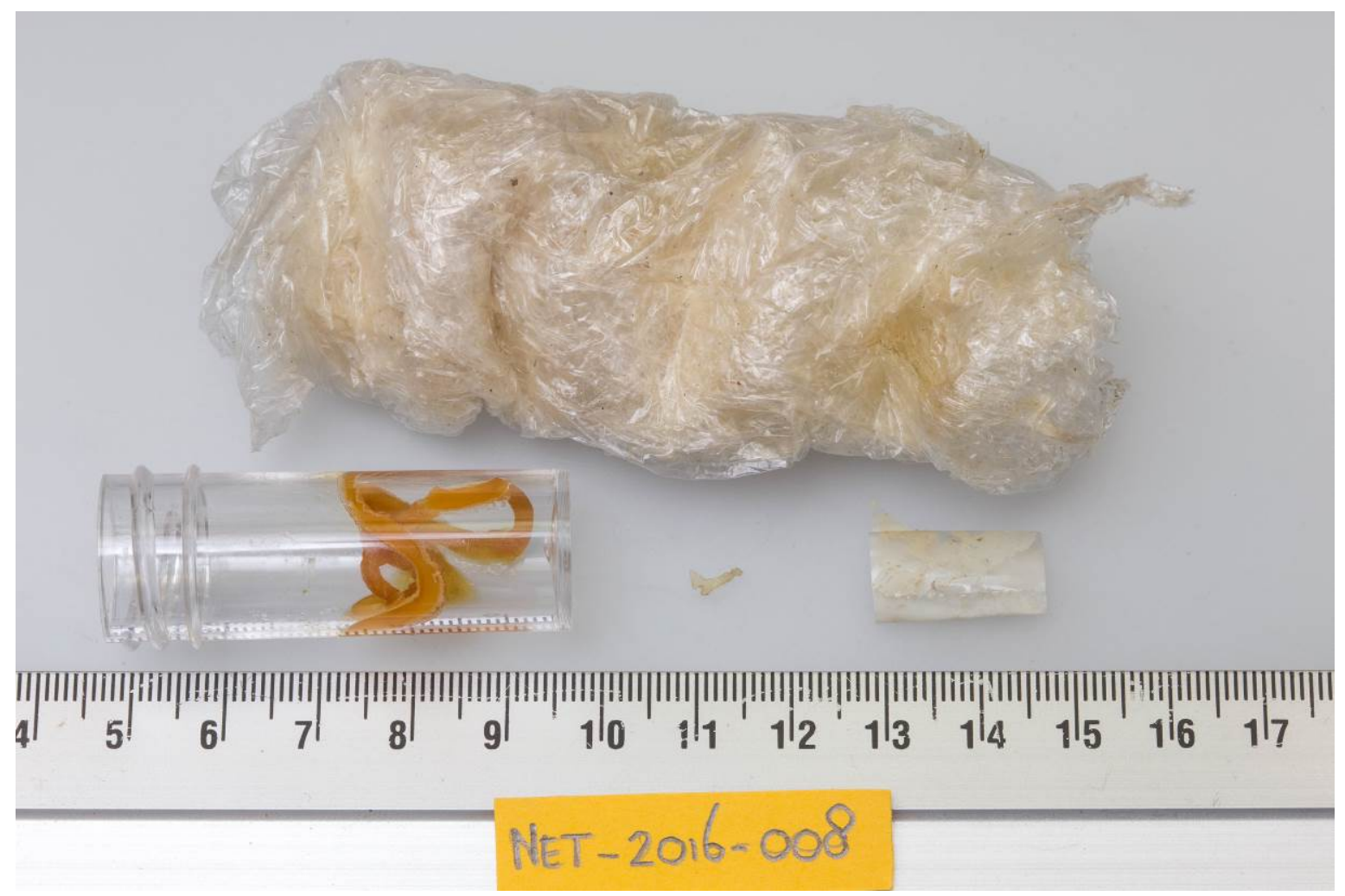

Photo

Sometimes ingested plastics are lethal. Clingfoil in the stomach content of Fulmar NET2016-008. In this bird passage of food through the stomach was blocked by a large piece of clingfoil, which was most likely the cause of death. Additional materials were a smaller sheet, tiny fragment, and rubber elastic band (in container, because degrading and sticky)

\section{Geometric Mean}

Sample sizes may not be large enough to average out the impact of occasional extreme outliers. Therefore data are often additionally presented as geometric means. Geometric mean is calculated as the average of logarithmically transformed data values, which is then back calculated to the normal arithmetic equivalent. Logarithmic transformation reduces the role of the higher values, but as a consequence the geometric mean is usually considerably lower than the arithmetic average for the same data. In mass data for plastics in the fulmar stomachs, geometric means are only about one third to half of the arithmetic averages. Geometric means are useful for comparative purposes between smaller sample sizes, for example when looking at annual data rather than at 5-year-periods. Logarithmic transformation cannot deal with the value zero, and thus the common approach chosen is to add a small value (e.g. $0.001 \mathrm{~g}$ in mass data) to all data-points, and then subtracting this again when the mean of log values is back-calculated to normal value. This however implies that geometric means become less reliable with an increasing number of zero values in a data-set. The natural logarithm (In) is used to run calculations for geometric means. Starting with this 2016 update, medians are included in some of the more detailed data sections of the report, as a different additional view on the strongly skewed data distributions that have to be handled.

\section{EcoQO performance}

For early Dutch reports, the analyses focused on trends in average or mean mass data for different categories. However, OSPAR (2010b) words its Ecological Quality Objective (EcoQO) for levels of litter (plastic) in stomachs of fulmars (the 'Fulmar-Litter-EcoQO') as:

"There should be less than $10 \%$ of Northern Fulmars (Fulmarus glacialis) having more than 0.1 gram plastic particles in the stomach in samples of 50 to 100 beach-washed fulmars from each of 4 to 5 different areas of the North Sea over a period of at least 5 years".

Thus, the information requested for OSPAR and the EcoQO focuses on the category of 'total plastic' and pooled data for 5-year periods over larger areas, and a simple decision rule for each stomach if the plastics in it weigh more than 0.1 gram or less, including zero.

EcoQO compliance or performance is defined as the percentage of birds in a sample that has $0.1 \mathrm{~g}$ or more plastic mass in the stomach. The OSPAR target is thus to reduce that percentage to under $10 \%$. The EcoQO format is a highly simplified form of data-presentation but through that simplicity escapes 
the problems faced by more sophisticated procedures as a consequence of excessive outliers or a large proportion of zero values in a data set. In the background however, details of various subcategories of litter continue to play an important role for correct interpretation of the EcoQO metric.

\section{Data pooling}

To avoid that short term variations cause erratic information on the level of ingested plastics, data are frequently pooled into 5-year periods. Such pooled data for 5-year periods are not derived from the annual averages, but are calculated from all individual birds over the full 5 year period. For data presentation, the Current Situation of plastic ingestion is defined as the figures for incidence and number or mass abundance for the most recent 5 year period, not the figures for the recent single year! Time related changes are illustrated in graphs by running 5-year averages, each time shifting one year and thus overlapping for four years.

For pooling study locations in the North Sea, the OSPAR ECoQO target definition has triggered a grouping into five areas or regions (Fig. 1): the Scottish I slands (Shetland and Orkney), East England (northeast and southeast England), the Channel (Normandy and Pas de Calais), South-Eastern North Sea (Belgium, Netherlands and Germany), and the Skagerrak (Skagen Denmark, Lista Norway and Swedish west coast).

\section{Statistical tests}

Data from dissections and stomach content analysis are recorded in Excel spreadsheets and next stored in an Oracle relational database. GENSTAT $18^{\text {th }}$ Edition was used for statistical tests. As concluded in the pilot study (Van Franeker \& Meijboom 2002) and later reports, statistical trend analysis is conducted using mass-data. Tests for trends over time are based on linear regressions fitting In-transformed plastic mass values for individual birds on the year of collection. Logarithmic transformation is needed because the original data are strongly skewed and need to be normalized for the statistical procedures. The natural logarithm ( $L n)$ is used. Tests for 'long term' trends use the full data set; 'recent' trends only use the past ten years of data. This 10 year period was derived from the pilot study (Van Franeker \& Meijboom 2002) which found that in the Dutch situation a series of about eight years was needed to have the potential to detect significant change. To be on the safe side in our approach, this period was arbitrarily increased to a standard period of 10 years for tests of current time related trends.

Statistical tests of regional differences (not included in this Dutch report) are conducted in GENSTAT 18th edition, using data from individual birds. Differences in plastic weight were evaluated by fitting a negative binominal generalized linear model with and without region included as a factor and differences between those two models were tested using a likelihood ratio test (Venables \& Ripley 2002; van Franeker et al. 2011). 


\section{Summary of data presentation and analysis:}

\section{$>$ Incidence (\% FO)}

The percentage of birds having plastic in the stomach.

$>$ Average \pm se

Arithmetic population average with standard error (includes zero's).

\section{$>$ Geometric mean}

Population average calculated using data transformation (natural logarithm).

\section{$>$ EcoQO performance}

The $\%$ of birds having more than 0.1 gram of plastic in the stomach.

\section{$>$ Pooled data}

Data pooled over 5 year period.

\section{$>$ Current level of plastic ingestion}

Average plastic number or mass from pooled data for the most recent 5 years.

\section{$>$ Running average}

Sequential data pooled over 5 years, shifting one year by data point, used as a visual illustration of trends over time, but without statistical relevance.

\section{$>$ Statistics}

Statistical analyses are solely based on the mass of plastic using In transformed data of individual birds. Tests for significance of trends over time are based on linear regressions of In-transformed plastic mass against year of collection. The long term trend is derived from the full dataset, the recent trend from only the most recent 10 years of data. 


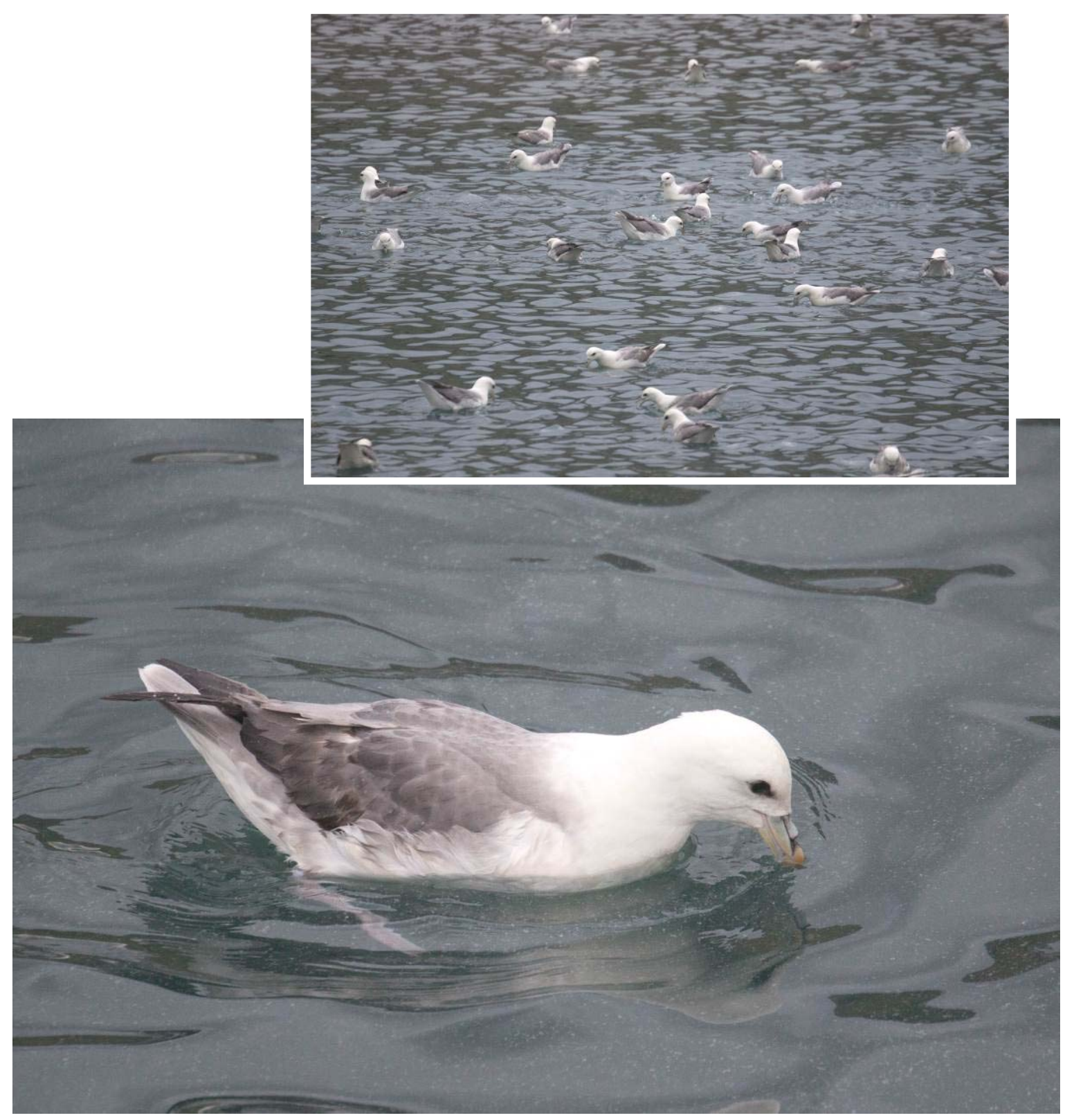

Photo: Fulmars are highly flexible foragers. Although a large fatty fish may be optimal prey, small food items, if occurring in sufficient density, can also be a profitable source of energy. The photo shows a fulmar feeding on very small droplets of fat and fish tissue released by the outlet from a fish processing factory. Flocks of fulmars may be attracted by such a food source (inset). In this mode of foraging it is well possible that small plastics are accidentally ingested. 


\section{$5 \quad$ Results \& Discussion}

\section{$5.1 \quad$ The year 2016}

In 2016, volunteer beach surveyors were able to collect 33 fulmar corpses for our research, but three had no or no complete stomach left, leaving us with 30 intact fulmar stomachs. This sample size is slightly below the desired sample of around 40 birds for a specific area and time-frame (Van Franeker $\&$ Meijboom 2002). Lower sample sizes are not a problem for the monitoring system, but may delay the detection of e.g. the significance of trends.

Among the 30 stomachs collected in 2016, plastics were found in $26(87 \%)$ with an average number of $31.5 \pm 13.4$ pieces of plastic and mass of $0.30 \pm 0.10 \mathrm{~g}$. Of these birds $50 \%$ exceeded the $0.1 \mathrm{~g}$ plastic level (Table 1a). These data contrasted the 2015 sample in which only $36 \%$ of 22 birds exceeded the $0.1 \mathrm{~g}$ level and the even smaller 2014 sample of 12 birds $\left(^{*}\right)$ with $83 \%$ over $0.1 \mathrm{~g}$. These strong interannual variations in smaller annual samples re-emphasize the need to largely ignore isolated annual data and to describe the 'current situation' by averaging over larger samples, such as in terms of 5-year averages.

(* the sample of 2014 was described as having 13 stomachs in earlier reports, but this was due to an error that included a sample of intestinal contents in the calculations; this has now been corrected)

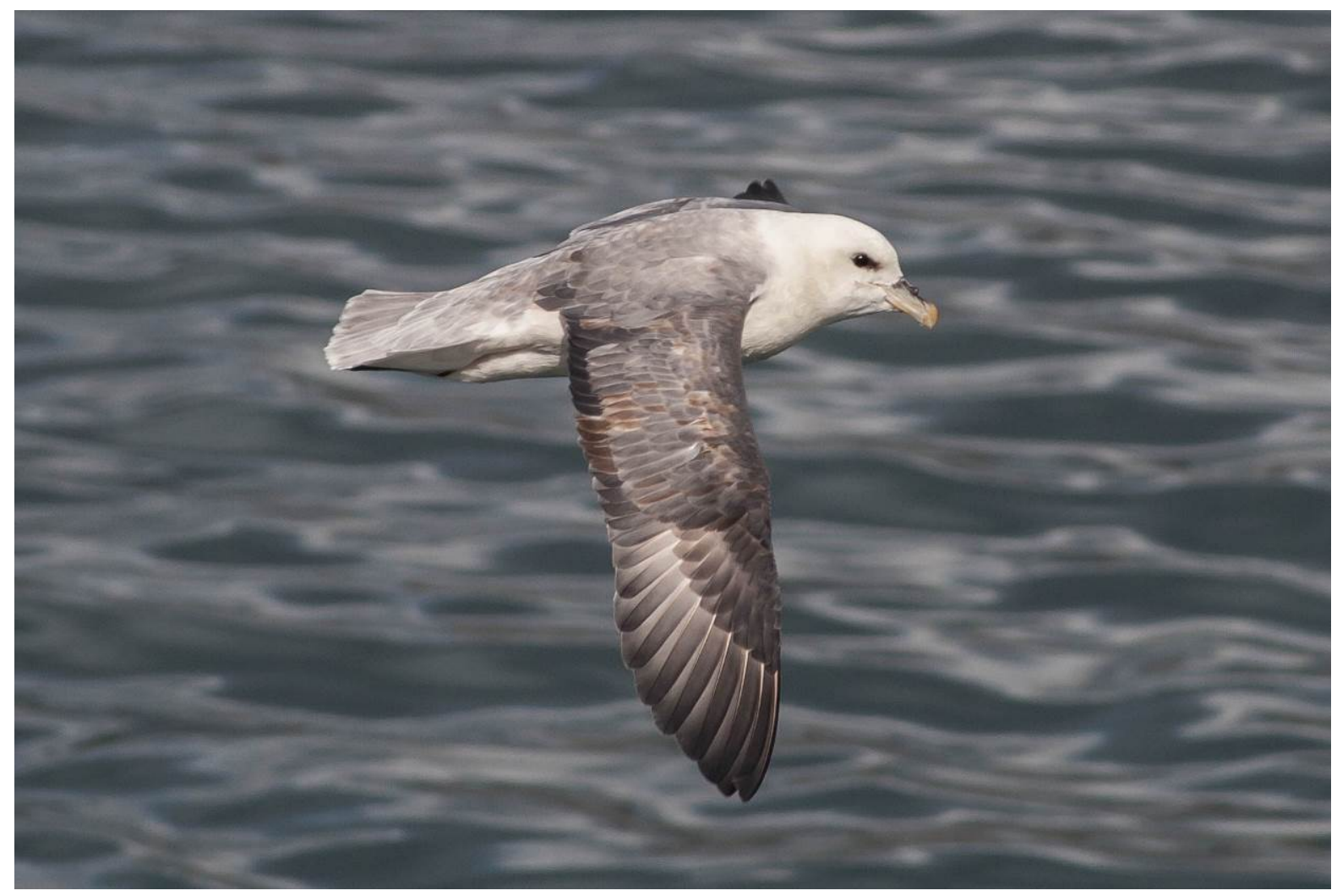

Photo Age of fulmars. The header of Tables $1 \mathrm{a}$ and $1 \mathrm{~b}$ provides the proportion of adult birds in the sample. In the background, age of birds in the samples is an important aspect of the fulmar monitoring program (see Fig. 4). Among our beached study birds, age is mostly assessed by condition of sex organs during the autopsies, but plumage characters can provide additional detail. For example, in their annual feather moult, fulmars rarely replace all their coverts. As a consequence, only first year juveniles have a fully uniform plumage whereas older birds almost always show a mix of fresh grey and worn browner feathers. In good light such characters can also be seen in birds at sea, as shown by the fulmar on the photo . 


\subsection{Current levels for the Netherlands (2012-2016)}

Because of occasional years of low sample size and incidental variability the 'current pollution level' in the monitoring system is considered on the basis of average stomach contents over the most recent 5 years. That period is also used in the OSPAR EcoQO target definition.

Current 5 year data for the 2012-2016 period (Table 1b) for the Dutch coast revealed that $91 \%$ in a sample of 169 beached fulmars had plastic debris in the stomach, in an average number of 22.3 particles and mass of 0.28 gram. The EcoQO threshold of 0.1 gram plastic is currently exceeded by $50 \%$ of the birds (Table 3B). Although still far off the long term OSPAR target, these 5-year data are the best on record throughout the history of fulmar monitoring in the Netherlands.

Table 1 Summary of sample characteristics and stomach contents of fulmars collected for Dutch marine litter monitoring in a) the year 2016 and b) the current 5-year period 20122016. The top line in each table shows sample composition in terms of age, sex, origin (by colour-phase; darker phases are of distant Arctic origin), death cause oil, and the average condition-index ( which ranges from emaciated condition $=0$ to very good condition $=9$ ). For each litter-(sub)category the table lists: Incidence, representing the proportion of birds with one or more items of the litter category present; average number of plastic items per bird stomach \pm standard error; average mass of plastic \pm standard error per bird stomach; and the maximum mass observed in a single stomach. The final column shows the geometric mean mass, which is calculated from In-transformed values as used in trend-analyses.

a) Year 2016

\begin{tabular}{|c|c|c|c|c|c|c|c|}
\hline & $\begin{array}{c}\text { The Netherlands } \\
2016 \\
\end{array}$ & $\begin{array}{c}\text { nr of birds } \\
30 \\
\end{array}$ & $\begin{array}{l}\text { adult } \\
19 \% \\
\end{array}$ & $\begin{array}{c}\text { LL colour } \\
87 \% \\
\end{array}$ & $\begin{array}{c}\text { death oil } \\
7 \% \\
\end{array}$ & $\begin{array}{c}\text { avg condition } \\
1.7 \\
\end{array}$ & \\
\hline & & incidence & $\begin{array}{c}\text { average number of items } \\
\text { (n/bird) } \pm \text { se }\end{array}$ & $\begin{array}{r}\text { average mas } \\
\text { (g/bird }\end{array}$ & $\begin{array}{l}\text { ass of litter } \\
\text { d) } \pm \text { se }\end{array}$ & $\begin{array}{r}\text { max. mass } \\
\text { recorded }\end{array}$ & $\begin{array}{c}\text { geometric mean } \\
\text { mass (g/bird) }\end{array}$ \\
\hline 1 & ALL PLASTICS & $87 \%$ & $31.5 \pm 13.376$ & 0.296 & \pm 0.104 & 3.0 & 0.0564 \\
\hline 1.1 & INDUSTRIAL PLASTIC & $47 \%$ & $2.1 \pm 0.686$ & 0.042 & \pm 0.015 & 0.4 & 0.0057 \\
\hline 1.2 & USER PLASTIC & $87 \%$ & $29.5 \pm 13.175$ & 0.254 & \pm 0.102 & 3.0 & 0.0479 \\
\hline 1.2 .2 & threads & $33 \%$ & $2.6 \pm 1.395$ & 0.008 & \pm 0.004 & 0.1 & 0.0012 \\
\hline 1.2 .3 & foamed & $37 \%$ & $1.4 \pm 0.546$ & 0.009 & \pm 0.006 & 0.2 & 0.0012 \\
\hline 1.2 .4 & fragments & $83 \%$ & $19.4 \pm 10.363$ & 0.121 & \pm 0.030 & 0.6 & 0.0294 \\
\hline 1.2 .5 & other plastic & $7 \%$ & $0.1 \pm 0.104$ & 0.024 & \pm 0.017 & 0.4 & 0.0005 \\
\hline 2 & OTHER RUBBISH & $30 \%$ & $3.3 \pm 2.663$ & 0.014 & \pm 0.006 & 0.2 & 0.0016 \\
\hline
\end{tabular}

b) 5-year period 2012-2016

\begin{tabular}{|c|c|c|c|c|c|c|c|}
\hline & $\begin{array}{c}\text { The Netherlands } \\
\text { 2012_16 }\end{array}$ & $\begin{array}{c}\text { nr of birds } \\
152 \\
\end{array}$ & $\begin{array}{l}\text { adult } \\
42 \% \\
\end{array}$ & $\begin{array}{c}\text { LL colour } \\
86 \% \\
\end{array}$ & $\begin{array}{c}\text { death oil } \\
1 \% \\
\end{array}$ & $\begin{array}{c}\text { avg condition } \\
1.7 \\
\end{array}$ & \\
\hline & & incidence & $\begin{array}{c}\text { average number of items } \\
\text { (n/bird) } \pm \text { se } \\
\end{array}$ & $\begin{array}{r}\text { average ma } \\
(\mathrm{g} / \mathrm{bird} \\
\end{array}$ & $\begin{array}{l}\text { ass of litter } \\
\text { d) } \pm \text { se }\end{array}$ & $\begin{array}{r}\text { max. mass } \\
\text { recorded }\end{array}$ & $\begin{array}{c}\text { geometric mean } \\
\text { mass (g/bird) }\end{array}$ \\
\hline 1.0 & ALL PLASTICS & $92 \%$ & $20.5 \pm 2.498$ & 0.283 & \pm 0.056 & 6.7 & 0.0712 \\
\hline 1.1 & INDUSTRIAL PLASTIC & $56 \%$ & $1.7 \pm 0.219$ & 0.038 & \pm 0.005 & 0.5 & 0.0077 \\
\hline 1.2 & USER PLASTIC & $91 \%$ & $18.8 \pm 2.397$ & 0.245 & \pm 0.055 & 6.6 & 0.0523 \\
\hline 1.2 .3 & foamed & $53 \%$ & $4.6 \pm 1.557$ & 0.032 & \pm 0.008 & 1.0 & 0.0034 \\
\hline 1.2 .4 & fragments & $85 \%$ & $9.8 \pm 1.162$ & 0.143 & \pm 0.039 & 5.5 & 0.0310 \\
\hline 1.2 .5 & other plastic & $18 \%$ & $0.2 \pm 0.053$ & 0.032 & \pm 0.021 & 3.1 & 0.0009 \\
\hline 2.0 & OTHER RUBBISH & $23 \%$ & $1.6 \pm 0.697$ & 0.095 & \pm 0.062 & 9.3 & 0.0012 \\
\hline
\end{tabular}


Table 2 Annual details for plastic abundance in fulmars from the Netherlands. For A. separate and B. combined plastic categories, incidence (\%) represents the proportion of birds with one or more items of that litter present; number $(n)$ abundance by average number of items per bird; and mass ( $\mathrm{g}$ ) abundance by average mass per bird in grams. Mass data for total plastics are also shown in terms of medians and geometric mean mass (for comparative purposes reducing the influence of outliers) and as level of performance in relation to the OSPAR ECOQO, viz. the percentage of birds having more than the threshold of 0.1 gram of plastic in the stomach. Note sample sizes $(n)$ to be very low for particular years implying low reliability of the annual averages for such years, not to be used as separate figures (only years with sample size over 10 birds are printed in bold).

Table 2A.

\section{Netherlands}

$\begin{array}{cc}\text { YEAR } & \text { sample } \\ n\end{array}$

1979

1980

1981

1982

1983

1984

1985

1986

1987

1988

1989

1990

1991

1992

1993

1994

1995

1996

1997

1998

1999

2000

2001

2002

2003

2004

2005

2006

2007

2008

2009

2010

2011

2012

2013

2014

2015

2016

0

0$$
2
$$

\begin{tabular}{ccc}
\hline \multicolumn{3}{c}{ Industrial granules } \\
\hline $\begin{array}{cc}\text { Inc. } \\
\%\end{array}$ & $\begin{array}{c}\text { avg number } \\
\mathrm{n} \pm \mathrm{se}\end{array}$ & $\begin{array}{c}\text { avg mass } \\
\mathrm{g} \pm \mathrm{se}\end{array}$ \\
\hline
\end{tabular}

$100 \%$

2.0

0.07

$$
100 \%
$$

$\mathbf{8 4 \%}$

$70 \%$

$100 \%$

$50 \%$

$\mathbf{8 2 \%}$

$0 \%$

$50 \%$

$0 \%$

0.0

$5.0 \pm 2$.
$8.8 \pm 2$.

$9.6 \pm 2.6$

$5.3 \pm 1.2$

$0.8 \pm 0.5$

$3.9 \pm 1.8$

0.0

$6.5 \pm 6.5$

$100 \%$

$75 \%$

$74 \%$

$69 \%$

$58 \%$

$61 \%$

$64 \%$

$68 \%$

$51 \%$

$54 \%$

$53 \%$

$78 \%$

$71 \%$

$65 \%$

$46 \%$

$58 \%$

$63 \%$

$59 \%$

$63 \%$

$75 \%$

$45 \%$

$47 \%$
$1.5 \pm 0.5$

$2.9 \pm 1.2$

$5.9 \pm 1.9$

$3.1 \pm 0.5$

$3.4 \pm 0.8$

$3.4 \pm 1.8$

$2.5 \pm 0.6$

$4.6 \pm 0.8$

$2.3 \pm 0.6$

$2.6 \pm 0.4$

$2.0 \pm 0.5$

$3.5 \pm 0.7$

$3.2 \pm 0.5$

$3.8 \pm 1.2$

$1.7 \pm 0.5$

$10.7 \pm 7.7$

$6.6 \pm 4.1$

$1.8 \pm 0.3$

$2.2 \pm 0.6$

$2.4 \pm 0.8$

$1.1 \pm 0.4$

$2.1 \pm 0.7$
$0.11 \pm 0.04$

$0.19 \pm 0.04$

$0.19 \pm 0.05$

$0.14 \pm 0.05$

$0.02 \pm 0.01$

$0.11 \pm 0.05$

0.00

$0.17 \pm 0.17$

0.00

$0.02 \pm 0.01$

$0.07 \pm 0.03$

$0.13 \pm 0.04$

$\mathbf{0 . 0 7} \pm \mathbf{0 . 0 1}$

$0.06 \pm 0.01$

$0.08 \pm 0.05$

$0.06 \pm 0.01$

$0.09 \pm 0.01$

$0.05 \pm 0.01$

$0.08 \pm 0.01$

$0.07 \pm 0.01$

$0.08 \pm 0.03$

$0.04 \pm 0.01$

$0.23 \pm 0.17$

$\mathbf{0 . 1 5} \pm \mathbf{0 . 1 0}$

$0.04 \pm 0.01$

$0.04 \pm 0.01$

$0.05 \pm 0.01$

$0.02 \pm 0.01$

$0.04 \pm 0.01$
$0.06 \pm 0.01$

$0.05 \pm 0.01$

\begin{tabular}{ccc}
\hline \multicolumn{3}{c}{ User plastics } \\
\hline $\begin{array}{ccc}\text { Inc. } & \text { avg number } & \text { avg mass } \\
\% & \mathrm{n} \pm \mathrm{se} & \mathrm{g} \pm \mathrm{se} \\
\end{array}$ \\
\hline
\end{tabular}

$100 \% \quad 3.0$

0.17

$\begin{array}{rll}67 \% & 6.0 \pm 3.2 & 0.50 \pm 0.33 \\ \mathbf{8 9 \%} & \mathbf{7 . 2} \pm \mathbf{1 . 8} & \mathbf{0 . 3 1} \pm \mathbf{0 . 1 2} \\ \mathbf{9 0 \%} & \mathbf{8 . 4} \pm \mathbf{3 . 1} & \mathbf{0 . 1 7} \pm \mathbf{0 . 0 9} \\ 100 \% & 5.0 \pm 2.5 & 0.14 \pm 0.08 \\ 75 \% & 4.8 \pm 1.7 & 0.06 \pm 0.04 \\ \mathbf{7 1 \%} & \mathbf{9 . 7} \pm \mathbf{2 . 7} & \mathbf{0 . 0 9} \pm \mathbf{0 . 0 4} \\ 100 \% & 2.0 & 0.04 \\ 100 \% & 6.0 \pm 3.0 & 0.25 \pm 0.23 \\ & & \\ 100 \% & 11.0 & 0.14\end{array}$

$100 \%$

$3.5 \pm 0.5$

$0.03 \pm 0.01$

$100 \%$

$24.5 \pm 13.7$

$0.19 \pm 0.10$

$\mathbf{9 7 \%}$

$29.8 \pm 6.8$

$0.60 \pm 0.17$

$\mathbf{9 5 \%}$

$25.9 \pm 5.2$

$0.88 \pm 0.35$

$\mathbf{9 7 \%}$

$31.8 \pm 5.7$

$0.38 \pm 0.11$

$100 \%$

$18.6 \pm 3.7$

$0.27 \pm 0.09$

$96 \%$

$20.1 \pm 3.8$

$0.18 \pm 0.05$

$96 \%$

$92 \%$

$47.2 \pm 11.9$

$0.41 \pm 0.19$

$91 \%$

$26.3 \pm 6.9$

$0.12 \pm 0.03$

$96 \%$

$93 \%$

$20.8 \pm 2.8$

$0.22 \pm 0.04$

$15.8 \pm 2.7$

$0.22 \pm 0.06$

$90 \%$

$30.4 \pm 7.2$

$0.23 \pm 0.07$

$\mathbf{9 5 \%}$

$32.3 \pm 5.5$

$0.30 \pm 0.04$

$96 \%$

$40.8 \pm 11.2$

$0.23 \pm 0.08$

$94 \%$

$17.6 \pm 3.2$

$0.18 \pm 0.03$

$95 \%$

$45.7 \pm 12.5$

$0.23 \pm 0.06$

$\mathbf{8 9} \%$

$37.0 \pm 10.4$

$0.27 \pm 0.09$

$92 \%$

$18.8 \pm 3.3$

$0.26 \pm 0.08$

$100 \%$

$24.6 \pm 7.9$

$0.14 \pm 0.03$

$91 \%$

$19.0 \pm 3.5$

$0.31 \pm 0.13$

$87 \%$

$0.24 \pm 0.15$

$29.5 \pm 13.2 \quad 0.25 \pm 0.10$ 
Table 2 B.

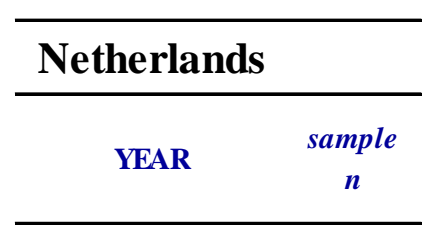

1979

1980

1981

1982

1983

1984

1985

1986

1987

1988

1989

1990

1991

1992

1993

1994

1995

1996

1997

1998

1999

2000

2001

2002

2003

2004

2005

2006

2007

2008

2009

2010

2011

2012

2013

2014

2015

2016

\begin{tabular}{cccccc}
\hline \multicolumn{4}{c}{ Total plastics } \\
\hline $\begin{array}{c}\text { Incidence } \\
\%\end{array}$ & $\begin{array}{c}\text { average number } \\
\mathrm{n} \pm \mathrm{se}\end{array}$ & $\begin{array}{c}\text { average } \\
\text { mass } \\
\mathrm{g} \pm \mathrm{se}\end{array}$ & $\begin{array}{c}\text { median } \\
\text { mass }\end{array}$ & $\begin{array}{c}\text { geometric } \\
\text { mean mass }\end{array}$ & $\begin{array}{c}\text { EcoQO } \% \\
\text { (over 0.1g) }\end{array}$ \\
\hline
\end{tabular}

$\begin{array}{lll}100 \% & 5.0 & 0.24\end{array}$

$\begin{array}{ccc}100 \% & 11.0 \pm 4.0 & 0.61 \pm 0.34 \\ \mathbf{1 0 0} \% & \mathbf{1 6 . 0} \pm \mathbf{2 . 5} & \mathbf{0 . 4 9} \pm \mathbf{0 . 1} \\ \mathbf{9 0 \%} & \mathbf{1 7 . 9} \pm \mathbf{5 . 5} & \mathbf{0 . 3 5} \pm \mathbf{0 . 1} \\ 100 \% & 10.3 \pm 1.5 & 0.28 \pm 0.07 \\ 75 \% & 5.5 \pm 1.8 & 0.08 \pm 0.05 \\ \mathbf{8 2} \% & \mathbf{1 3 . 6} \pm \mathbf{4 . 0} & \mathbf{0 . 1 9} \pm \mathbf{0 . 0} \\ 100 \% & 2.0 & 0.04 \\ 100 \% & 12.5 \pm 9.5 & 0.43 \pm 0.40 \\ & & \\ 100 \% & 11.0 & 0.14\end{array}$

$100 \%$

$$
5.0 \pm 1.0
$$

$0.06 \pm 0.02$

$100 \%$

$$
27.4 \pm 13.7
$$

$\mathbf{9 7 \%}$

$35.8 \pm 7.3$

$96 \%$

$29.0 \pm 5.3$

$98 \%$

$35.3 \pm 6.2$

$100 \%$

$22.0 \pm 5.2$

$96 \%$

$\mathbf{9 8 \%}$

$22.7 \pm 4.2$

$51.8 \pm 12.5$

$28.5 \pm 7.2$

$23.4 \pm 3.0$

$91 \%$

$23.4 \pm 3.0$

$98 \%$

$17.8 \pm 2.8$

$33.9 \pm 7.6$

$35.5 \pm 5.7$

$44.5 \pm 12.3$

$19.3 \pm 3.6$

$56.4 \pm 16.3$

$43.6 \pm 13.1$

$20.6 \pm 3.4$

$26.8 \pm 8.3$

$21.4 \pm 3.9$

$12.0 \pm 3.3$

$31.5 \pm 13.3$
$0.26 \pm 0.11$

$0.73 \pm 0.17$

$0.95 \pm 0.36$

$0.44 \pm 0.11$

$0.35 \pm 0.13$

$0.24 \pm 0.05$

$0.50 \pm 0.20$

$0.17 \pm 0.03$

$\mathbf{0 . 2 7} \pm \mathbf{0 . 0 4}$

$0.27 \pm 0.06$

$\mathbf{0 . 3 0} \pm \mathbf{0 . 0 8}$

$0.37 \pm 0.05$

$0.31 \pm 0.10$

$0.22 \pm 0.04$

$0.46 \pm 0.20$

$0.43 \pm 0.19$

$\mathbf{0 . 3 0} \pm \mathbf{0 . 0 9}$

$0.18 \pm 0.04$

$0.36 \pm 0.14$

$0.26 \pm 0.16$

$0.30 \pm 0.10$
0.302

0.160

0.284

0.073

$89 \%$

$55 \%$

0.112

0.056

$59 \%$

$\begin{array}{lll}0.325 & 0.298 & 84 \%\end{array}$

$0.187 \quad 0.168 \quad 72 \%$

$0.138 \quad 0.123 \quad 61 \%$

$0.094 \quad 0.088 \quad 49 \%$

$0.227 \quad 0.154 \quad 68 \%$

$0.135 \quad 0.068 \quad 54 \%$

$0.140 \quad 0.081 \quad 60 \%$

$0.094 \quad 0.089 \quad 47 \%$

$0.199 \quad 0.131 \quad 85 \%$

$0.274 \quad 0.131 \quad 71 \%$

$0.196 \quad 0.104 \quad 55 \%$

$0.075 \quad 0.084 \quad 46 \%$

$0.127 \quad 0.112 \quad 64 \%$

$0.214 \quad 0.183 \quad 79 \%$

$0.098 \quad 0.075 \quad 49 \%$

$0.083 \quad 0.067 \quad 46 \%$

$0.176 \quad 0.184 \quad 83 \%$

$0.061 \quad 0.058 \quad 36 \%$

$0.116 \quad 0.056 \quad 50 \%$
$0.160 \quad 0.129 \quad 61 \%$ 
Table 3 Running averages by 5-year period for plastic abundance in fulmars from the

Netherlands. For A. separate and B. combined plastic categories: incidence (\%) represents the proportion of birds with one or more items of that litter present; number $(n)$ abundance by average number of items per bird; and mass ( $\mathrm{g}$ ) abundance by average mass per bird in grams. Mass data for total plastics are also shown in terms of medians and geometric mean mass (for comparative purposes reducing the influence of outliers) and as level of performance in relation to the OSPAR ECOQO, viz. the percentage of birds having more than the $0.1 \mathrm{gram}$ threshold of plastic in the stomach. Results are not shown where sample size was 10 stomachs or less.

Table 3A.

\section{NETHERLANDS}

\begin{tabular}{cc}
\hline 5-year period & sample \\
& $n$ \\
\hline
\end{tabular}

1979-83 23

1980-84 42

1981-85 45

1982-86

1983-87

1984-88

1985-89

1986-90

1987-91

1988-92

1989-93

1990-94

1991-95

1992-96

1993-97

1994-98

1995-99

1996-00

1997-01

1998-02

1999-03

2000-04

2001-05

2002-06

2003-07

2004-08

2005-09

2006-10

2007-11

2008-12

2009-13

2010-14

2011-15

2012-16

23

42

49

49

63

45

27

24

21

4

3

1

3

10

41

115

115

222

258

305

330

295

319

332

304

310

291

228

213

205

224

228

172

158

169

\section{Industrial granules}

\begin{tabular}{ccc}
\hline $\begin{array}{c}\text { Inc. } \\
\%\end{array}$ & $\begin{array}{c}\text { avg number } \\
\mathrm{n} \pm \mathrm{se}\end{array}$ & $\begin{array}{c}\text { avg mass } \\
\mathrm{g} \pm \mathrm{se}\end{array}$ \\
\hline & & \\
$87 \%$ & $8.0 \pm 1.8$ & $0.17 \pm 0.04$ \\
$79 \%$ & $8.9 \pm 1.6$ & $0.18 \pm 0.03$ \\
$80 \%$ & $8.6 \pm 1.5$ & $0.18 \pm 0.03$ \\
$78 \%$ & $8.0 \pm 1.4$ & $0.17 \pm 0.03$ \\
$78 \%$ & $7.0 \pm 1.2$ & $0.15 \pm 0.02$ \\
$73 \%$ & $6.1 \pm 1.4$ & $0.14 \pm 0.03$ \\
$74 \%$ & $3.6 \pm 1.2$ & $0.10 \pm 0.03$ \\
$71 \%$ & $3.4 \pm 1.4$ & $0.09 \pm 0.04$ \\
$71 \%$ & $3.8 \pm 1.5$ & $0.10 \pm 0.04$
\end{tabular}

\section{User plastics}

\begin{tabular}{ccc}
\hline $\begin{array}{c}\text { Inc. } \\
\%\end{array}$ & $\begin{array}{c}\text { avg number } \\
\mathrm{n} \pm \mathrm{se}\end{array}$ & $\begin{array}{c}\text { avg mass } \\
\mathrm{g} \pm \mathrm{se}\end{array}$ \\
\hline & & \\
$87 \%$ & $6.9 \pm 1.5$ & $0.32 \pm 0.10$ \\
$88 \%$ & $7.7 \pm 1.7$ & $0.25 \pm 0.07$ \\
$89 \%$ & $7.5 \pm 1.6$ & $0.25 \pm 0.07$ \\
$88 \%$ & $7.3 \pm 1.4$ & $0.23 \pm 0.06$ \\
$84 \%$ & $8.0 \pm 1.3$ & $0.18 \pm 0.05$ \\
$82 \%$ & $8.2 \pm 1.7$ & $0.12 \pm 0.04$ \\
$78 \%$ & $7.9 \pm 1.8$ & $0.10 \pm 0.03$ \\
$75 \%$ & $8.3 \pm 2.0$ & $0.10 \pm 0.03$ \\
$76 \%$ & $9.0 \pm 2.3$ & $0.10 \pm 0.04$
\end{tabular}

$\begin{array}{llllll}76 \% & 5.1 \pm 1.5 & 0.12 \pm 0.03 & 98 \% & 27.5 \pm 5.8 & 0.49 \pm 0.13 \\ 71 \% & 3.8 \pm 0.6 & 0.09 \pm 0.01 & 96 \% & 26.5 \pm 3.9 & 0.74 \pm 0.23 \\ 65 \% & 3.6 \pm 0.5 & 0.07 \pm 0.01 & 96 \% & 29.1 \pm 3.4 & 0.57 \pm 0.13 \\ 64 \% & 3.6 \pm 0.5 & 0.08 \pm 0.01 & 97 \% & 27.7 \pm 3.0 & 0.53 \pm 0.11 \\ 64 \% & 3.4 \pm 0.4 & 0.07 \pm 0.01 & 97 \% & 26.4 \pm 2.6 & 0.47 \pm 0.10 \\ 63 \% & 3.4 \pm 0.4 & 0.07 \pm 0.01 & 97 \% & 29.6 \pm 3.1 & 0.45 \pm 0.09 \\ 60 \% & 3.3 \pm 0.4 & 0.07 \pm 0.01 & 97 \% & 30.1 \pm 3.3 & 0.30 \pm 0.06 \\ 59 \% & 3.0 \pm 0.3 & 0.06 \pm 0.01 & 94 \% & 25.7 \pm 2.7 & 0.24 \pm 0.04 \\ 58 \% & 2.8 \pm 0.3 & 0.06 \pm 0.01 & 94 \% & 25.0 \pm 2.6 & 0.23 \pm 0.04 \\ 58 \% & 2.9 \pm 0.3 & 0.06 \pm 0.01 & 93 \% & 26.4 \pm 2.8 & 0.24 \pm 0.04 \\ 59 \% & 2.7 \pm 0.2 & 0.06 \pm 0.01 & 92 \% & 23.8 \pm 2.0 & 0.22 \pm 0.02 \\ 60 \% & 2.8 \pm 0.3 & 0.06 \pm 0.01 & 92 \% & 24.7 \pm 2.1 & 0.24 \pm 0.02 \\ 60 \% & 2.6 \pm 0.3 & 0.06 \pm 0.01 & 94 \% & 24.7 \pm 2.3 & 0.23 \pm 0.02 \\ 61 \% & 4.1 \pm 1.3 & 0.09 \pm 0.03 & 93 \% & 30.4 \pm 3.2 & 0.23 \pm 0.02 \\ 59 \% & 4.4 \pm 1.4 & 0.10 \pm 0.03 & 94 \% & 31.0 \pm 3.3 & 0.24 \pm 0.02 \\ 56 \% & 3.8 \pm 1.3 & 0.08 \pm 0.03 & 93 \% & 26.2 \pm 2.9 & 0.23 \pm 0.04 \\ 56 \% & 3.6 \pm 1.3 & 0.08 \pm 0.03 & 93 \% & 24.8 \pm 2.8 & 0.22 \pm 0.03 \\ 61 \% & 4.3 \pm 1.7 & 0.10 \pm 0.04 & 92 \% & 27.3 \pm 3.5 & 0.24 \pm 0.04 \\ 59 \% & 2.4 \pm 0.5 & 0.05 \pm 0.01 & 91 \% & 20.8 \pm 2.5 & 0.24 \pm 0.05 \\ 57 \% & 1.8 \pm 0.2 & 0.04 \pm 0.01 & 90 \% & 20.5 \pm 3.1 & 0.24 \pm 0.05\end{array}$


Table 3 B.

\begin{tabular}{|c|c|c|c|c|c|c|c|}
\hline \multicolumn{2}{|c|}{ NETHERLANDS } & \multicolumn{6}{|c|}{ Total plastics } \\
\hline 5-year period & $\begin{array}{c}\text { sample } \\
n \\
\end{array}$ & $\begin{array}{c}\text { Incidence } \\
\% \\
\end{array}$ & $\begin{array}{c}\text { average number } \\
\mathrm{n} \pm \mathrm{se} \\
\end{array}$ & $\begin{array}{c}\text { arithmetic average } \\
\text { mass } \mathrm{g} \pm \mathrm{se}\end{array}$ & $\begin{array}{c}\text { median } \\
\text { mass }\end{array}$ & $\begin{array}{c}\text { geometric } \\
\text { mean mass } \\
\end{array}$ & $\begin{array}{c}\text { EcoQO \% } \\
\text { (over } 0.1 \mathrm{~g} \text { ) } \\
\end{array}$ \\
\hline 1979-83 & 23 & $100 \%$ & $14.9 \pm 2.2$ & $0.50 \pm 0.11$ & 0.302 & 0.298 & $91 \%$ \\
\hline $1980-84$ & 42 & $95 \%$ & $16.5 \pm 2.9$ & $0.43 \pm 0.09$ & 0.255 & 0.154 & $74 \%$ \\
\hline 1981-85 & 45 & $96 \%$ & $16.1 \pm 2.7$ & $0.42 \pm 0.08$ & 0.265 & 0.159 & $76 \%$ \\
\hline $1982-86$ & 49 & $94 \%$ & $15.3 \pm 2.5$ & $0.40 \pm 0.07$ & 0.220 & 0.137 & $71 \%$ \\
\hline 1983-87 & 63 & $90 \%$ & $15.0 \pm 2.2$ & $0.33 \pm 0.06$ & 0.161 & 0.102 & $67 \%$ \\
\hline 1984-88 & 45 & $87 \%$ & $14.3 \pm 2.9$ & $0.26 \pm 0.07$ & 0.127 & 0.064 & $56 \%$ \\
\hline 1985-89 & 27 & $85 \%$ & $11.5 \pm 2.6$ & $0.20 \pm 0.06$ & 0.112 & 0.063 & $56 \%$ \\
\hline $1986-90$ & 24 & $83 \%$ & $11.7 \pm 3.0$ & $0.19 \pm 0.07$ & 0.102 & 0.052 & $50 \%$ \\
\hline $1987-91$ & 21 & $86 \%$ & $12.8 \pm 3.3$ & $0.21 \pm 0.07$ & 0.112 & 0.063 & $57 \%$ \\
\hline 1988-92 & 4 & & & & & & \\
\hline 1989-93 & 3 & & & & & & \\
\hline 1990-94 & 1 & & & & & & \\
\hline 1991-95 & 3 & & & & & & \\
\hline $1992-96$ & 10 & & & & & & \\
\hline 1993-97 & 41 & $98 \%$ & $32.6 \pm 6.1$ & $0.61 \pm 0.13$ & 0.286 & 0.217 & $76 \%$ \\
\hline 1994-98 & 115 & $97 \%$ & $30.3 \pm 4.0$ & $0.83 \pm 0.23$ & 0.224 & 0.184 & $73 \%$ \\
\hline 1995-99 & 222 & $97 \%$ & $32.7 \pm 3.7$ & $0.64 \pm 0.13$ & 0.172 & 0.151 & $67 \%$ \\
\hline $1996-00$ & 258 & $98 \%$ & $31.3 \pm 3.2$ & $0.60 \pm 0.12$ & 0.175 & 0.149 & $67 \%$ \\
\hline 1997-01 & 305 & $97 \%$ & $29.9 \pm 2.8$ & $0.55 \pm 0.10$ & 0.155 & 0.137 & $64 \%$ \\
\hline 1998-02 & 330 & $98 \%$ & $33.0 \pm 3.3$ & $0.52 \pm 0.10$ & 0.151 & 0.130 & $62 \%$ \\
\hline 1999-03 & 295 & $98 \%$ & $33.5 \pm 3.6$ & $0.37 \pm 0.06$ & 0.141 & 0.112 & $59 \%$ \\
\hline 2000-04 & 319 & $95 \%$ & $28.7 \pm 2.9$ & $0.30 \pm 0.04$ & 0.141 & 0.095 & $59 \%$ \\
\hline 2001-05 & 332 & $95 \%$ & $27.8 \pm 2.7$ & $0.29 \pm 0.04$ & 0.134 & 0.091 & $57 \%$ \\
\hline 2002-06 & 304 & $94 \%$ & $29.3 \pm 3.0$ & $0.30 \pm 0.04$ & 0.142 & 0.094 & $61 \%$ \\
\hline 2003-07 & 310 & $93 \%$ & $26.5 \pm 2.1$ & $0.28 \pm 0.02$ & 0.150 & 0.092 & $62 \%$ \\
\hline 2004-08 & 291 & $93 \%$ & $27.4 \pm 2.2$ & $0.30 \pm 0.03$ & 0.164 & 0.097 & $62 \%$ \\
\hline 2005-09 & 228 & $95 \%$ & $27.3 \pm 2.5$ & $0.29 \pm 0.03$ & 0.139 & 0.103 & $58 \%$ \\
\hline 2006-10 & 213 & $94 \%$ & $34.5 \pm 3.8$ & $0.32 \pm 0.04$ & 0.150 & 0.108 & $62 \%$ \\
\hline 2007-11 & 205 & $95 \%$ & $35.4 \pm 4.0$ & $0.33 \pm 0.04$ & 0.149 & 0.111 & $60 \%$ \\
\hline 2008-12 & 224 & $94 \%$ & $30.0 \pm 3.6$ & $0.31 \pm 0.05$ & 0.116 & 0.092 & $54 \%$ \\
\hline 2009-13 & 228 & $94 \%$ & $28.4 \pm 3.4$ & $0.30 \pm 0.05$ & 0.109 & 0.088 & $53 \%$ \\
\hline 2010-14 & 172 & $93 \%$ & $31.5 \pm 4.3$ & $0.34 \pm 0.06$ & 0.129 & 0.094 & $58 \%$ \\
\hline 2011-15 & 158 & $93 \%$ & $23.1 \pm 2.8$ & $0.30 \pm 0.06$ & 0.118 & 0.085 & $53 \%$ \\
\hline 2012-16 & 169 & $91 \%$ & $22.3 \pm 3.2$ & $0.28 \pm 0.05$ & 0.099 & 0.072 & $50 \%$ \\
\hline
\end{tabular}



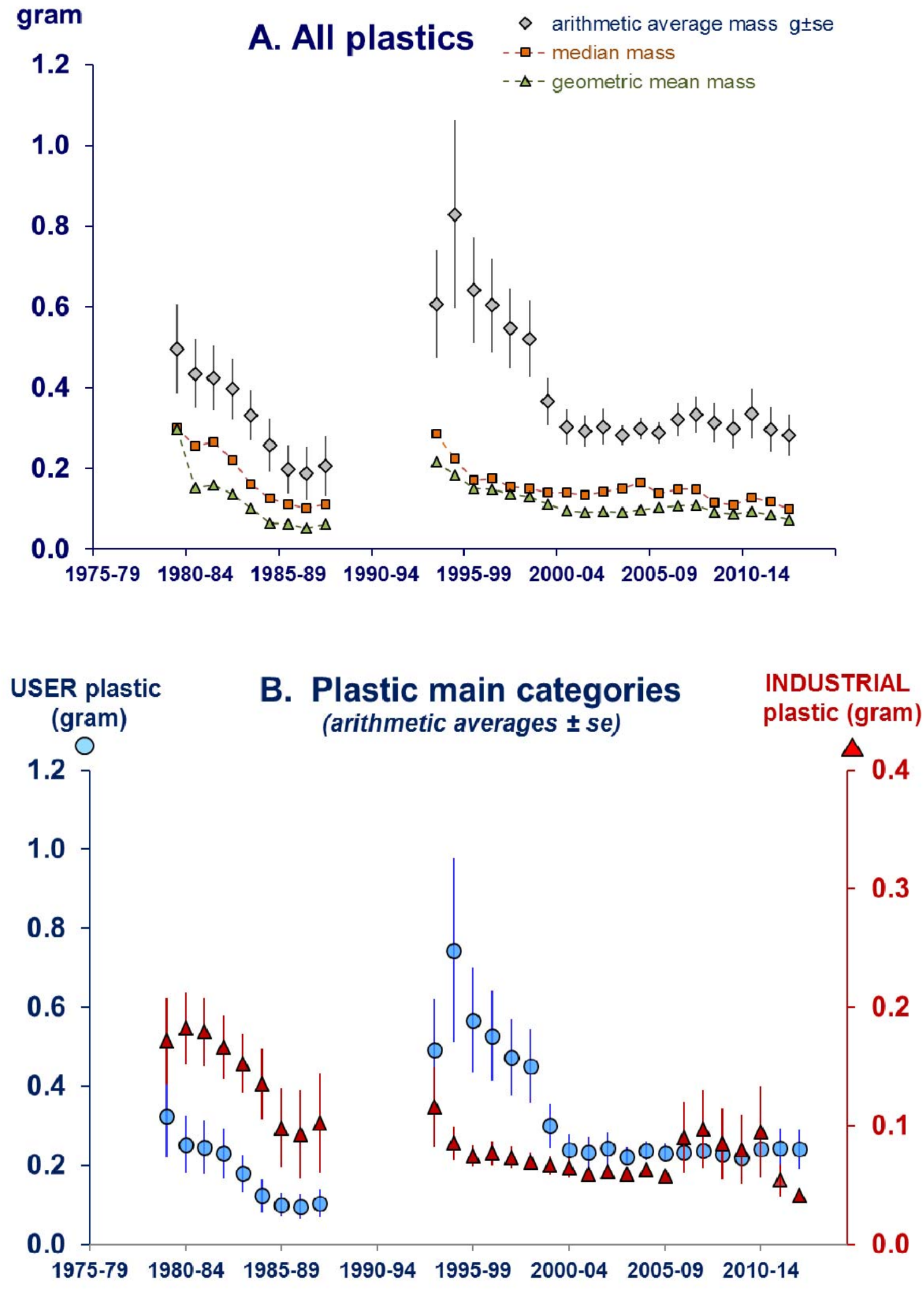

\section{5-year period}

Figure 2 Plastic mass in stomachs of fulmars from the Netherlands 1979-2016. A: Data for all plastics combined visualising changes in arithmetic average mass \pm se (grey diamonds) median mass (oranges squares) and geometric mean mass (green triangles); B: arithmetic mass data split into user plastic (blue circles, left y-axis) and industrial plastic (red triangles, right $y$-axis). Data are visualized as running 5 year averages (i.e. data points shift one year ahead at a time) and do not represent statistical trends. 


\subsection{Trends}

Trends focus on the mass of plastics in stomachs, rather than on incidence or number of plastic particles. In trend discussions, a distinction is made between:

\subsection{1 long-term trends}

The 'long-term trend' is defined as the trend over all years in the dataset (now 1979-2016). Long term trends are influenced by the fact that in initial years, trends for industrial and user plastics were opposite (Fig. 2B, Fig. 3A, Table 4A ). The industrial plastics halved from early 1980s to mid1990s while user plastics nearly tripled. Measured over the full period of over 30 years of data for the Netherlands, the initial strong decrease of industrial plastics still contributes strongly to the long term significant decline in industrial plastic $(p<0.001)$, in spite of the fact that since the early $2000 \mathrm{~s}$ changes have been much less evident (Table 2 ). The decrease in abundance of industrial plastics in the marine environment has been signalled in different oceanographic regions (Van Franeker $\&$ Meijboom 2002, Vlietstra \& Parga 2002, Ryan 2008, Van Franeker et al. 2011; Van Franeker \& Law 2015). For user plastics, the initial increase from the 1980s to mid-1990s was largely 'compensated' by a rapid decrease from late 1990s to around 2003, and relative small changes after that, resulting in absence of a significant overall long-term trend in mass of user plastics. However, due to the decrease in industrial plastic, the long-term trend for all plastics combined is a significant reduction $(p=0.006)$. Trends are similar in the different age groups, but due to smaller samples sizes do not reach the same significance level.

\subsubsection{Recent trends}

The 'recent trend' is defined as the trend over the past 10 years, so in this report: 2007-2016.

After the early 2000s, changes were not evident, and recent trends were generally described as stable or as potential slow non-significant decline. However, the previous analysis of the period 2006 to 2015 for the first time demonstrated significant 10 year declines in industrial plastics $(p=0.015)$ as well as user plastics $(p=0.047)$. Over the current period 2007-2016, the industrial plastic trend does not reach significance $(p=0.054)$ but trends for user plastics $(p=0.040)$ and total plastics $(p=0.040)$ are significant and confirm a recent trend of a slow, but significant reduction in quantities of ingested plastics. For separate age groups, due to reduced sample sizes, significance is not reached (Table 4.B), but from Fig. 4 it is evident that different agegroups contribute in a similar manner.

Trend analyses may be used to predict future developments in relation to e.g. policy relevant issues. For example, a question could be to provide an estimate where in future average mass of plastic would be expected to go below a specific level, or when the long term OSPAR EcoQO target might be reached. Preliminary models are currently explored and will be incorporated in future reporting. 
Details of linear regression analyses for time related trends in plastic abundance by mass in stomachs of fulmars in the Netherlands. Analysis by linear regression, fitting In-transformed litter mass values for individual birds on the year of collection. Tests were conducted over the full time period (Table $4 \mathrm{~A}$ ) and the most recent 10 years of data (Table 4B). The regression line ('trend') is described by $y=$ Constant + estimate* $x$ in which $y$ is the calculated value of the regression-line for year $x$. When the $t$-value of a regression is negative it indicates a decrease in the tested litter-category; a positive t-value indicates increase. A trend is considered significant when the probability $(p)$ of misjudgement of data is less than $5 \%(p<0.05)$. Significant trends in the table are labelled with positive signs in case of increase $(+)$ or negative signs in case of decrease $(-)$. Significance at the $5 \%$ level $(p<0.05)$ is labelled as - or + ; at the $1 \%$ level $(p<0.01)$ as -- or ++ ; and at the $0.1 \%$ level $(p<0.001)$ as --- or +++ . Where test results are not significant (n.s.) but close $(p<0.1)$, upward or downward arrow indicates the potential direction of change.

A.

LONG TERM TRENDS 1979-2016

for plastics in Fulmar stomachs, the Netherlands

\begin{tabular}{|c|c|c|c|c|c|c|}
\hline Industrial plastics (InGIND) & $n$ & constant & slope & s.e. & $\mathbf{t}$ & $\mathbf{p}$ \\
\hline all ages & 1064 & 88.0 & -0.0461 & 0.0092 & -4.99 & $<.001$ \\
\hline adults & 543 & 78.4 & -0.0414 & 0.0147 & -2.82 & 0.005 \\
\hline non adults & 496 & 100.4 & -0.0521 & 0.0119 & -4.37 & $<.001$ \\
\hline
\end{tabular}

\begin{tabular}{lcrrrrrr} 
User plastics (InGUSE) & $\boldsymbol{n}$ & constant & slope & s.e. & $\mathbf{t}$ & $\mathbf{p}$ & \\
\hline all ages & 1064 & -0.4 & -0.0011 & 0.0080 & -0.14 & 0.889 & n.s. \\
adults & 543 & 18.7 & -0.0108 & 0.0133 & -0.81 & 0.417 & n.s. \\
non adults & 496 & -10.8 & 0.0042 & 0.0100 & 0.42 & 0.672 & n.s.
\end{tabular}

\begin{tabular}{lcrrrrrr} 
All plastics combined (InGPLA) & $\boldsymbol{n}$ & constant & slope & s.e. & t & $\mathbf{p}$ & \\
\hline all ages & 1064 & 41.2 & -0.0217 & 0.0078 & -2.78 & 0.006 & $-\downarrow$ \\
adults & 543 & 40.6 & -0.0215 & 0.0131 & -1.64 & 0.101 & n.s. \\
non adults & 496 & 44.5 & -0.0232 & 0.0094 & -2.48 & 0.014 & $-\downarrow$
\end{tabular}

B.

RECENT 10-YEAR TRENDS 2007-2016

for plastics in Fulmar stomachs, the Netherlands

\begin{tabular}{lcrrrrrr} 
& Industrial plastics (InGIND) & $\boldsymbol{n}$ & Constant & estimate & s.e. & $\mathbf{t}$ & $\mathbf{p}$ \\
\hline all ages & 374 & 151.9 & -0.0778 & 0.0402 & -1.94 & 0.054 & n.s. $\downarrow$ \\
adults & 149 & 267.0 & -0.1354 & 0.0684 & -1.98 & 0.050 & n.s. $\downarrow$ \\
non adults & 208 & 131.0 & -0.0671 & 0.0515 & -1.30 & 0.194 & n.s.
\end{tabular}

\begin{tabular}{lcrrrrrr} 
User plastics (InGUSE) & $\boldsymbol{n}$ & Constant & estimate & s.e. & $\mathbf{t}$ & $\mathbf{p}$ & \\
\hline all ages & 374 & 144.6 & -0.0732 & 0.0355 & -2.06 & 0.040 & $-\downarrow$ \\
adults & 149 & 235.0 & -0.1182 & 0.0658 & -1.80 & 0.075 & n.s. $\downarrow$ \\
non adults & 208 & 138.4 & -0.0700 & 0.0423 & -1.65 & 0.100 & n.s.
\end{tabular}

\begin{tabular}{lcrrrrrr} 
All plastics combined (InGPLA) & $\boldsymbol{n}$ & Constant & estimate & s.e. & $\mathbf{t}$ & $\mathbf{p}$ & \\
\hline all ages & 374 & 144.1 & -0.0728 & 0.0353 & -2.07 & 0.040 & $-\downarrow$ \\
adults & 149 & 248.0 & -0.1246 & 0.0649 & -1.92 & 0.057 & n.s. $\downarrow$ \\
non adults & 208 & 126.2 & -0.0638 & 0.0421 & -1.52 & 0.131 & n.s. \\
\hline
\end{tabular}




\section{A. long term trends}

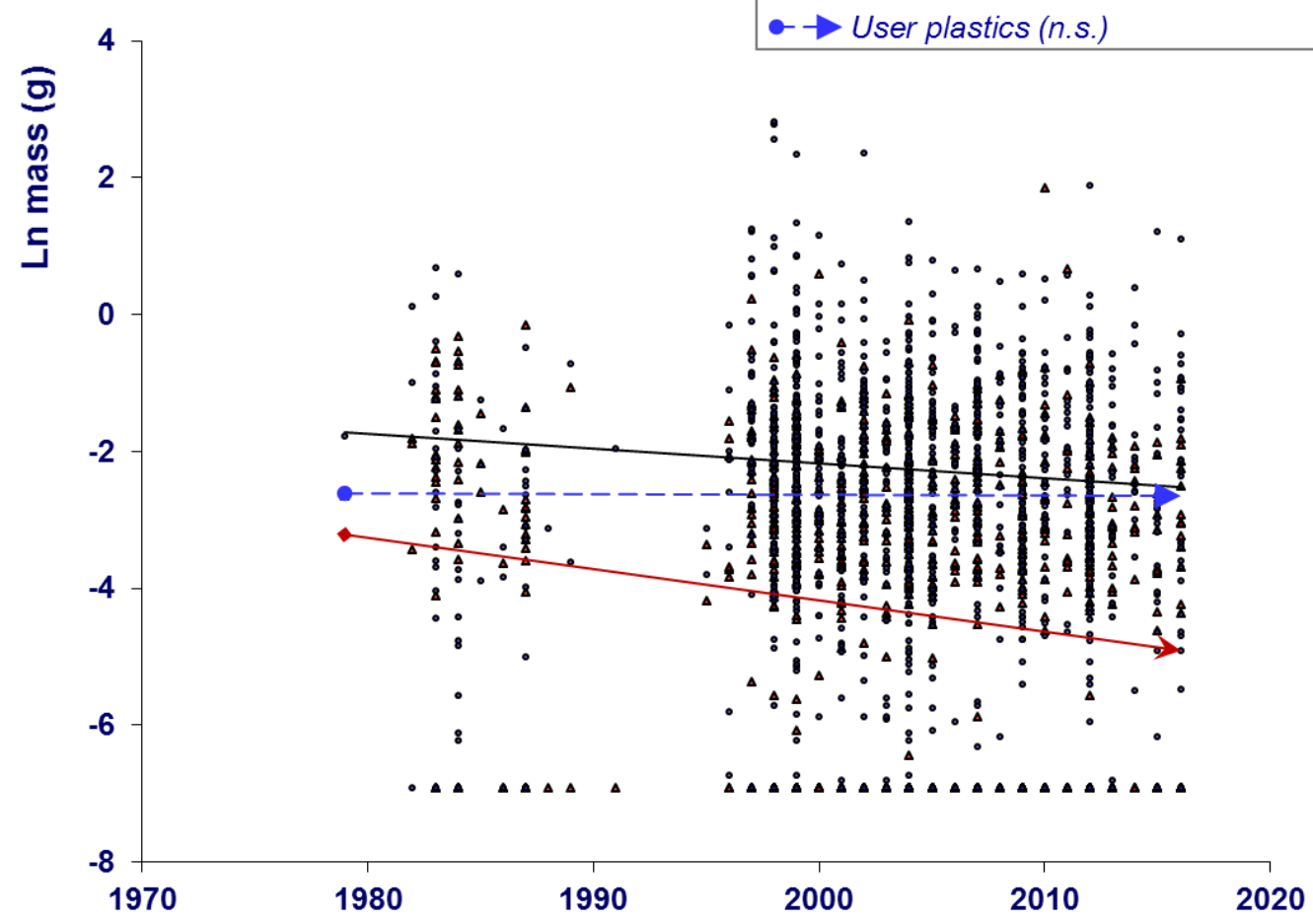

\section{B. recent (10 year) trends}

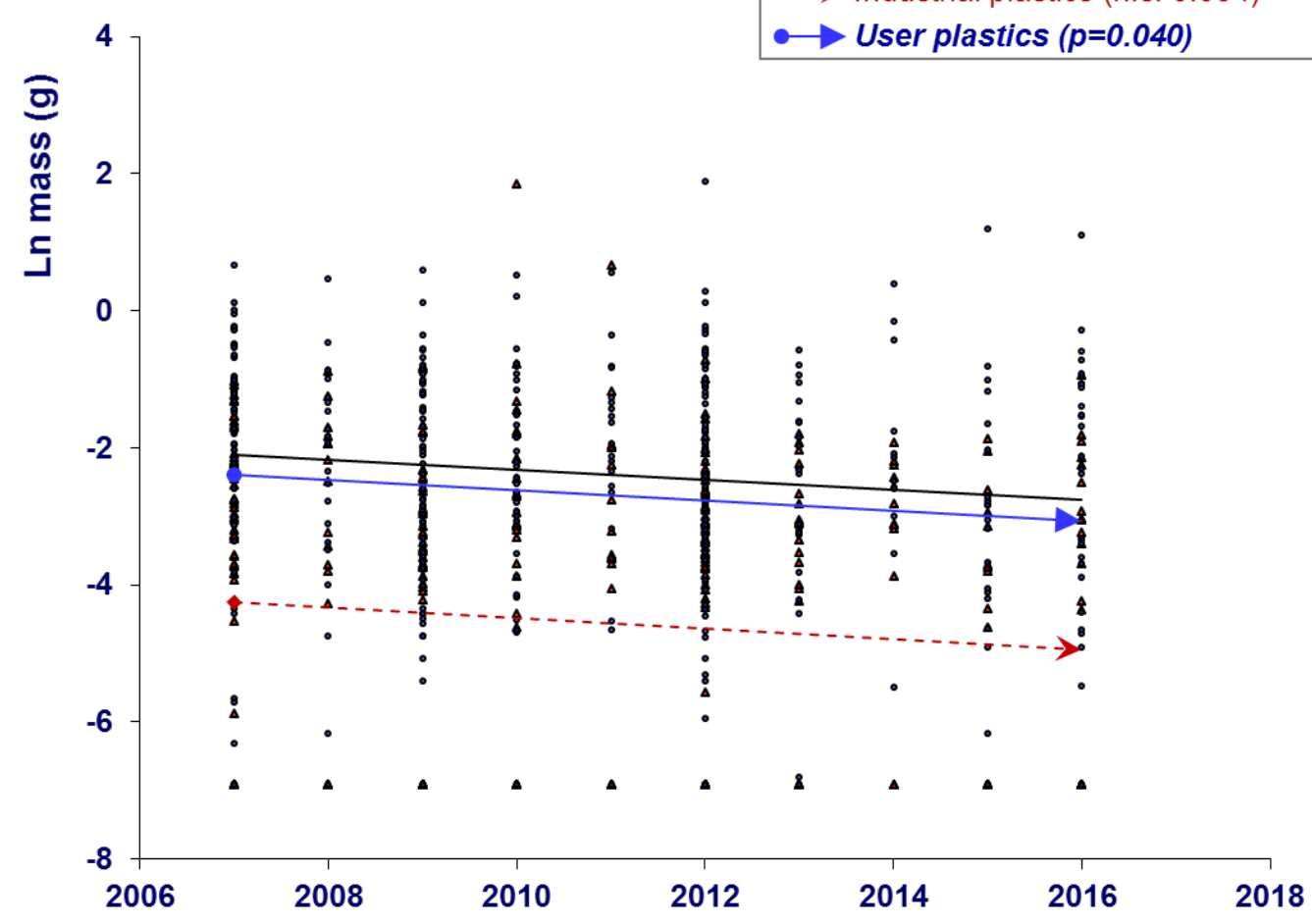

Figure 3 Statistical trends in plastic mass in stomachs of fulmars from the Netherlands 19792016. Graphs show plotted In-transformed mass data for industrial plastic and user plastic in stomachs of individual fulmars, plotted against year, and linear trendlines for industrial (lower, red line), user (middle blue line) and total plastics (top black line). Figure A shows long term trends and $B$ the recent trend over the past 10 years of data. Full details for results of statistical tests for trends are available in Table 4. n.s. means that the test result is not significant.

Significant test results indicated by solid trendline, non-significant results by a dashed line. 
Younger fulmars (the 'non-adult' category which includes both juveniles and immatures up to several years of age), have consistently higher levels of ingested plastics than adult birds. Nevertheless, in EcoQO monitoring, all age groups are combined on the assumption that in the long term, there will be no major directional change in the age-composition of beached birds. Fig. 4 illustrates age related variations in our monitoring data: in geometric means, the persistent difference in plastic loads between adults and non-adults is very clear: both age groups follow, at a different level, a very similar pattern, which strengthens the validity of the monitoring approach. The graph shows a drop over the three most recent running 5-year averages in both age groups. These changes are not yet evidenced in the statistical tests, but may suggest a change for the good.

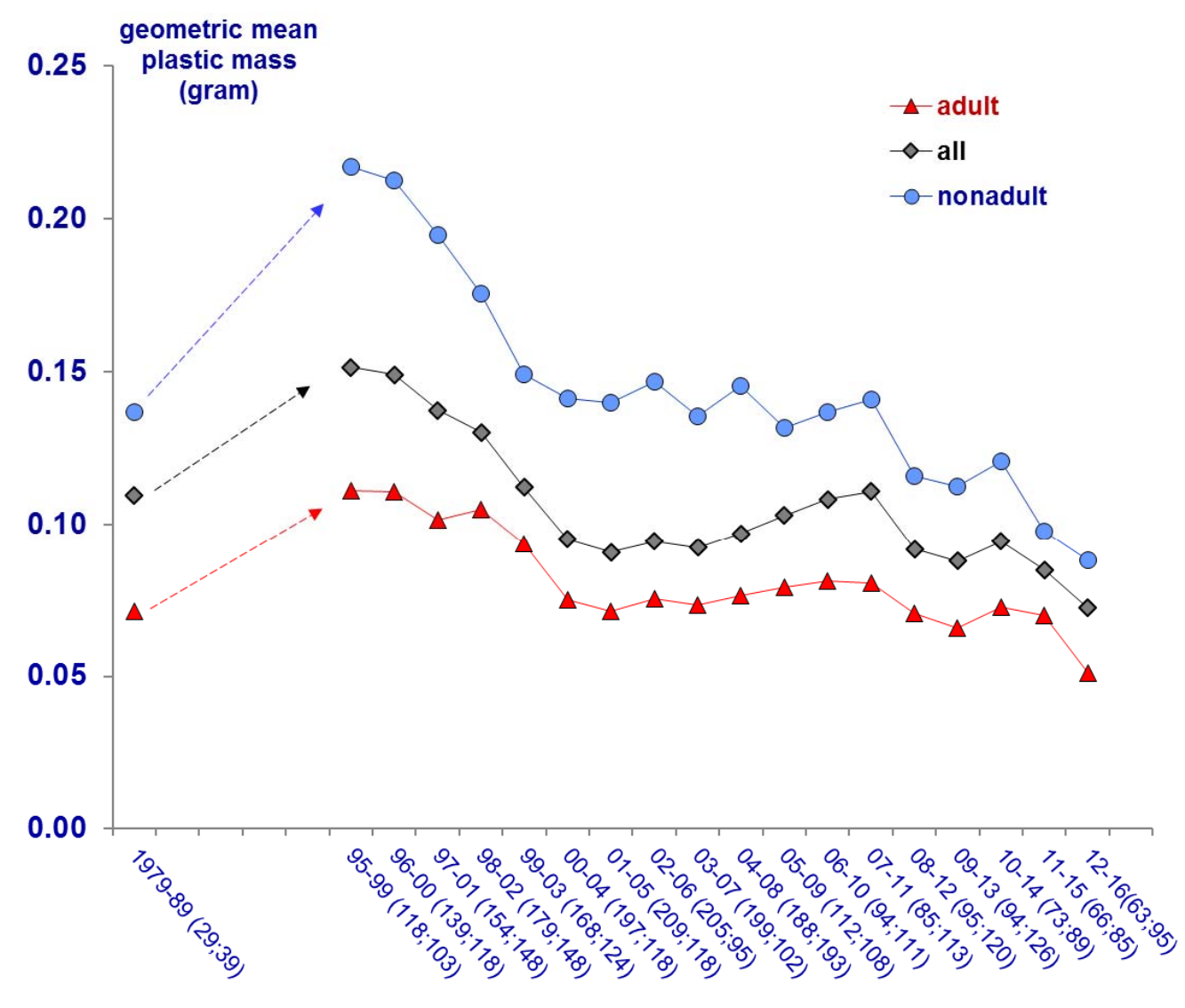

5-year period (sample size adult; non-adult)

Figure 4 Geometric mean mass of plastics in stomachs of beached fulmars from the Netherlands 1979-2016 for all age groups combined (grey diamonds; including birds of unknown age), adult birds (red triangles) and non-adults, with respective sample sizes in brackets in the $x$-axis labels. Data illustrate the trends and consistency in age-differences that allow usage of the all-age trend-line in the summary. This graphic visualization does not represent a statistical trend analysis.

\subsection{Dutch data in terms of the OSPAR EcoQO metric}

ICES working groups (e.g. ICES-WGSE 2001, 2003), followed by OSPAR (2008, 2009), have initiated the approach in which the ECOQO metric for marine litter is expressed in terms of a percentage of birds exceeding a critical value of plastic in the stomach. At first sight, one might argue that it would be easier to use an EcoQO definition based on for example only the average mass of plastics.

However, whether intentional or not, the 'percentage above critical value' definition represents a simplified procedure to avoid the mathematical problems caused by a few excessive stomach contents that distort comparative analyses. In the statistical testing procedures and calculations of geometric means, such problems are overcome by logarithmic transformation of data. And although this is a standard statistical procedure, it is not always easily conveyed to the general public, and differences between arithmetic averages versus geometric means can be confusing. The EcoQO metric avoids 
such problems by using classes of birds in which the exceptional stomach contents lose their influence. Currently, the target for acceptable ecological quality has been defined as the situation in which

“less than $10 \%$ of Northern Fulmars (Fulmarus glacialis) have more than 0.1 gram plastic particles in the stomach in samples of 50 to 100 beach-washed fulmars from each of 4 to 5 different areas of the North Sea over a period of at least 5 years".

In such a definition, an excessive stomach content of e.g. 10 gram of plastic does not change the metric compared to the situation in which that bird would have had for example only $0.2 \mathrm{~g}$ in its stomach. Using the same data as in earlier sections of this report, Fig. 5 shows the time trends in the 5-year average EcoQO performance of fulmars found in the Netherlands and emphasizes the distance from the 10\% EcoQO target set by OSPAR. Fairly rapid decreases in the proportion of birds exceeding the 0.1 gram level were seen during the 1980s, increased pollution by mid-1990s, followed by an initially clear decrease that however slowed down and became more erratic in the 21st century. Nevertheless, in the current data set 2007-2016, it can be shown there is a significant downward trend in plastic occurrence in fulmar stomachs: over the integrated recent 5-year period 2012-2016, $50 \%$ of Dutch fulmars exceed the 0.1 gram critical threshold EcoQO level.

\section{$\%$ birds with \\ $>0.1 \mathrm{~g}$ plastic}

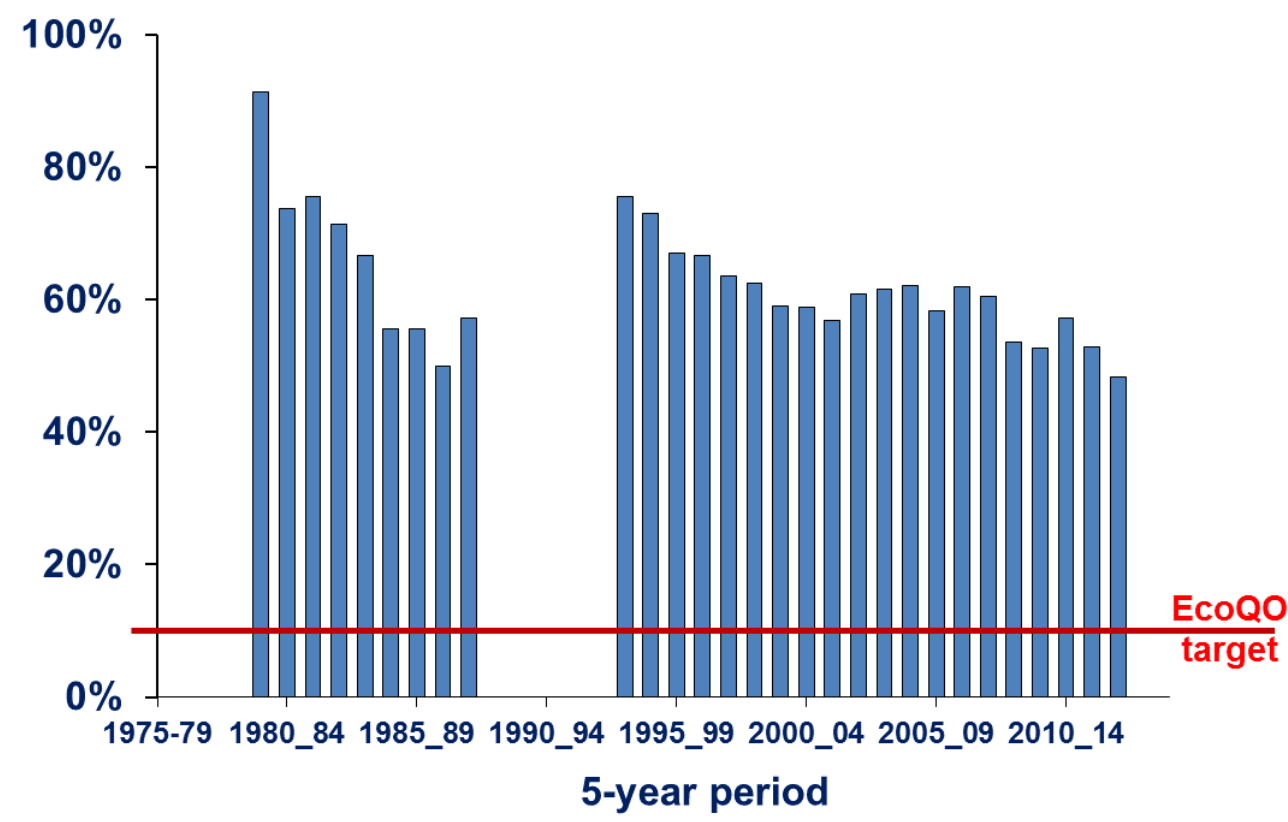

Figure 5 EcoQO performance of fulmars in the Netherlands over running 5-year periods up to 2016. The red line illustrates the OSPAR EcoQO target to reduce the percentage of birds with more than 0.1 gram of plastic in the stomach to below $10 \%$. This graphic visualization does not represent a statistical trend analysis.

\subsection{Concluding remarks}

It is difficult to pinpoint specific events that triggered the strong increase in consumer plastics and simultaneous decrease in industrial plastics from the 1980s to the 1990s, nor can we identify a clear background for the subsequent decrease in user debris. In earlier reports, no significant changes were observed in the fulmar monitoring approach since the early 2000s, at best weak patterns of reduction. But now, in the 2007-2016 analysis, for the second time in row, a gradual but statistically significant reduction of plastics in fulmar stomachs can be demonstrated. High media attention raised for the 'Pacific garbage patch' and 'plastic soup' started in the early 2000s. That likely has led to increased awareness, with associated policies and actions by authorities, industry and general public gradually taking effect.

As an example of a gradually changing sector, the shipping industry may be considered. A detailed study on Texel in the Netherlands in 2005 showed that most beached debris along the Dutch coast had its origin in or near the North Sea itself and was primarily linked to merchant shipping and 
fisheries: among plastic wastes, $57 \%$ of mass were fishing nets and ropes and the major part of the remainder consisted of jerrycans, fishboxes, and other large items clearly linked to sea based activities. Using various other details of beached items, sea based sources were considered to be responsible for about $90 \%$ of the mass coastal debris found on Texel. With regard to shipping as a source of debris, the implementation of the EU Directive 2000/59/EC on Port Reception Facilities since 2004 likely contributes to the gradual improvement. More recently, in 2013, international legislation for waste disposal by ships in MARPOL Annex $V$ was strongly improved. Participation of the fishing industry has boosted in the 'Fishing for Litter' initiative. The general public is strongly involved in beach clean-ups. Developments are underway for governmental implementation of the European Marine Strategy Directive (2008/56/EC) and its requirements towards Good Environmental Status. As already indicated in our earlier OSPAR EcoQO reports, the interpretation of results of fulmar EcoQO monitoring should take into account that activities in the marine environment and the proportion of plastic in consumer wastes have strongly increased. Fig. 6 illustrates trends in plastic production and shipping activity in comparison to the abundance of plastics in stomachs of fulmars. The various graph lines should not be viewed proportionally, but do indicate that slow improvement in EcoQO performance does not necessarily mean that policy measures like various MARPOL regulations and the EU Directive on Port Reception Facilities have had little effect.

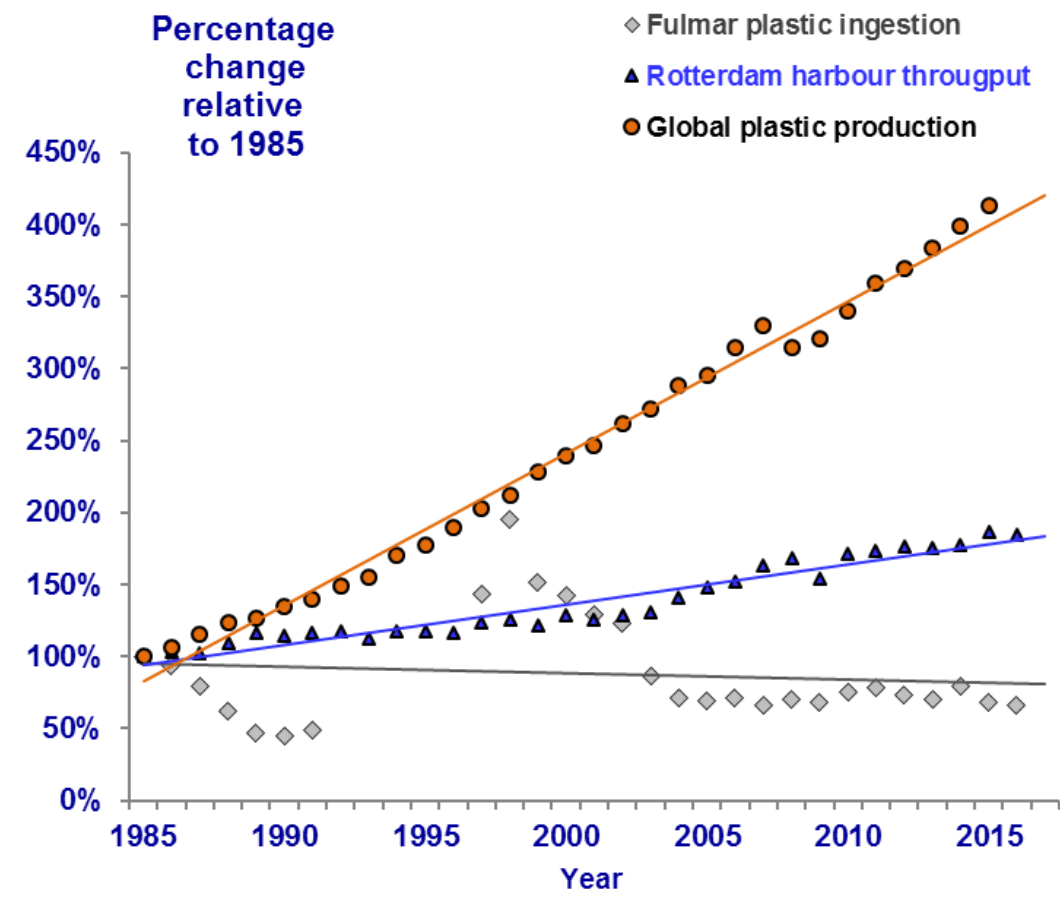

Figure 6 Comparative Trends in global plastic production, freight quantities handled by Port of Rotterdam, and mass quantities of industrial and user plastics in stomachs of fulmars (5-year arithmetic averages). Shown are cumulative percentage changes from reference year 1985. (Sources: Port of Rotterdam, 2017; PlasticsEurope 2016; this report)

\section{CONCLUSION}

Stomach contents of fulmars in the Netherlands demonstrate that the marine litter situation off the Dutch coast over the last decade is slowly but significantly improving. EcoQO performance, that is the proportion of fulmars exceeding a threshold value of $0.1 \mathrm{gram}$ of plastic in the stomach, is currently 50 . Although still far off the long term goal set by OSPAR, aiming at a reduction of this figure to below $10 \%$, the direction of change is positive. Clear-cut cause-effect relations are hard to show, but likely increased awareness and measures among public, stakeholders and authorities are gradually taking effect. 


\section{Acknowledgements}

Fulmar monitoring in the Netherlands is supported financially by the Netherlands Ministry of Infrastructure and the Environment (I\&M). The idea of an EcoQO based on the abundance of plastics in seabird stomachs was initiated by the ICES Working Group on Seabird Ecology and guided in several workgroups within ICES and OSPAR. The EU Interreg IIIB North Sea program supported the work in the 2002-2004 Save the North Sea project. The work has also been funded by the NYK Group Europe Ltd and Chevron Upstream Europe.

Mrs. S. Kühn is currently participating in this marine litter research as PhD in the JPI Oceans PLASTOX project 'Direct and indirect ecotoxicological impacts of microplastics on marine organisms' under ALWNOW project number 856.15.001.

Beached fulmars are mainly collected by volunteers without whom a project such as this is totally impossible. Below is a list of beach surveyors that contributed to the collection of beached fulmars. If people find that their name or group is listed incorrectly, or worse, not at all, our sincere apologies and please take up contact.

A van der Spoel, A Varkevisser, Albert van den Ende, Alma de Groot, André Meijboom, Annet de Willigen, Anthony James, Arnold Gronert, Barend Kuiken, Bart Ebbinge, Ben Brugge, Bert Winters, BJ Bulsink, Bob Loos, Boogaart, Bram Fey, Buijtelaar, Carl Zuhorn, C Boele, CJ de Graaf, CDI Lelystad, Cees Swennen, Cees van Hoven, Chris Braat, Chris Winter, Coby Kuiken, De Windbreker Petten, Dick Schermer, Dick Veenendaal, Dirk Bruin, Dirk Kuiken, Dirk Moerbeek, E-Connection, ECOMARE, Eddie Douwma, Edward Soldaat, Elisa Bravo Rebolledo, Ep van Hijum, Floor Arts DPM, Florian Müller, Folkert Janssens, Frank van den Ende, Frank Willems, Frits-Jan Maas, G. Fuchs, G.J . Bruin, Guido Keijl, Guus van Duin, H. de Groot, H. Horn, Hans Schekkerman, Hans Verdaat, Hauke Flores, Hein Verkade, Henk Brugge, Henk Mellema, Henk Sandee, Ilse Kootkar, Ingrid Tulp, Jacky Kuiper, J. Alewijn Dijkhuizen, J. Appeloo, J.T. Kuiken, J.W. Vergeer, Jaap Boersma, Jaap Hiele, Jack van Velzen, Jan den Ouden, Jan F. de Jong, Jan Goedbloed, Janne Ouwehand, Jannes Heusinkveld, J effrey Huizenga, Jelle van Dijk, Jeroen Reneerkens, J ob ten Horn, Johan Krol, K Post, K Boele, Kees Borrius, Kees Camphuysen, Kees de Graaf, Kees Kooiker, Kees Roselaar, Kees Woutersen, Klaas de J ong, Klaas van Dijk, LH Kuiken, Lars Gaedicke, Laurens Kikkert, Laurens van Kooten, Leon Kelder, M J anssen, Maarten Brugge, Maarten Platteeuw, Marc Kerkhove, Marc Plomp, Mardik Leopold, Maria Elisa Hobbelink, Mariëtte Smit, Mark Fonds, Mark van Veen, Martin Baptist, Martin de J ong, Martin Poot, Meinte Engelmoer, Nicole J aninhoff, Noordwester Vlieland, P Bison, Peter de Boer, Peter Meininger, Peter Quist, Peter Spannenburg, Peter van Horssen, Pierre Bonnet, Piet Zumkehr, Pieter Duin, Pieter van Klaveren, Pim Wolff, REP Maan, Rob Dekker, Rob Mantel, Rob Strietman, Rob van Bemmelen, Rob Vink, Roel Draijer, Romke Kats, Roy de Hey, Ruud Costers, Ruud van Halewijn, S. Smit, SC Kipp, Salko de Wolf, Saskia Kipp, SBB, Sharon Lexmond, Simon de Vries, Simon Hart, Sophie Brasseur, St. Damland Bergen, Susanne Kühn, T Pieters, Theo Kiewiet, Theunis Piersma, Tim van Nus, Tom van Spanje, Tonny van Kooten, van Eck, Vogelasiel Bergen, Vogelasiel de Groot, Vogelasiel Fugelpits, Vogelasiel Zandvoort, Vogelasiel De Wulp,

VogelRampenFonds Haarlem, VWG Steenloper, Wiebe Boomsma, Willem Pompert, Wim de Winter, Wouter Vahl, Y de Jong, Yvonne Hermes. 


\section{$7 \quad$ References}

Acampora, H., Lyashevska, O., Van Franeker, J.A. \& O'Connor, I. 2016. The use of beached bird surveys for marine plastic litter monitoring in Ireland. Marine Environmental Research 120: 122129. http://dx.doi.org/10.1016/i.marenvres.2016.08.002

Andrady, A.L. \& Neal, M.A. 2009. Applications and societal benefits of plastics. Philosophical Transactions of the Royal Society B 364: 1977-1984 (http://dx.doi.org/10.1098/rstb.2008.0304)

Arthur, C., Baker, J. \& Bamford, H. (Eds.) 2009. Proceedings of the International Research Workshop on the Occurrence, Effects and Fate of Microplastic Marine Debris. Sep 9-11, 2008. NOAA Technical Memorandum NOS-OR\&R-30. NOAA, Silver Spring 530pp. https://marinedebris.noaa.gov/file/2192/download?token $=5$ dvqb-YY

Avery-Gomm, S., O'Hara, P.D., Kleine, L., Bowes, V., Wilson, L.K. \& Barry, K.L. 2012. Northern fulmars as biological monitors of trends of plastic pollution in the eastern North Pacific. Marine Pollution Bulletin 64: 1776-1781. http://dx.doi.org/10.1016/j.marpolbul.2012.04.017

Baltz, D.M. \& Morejohn, G.V. 1976. Evidence from seabirds of plastic pollution off central California. Western Birds 7: 111-112. https://www. westernfieldornithologists.org/archive/V07/7(3)\% 20p0111p0112.pdf

Beaman, J., \& Bergeron, C. (Eds.) 2016. State of the Science White Paper - A Summary of Literature on the Chemical Toxicity of Plastics Pollution to Aquatic Life and Aquatic-Dependent Wildlife. EPA-822-R-16-009, United States Environmental Protection Agency, Washington DC, 50pp. https://www.epa.gov/sites/production/files/2017-02/documents/tfw-trash_free_waters_plasticsaquatic-life-report-2016-12.pdf

Bergmann, M., Gutow, L. \& Klages, M. (eds) 2015. Marine Anthropogenic Litter. Springer, Berlin, 447pp. http://link.springer.com/book/10.1007\%2F978-3-319-16510-3

Besseling, E., Foekema, E.M., Van den Heuvel-Greve, M.J., \& Koelmans, A.A. 2017. The effect of microplastic on the uptake of chemicals by the lugworm Arenicola marina (L.) under environmentally relevant exposure conditions. Environmental Science and Technology 51: 87958804 http://dx.doi.org/10.1021/acs.est.7b02286

Blight, L.K. \& Burger, A.E. 1997. Occurrence of plastic particles in seabirds from the eastern North Pacific. Marine Pollution Bulletin 34: 232-325. http://web.uvic.ca/ mamu/pdf/Blight\% 20\&\%20Burger\% 201997\%20plastic\% 20MPB.pdf

Bond, A.L., Provencher, J.F., Daoust, P.-Y. \& Lucas, Z.N. 2014. Plastic ingestion by fulmars and shearwaters at Sable Island, Nova Scotia, Canada. Marine Pollution Bulletin 87: 68-75 http://dx.doi.org/10.1016/i.marpolbul.2014.08.010

Booth, A.M., Hansen, B.H., Frenzel, M., Johnsen, H. \& Altin, D. 2016. Uptake and toxicity of methylmethacrylate-based nanoplastic particles in aquatic organisms. Environmental Toxicology and Chemistry 35: 1641-1649. http://dx.doi.org/10.1002/etc.3076

Bourne, W.R.P. 1976. Seabirds and Pollution. in: R. Johnston, (Ed.), Marine Pollution. Academic Press, London. pp 403-502.

Bravo Rebolledo, E.L., Van Franeker, J.A., Jansen, O.E. \& Brasseur, M.J.M. 2013. Plastic ingestion by harbour seals (Phoca vitulina) in The Netherlands. Marine Pollution Bulletin 67: 200-202. http://dx.doi.org/10.1016/j.marpolbul.2012.11.035

Browne, M.A., Sissanayake, A., Galloway, T.S., Lowe, D.M. \& Thompson, R.C. 2008. Ingested microscopic plastic translocates to the circulatory system of the Mussel, Mytilus edulis (L.) . Environmental Science and Technology 42: 5026-5031 http://dx.doi.org/10.1021/es800249a

Browne, M.A., Niven, S.J., Galloway, T.S., Rowland, S.J . \& Thompson, R.C. 2013. Microplastic moves pollutants and additives to worms, reducing functions linked to health and biodiversity. Current Biology 23: 2388-2392 http://dx.doi.org/10.1016/j.cub.2013.10.012

Browne, M.A., Underwood, A.J., Chapman, M.G., Williams, R., Thompson, R.C. \& Van Franeker, J.A. 2015. Linking effects of anthropogenic debris to ecological impacts. Proceedings Royal Society B 282: 20142929 (11pp). http://dx.doi.org/10.1098/rspb.2014.2929

Camphuysen C.J . 2017. Monitoring and assessment of the proportion of oiled Common Guillemots from beached bird surveys in The Netherlands: update winter 2015/16. NIOZ Report 2017-01, RWS Centrale Informatievoorziening BM 15.19, Nov 2015. Royal Netherlands Institute for Sea Research, Texel. 26pp. http://publicaties.minienm.nl/download-bijlage/87459/monitoring-andassessment-of-the-proportion-of-oiled-common-guillemots.pdf.

CBD 2016. Marine debris: understanding, preventing and mitigating the significant adverse impacts on marine and coastal biodiversity. Technical Series No.83. Secretariat of the Convention on Biological Diversity, Montreal, 78 pages. https://www.cbd.int/doc/publications/cbd-ts-83-en.pdf

Chua, E.M., Shimeta, J., Nugegoda, D., Morrison, P.D. \& Clarke, O.B. 2014. Assimilation of Polybrominated Diphenyl Ethers from Microplastics by the Marine Amphipod, Allorchestes compressa. Environmental Science and Technology 48(14): 8127-8134 http://dx.doi.org/10.1021/es405717z. 
Cole, M., Lindeque, P., Fileman, E., Halsband, C. \& Galloway, T.S. 2015. The impact of polystyrene microplastics on feeding, function and fecundity in the marine copepod Calanus helgolandicus. Environmental Science and Technology 49: 1130-1137 http://dx.doi.org/10.1021/es504525u.

Cózar, A., Martí, E., Duarte, C.M., García-de-Lomas, J., Van Sebille, E., Ballatore, T.J., Eguíluz, V.M., González-Gordillo, J.I., Pedrotti, M.L., Echevarría, F., Troublè, R., Irigoien, X. 2017. The Arctic Ocean as a dead end for floating plastics in the North Atlantic branch of the Thermohaline Circulation. Science Advances 3: e1600582 (8pp). http://dx.doi.org/10.1126/sciadv.1600582

Dagevos, J.J., Hougee, M., Van Franeker, J.A., Wenneker, B., Van Loon, W.M.G.M. \& Oosterbaan, L. 2013. OSPAR Beach Litter Monitoring in the Netherlands First annual report 2002-2012. Stichting de Noordzee Report BLM.afv-2310. Stichting de Noordzee, Utrecht, 36pp. https://www.noordzee.nl/project/userfiles/OSPAR_Beach_Litter_Monitoring_2013.pdf

Danielsen, J., Van Franeker, J.A., Olsen, B. \& Bengtson, S.-A. 2010. Preponderance of mesopelagic fish in the diet of the Northern Fulmar (Fulmarus glacialis) around the Faroe Islands. Seabird 23: 66-75. http://www. seabirdgroup.org.uk/journals/seabird-23/seabird-23-66.pdf

Day, R.H., Wehle, D.H.S., Coleman, F.C. 1985. Ingestion of plastic pollutants by marine birds. pp 344386 in: R.S. Shomura and H.O. Yoshida (Eds.), Proceedings of the workshop on the fate and impact of Marine debris, 26-29 November 1984, Honolulu, Hawaii. U.S. Dep. Commerce, NOAA Tech. Memo. NMFS, NOAA-TM-NMFS-SWFC-54. http://www.st.nmfs.noaa.gov/tm/swfc/swfc054.pdf

Derraik, J.G.B 2002. The pollution of the marine environment by plastic debris: a review. Marine Pollution Bulletin 44: 842-852. https://doi.org/10.1016/S0025-326X(02)00220-5

Donnelly-Greenan, E.L., Harvey, J.T., Nevins, H.M., Hester, M.M. \& Walker, W.A. 2014. Prey and plastic ingestion of Pacific Northern Fulmars (Fulmarus glacialis rogersii) from Monterey Bay, California. Marine Pollution Bulletin 85: 214-224. http://dx.doi.org/10.1016/i.marpolbul.2014.05.046.

EC 2000. Directive 2000/59/EC of the European Parliament and of the Council of 27 November 2000 on port reception facilities for ship-generated waste and cargo residues. Official J ournal of the European Communities L 332: 81-90 (28 Dec 2000). http://eurlex.europa.eu/resource. html?uri=cellar: $15945 \mathrm{efb}-\mathrm{a} 7 \mathrm{e} 8 \mathrm{-}-4840-\mathrm{ab} 4 \mathrm{~d}-$ 0535f12692a8.0004.02/DOC_1\&format=PDF

EC 2008. Directive 2008/56/EC of the European Parliament and of the Council of 17 J une 2008 establishing a framework for community action in the field of marine environmental policy (Marine Strategy Framework Directive). Official J ournal of the European Union L 164: 19-40 (25 J un 2008). http://eur-lex.europa.eu/legal-content/EN/TXT/PDF/?uri=CELEX:32008L0056\&from=EN

EC 2010. Commission Decision of 1 September 2010 on criteria and methodological standards on good environmental status of marine waters (notified under document C(2010) 5956) (Text with EEA Relevance) (2010/477/EU). Official J ournal of the European Union L232: 14-24. http://eurlex.europa.eu/legal-content/EN/TXT/PDF/?uri=CELEX:32010D0477(01)\&from=EN

Edwards, R. 2005. Litter at sea means a bellyful of plastic. New Scientist 185(2481): 11. http://www. lexisnexis.com. ezproxy. library. wur. nl/hottopics/Inacademic/?verb $=\mathrm{sr} \& \mathrm{csi}=158275 \& \mathrm{sr}=\mathrm{BYLI}$ NE(edwards) +AND+HLEAD(Litter+at+sea+means+a+bellyful+of+plastic) +AND+DATE+IS +2005

Endo, S., Takizawa, R., Okuda, K., Takada, H., Chiba, K., Kanehiro, H., Ogi, H., Yamashita, R. \& Date, T. 2005. Concentration of polychlorinated biphenyls (PCBs) in beached resin pellets: Variability among individual particles and regional differences. Marine Pollution Bulletin 50: 1103-1114. http://dx.doi.org/10.1016/i.marpolbul.2005.04.030

Endo, D., Yuyama, M., Takada, H. 2013. Desorption kinetics of hydrophobic organic contaminants from marine plastic pellets. Marine Pollution Bulletin 74: 125-131 http://dx.doi.org/10.1016/j.marpolbul.2013.07.018

Fischer, V., Elsner, N.O. Brenke, N., Schwabe, E., Brandt, A. 2015. Plastic pollution of the KurilKamchatka-trench area (NW Pacific). Deep-Sea Research II 111: 399-405. http://dx.doi.org/10.1016/i.dsr2.2014.08.012

Fleet, D.M 2003. Untersuchung der Verschmutzung der Spülsäume durch Schiffsmüll and der deutschen Nordseeküste. (UFOPLAN) FAZ 20296 183, im Auftrag des Umweltbundesamtes, Hochschule Bremen. 194pp.

Foekema, E.M., De Gruijter, C., Mergia, M.T., Van Franeker, J.A., Murk, T.J . \& Koelmans, A.A. 2013. Plastic in North Sea fish. Environmental Science \& Technology 47: 8818-8824. http://dx.doi.org/10.1021/es400931b

Furness, R.W. 1985. Plastic particle pollution: accumulation by Procellariiform seabirds at Scottish colonies. Marine Pollution Bulletin 16: 103-106. https://doi.org/10.1016/0025-326X(85)90531-4

Galgani, F., Fleet, D., Van Franeker, J., Katsanevakis, S., Maes, T., Mouat, J., Oosterbaan, L., Poitou, I., Hanke, G., Thompson, R., Amato, E., Birkun, A. \& Janssen, C. 2010. Marine Strategy Framework Directive - Task Group 10 Report Marine litter. J RC Scientific and Technical Reports (EUR collection), Publications Office of the European Union - EUR 24340 EN OPOCE LB-NA-24340EN-N, 57pp. http://dx.doi.org/10.2788/86941

Geyer, R., Jambeck, J.R., Law, K.L. 2017. Production, use, and fate of all plastics ever made.. Science Advances 3: e1700782 (5pp + suppl). https://doi.org/10.1126/sciadv.1700782

Gigault, J., Pedrono, B., Maxit, B., Ter Halle, A. 2016. Marine plastic litters: the unanalyzed nanofraction. Environmental Science: Nano 3: 346-350 http://dx.doi.org/10.1039/C6EN00008H . 
Gouin, T., Roche, N., Lohmann, R. \& Hodges, G. 2011. A thermodynamic approach for assessing the environmental exposure of chemicals absorbed to microplastic. Environmental Science \& Technology 45: 1466-1472. http://dx.doi.org/10.1021/es1032025

Guse, N., Fleet, D., van Franeker, J. \& Garthe, S. 2005. Der Eissturmvogel (Fulmarus glacialis)Mülleimer der Nordsee? Seevögel 26(2): 3-12.

Hall, K. 2000. Impacts of marine debris and oil: economic and social costs to coastal communities. KIMO, c/o Shetland Islands Council, Lerwick. 104pp.

Hatch, S.A. \& Nettleship, D.N. 1998. Northern Fulmar (Fulmarus glacialis). No. 361 (31 pp) in: A. Poole and F. Gill, (Eds.), The Birds of North America, Inc. Philadelphia, P.A.

Hauser, R., Skakkebaek, N.E., Hass, U., Toppari, J., Juul, A., Andersson, A. M., Kortenkamp, A., Heindel, J.J . \& Trasande, L. 2015. Male Reproductive Disorders, Diseases, and Costs of Exposure to Endocrine-Disrupting Chemicals in the European Union. J ournal of Clinical Endocrinology \& Metabolism 100: 1267-1277. http://dx.doi.org/10.1210/jc.2014-4325

Heindler, F.M., Alajmi, F., Huerlimann, R., Zeng, C., Newman, S.J., Vamvounis, G., Van Herwerden, L. 2017. Toxic effects of polyethylene terephthalate microparticles and $\mathrm{Di}(2$-ethylhexyl)phthalate on the calanoid copepod, Parvocalanus crassirostris. Ecotoxicology and Environmental Safety 141: 298-305. http://doi.org/10.1016/j.ecoenv.2017.03.029

Hermabessiere, L., Dehaut, A., Paul-Pont, I., Lacroix, C., Jezequel, R., Soudant, P. \& Duflos, G. 2017. Occurrence and effects of plastic additives on marine environments and organisms: A review. Chemosphere 182: 781-793. http://dx.doi.org/10.1016/j.chemosphere.2017.05.096

Hunt, P., Sathyanarayana, S., Fowler, P.A. \& Trasande, L. 2016. Female Reproductive Disorders, Diseases, and Costs of Exposure to Endocrine Disrupting Chemicals in the European Union. The J ournal of Clinical Endocrinology \& Metabolism 101:1562-1570. http://dx.doi.org/10.1210/jc.2015$\underline{2873}$

ICES-WGSE 2001. Report of the Working Group on Seabird Ecology. I ces Headquarters, 16-19 March 2001. ICES CM 2001/C:05. Copenhagen. 68pp http://www.ices.dk/sites/pub/CM\%20Doccuments/2001/C/C0501.pdf

ICES-WGSE 2003. Report of the Working Group on Seabird Ecology. I ces Headquarters, 7-10 March 2003. ICES CM 2003/C:03. Copenhagen. 89pp http://www.ices.dk/sites/pub/CM\%20Doccuments/2003/C/C0303.PDF

Jambeck, J.R., Geyer, R., Wilcox, C., Siegler, T.R., Perryman, M., Andrady, A., Narayan, R. \& Law, K.L. 2015. Plastic waste inputs from land into the ocean. Science 347(6223): 768-771. http://dx.doi.org/10.1126/science.1260352

Jahnke, A., Arp, H.P.H., Escher, B.I., Gewert, B., Gorokhova, E., Kühnel, D., Ogonowski, M., Potthoff, A., Rummel, C., Schmitt-Jansen, M., Toorman, E., MacLeod, M. 2017. Reducing Uncertainty and Confronting I gnorance about the Possible Impacts of Weathering Plastic in the Marine Environment. Environmental Science and Technology Letters 4: 85-90. http://dx.doi.org/10.1021/acs. estlett.7b00008

Kershaw, P., Katsuhiko, S., Lee, S., Samseth, J. \& Woodring, D. 2011. Plastic Debris in the Ocean. pp 20-33 in: UNEP Year Book 2011: Emerging issues in our global environment, United Nations Environment Programme, Nairobi. Published February 2011. http://www.unep.org/yearbook/2011

Koelmans, A.A., Besseling, E., Wegner, A. \& Foekema, E. M. 2013a. Plastic as a carrier of POPs to aquatic organisms: A model analysis. Environmental Science \& Technology 47: 7812-7820 http://dx.doi.org/10.1021/es401169n

Koelmans, A.A., Besseling, E., Wegner, A. \& Foekema, E.M. 2013b. Correction to Plastic As a Carrier of POPs to Aquatic Organisms: A Model Analysis. Environmental Science \& Technology 47: 89928993 http://pubs.acs.org/doi/pdf/10.1021/es403018h

Koelmans, A.A., Besseling, E. \& Foekema, E.M. 2014. Leaching of plastic additives to marine organisms. Environmental Pollution 187: 49-54 http://dx.doi.org/10.1016/i.envpol.2013.12.013

Koelmans, A.A., Besseling, E. \& Shim, W.J. 2015. Nanoplastics in the aquatic environment. Critical review. pp 325-340 Chpt.12 In: Bergmann, M., Gutow, L., and Klages, M. (eds). Marine Anthropogenic Litter. Springer, Berlin. http://link.springer.com/book/10.1007\%2F978-3-319-16510$\underline{3}$

Koelmans, A.A., Bakir, A., Burton, G.A. \& Janssen, C.R. 2016. Microplastic as a vector for chemicals in the aquatic environment: critical review and model-supported reinterpretation of empirical studies.. Environmental Science \& Technology 50: 3315-3326. http://dx.doi.org/10.1021/acs. est.5b06069

Kühn, S. \& Van Franeker, J.A. 2012. Plastic ingestion by the Northern Fulmar (Fulmarus glacialis) in I celand. Marine Pollution Bulletin 64: 1252-1254 http://dx.doi.org/10.1016/j.marpolbul.2012.02.027

Kühn, S., Bravo Rebolledo E.L. \& Van Franeker, J.A. 2015. Deleterious effects of litter on marine life. Pp 75-116 in: Bergmann, M., Gutow, L., and Klages, M. (Eds). Marine Anthropogenic Litter. Springer, Berlin (open access). http://dx.doi.org/10.1007/978-3-319-16510-3_4

Laist, D.W. 1987. Overview of the biological effects of lost and discarded plastic debris in the marine environment. Marine Pollution Bulletin 18(6B): 319-326. https://doi.org/10.1016/S0025326X(87)80019-X

Laist, D.W. 1997. Impacts of marine debris: entanglement of marine life in marine debris including a comprehensive list of species with entanglement and ingestion records. pp 99-140 in: Coe, J.M. and Rogers, D.B. (Eds.). Marine debris sources, impacts and solutions. Springer Series on 
Environmental Management. Springer Verlag, New York. 432pp.

http://plastics. earthmind.net/files/ART_Laist_1997.pdf

Law, K.L., Moret-Ferguson, S., Maximenko, N.A., Proskurowski, G., Peacock, E., Hafner, J. \& Reddy, C.M. 2010. Plastic Accumulation in the North Atlantic Subtropical Gyre. Science 329: 1185-1188. http://dx.doi.org/10.1126/science.1192321

Liu, L., Fokkink, R. \& Koelmans, A.A. 2016. Sorption of polycyclic aromatic hydrocarbons to polystyrene nanoplastic. Environmental Toxicology and Chemistry 35: 1650-1655. DOI: http://dx.doi.org/10.1002/etc.3311

Lozano, R.L. \& Mouat, J. 2009. Marine litter in the North-East Atlantic Region, Assessment and priorities for response. OSPAR/KIMO/UNEP. Biological Diversity and Ecosystems Nr 386. OSPAR, London, 127 pp. https://gsr2010.ospar.org/media/assessments/p00386_Marine_Litter_in_the_NorthEast_Atlantic_with_addendum.pdf

Mallory, M.L., Roberston, G.J. \& Moenting, A. 2006. Marine plastic debris in northern fulmars from Davis Strait, Nunavut, Canada. Marine Pollution Bulletin 52: 813-815. https://doi.org/10.1016/i.marpolbul.2006.04.005

Mallory, M.L. 2008. Marine plastic debris in northern fulmars from the Canadian High Arctic. Marine Pollution Bulletin 56: 1486-1512. https://doi.org/10.1016/i.marpolbul.2008.04.017

Matiddi, M., Hochsheid, S., Camedda, A., Baini, M., Cocumelli, C., Serena, F., Tomassetti, P., Travaglini, A., Marra, S., Campani, T., Scholl, F., Mancusi, M,, Amato, E., Briguglio, P., Maffucci, F., Fossi, M.C., Bentivegna, F. \& Andrea de Lucia, G. 2017. Loggerhead sea turtles (Caretta caretta): A target species for monitoring litter ingested by marine organisms in the Mediterranean Sea.. Environmental Pollution 230: 199-209. http://dx.doi.org/10.1016/j.envpol.2017.06.054

Maximenko, N., Hafner, J. \& Niiler, P. 2012. Pathways of marine debris derived from trajectories of Lagrangian drifters. Marine Pollution Bulletin 65: 51-62 http://dx.doi.org/10.1016/j.marpolbul.2011.04.016

MEPC 2011. Amendments to the Annex of the Protocol of 1978 relating to the International Convention for the Prevention of Pollution from Ships, 1973 (Revised MARPOL Annex V). RESOLUTION MEPC.201(62) IMO, London 12pp. http://www.imo.org/en/OurWork/Environment/PollutionPrevention/Garbage/Documents/2014\%20revisi on/RESOLUTION\% 20MEPC. 201(62)\% 20Revised\% 20MARPOL\%20Annex\% 20V.pdf

Moore, C.J. 2008. Synthetic polymers in the marine environment: a rapidly increasing, long-term threat. Environmental Research 108: 131-139. https://doi.org/10.1016/i.envres.2008.07.025

Moser, M.L. \& Lee, D.S. 1992. A fourteen-year survey of plastic ingestion by western North Atlantic seabirds. Colonial Waterbirds 15: 83-94. http://dx.doi.org/10.2307/1521357

Mouat, J., Lozano, R.L., Bateson, H. 2010. Economic impacts of marine litter. KIMO Report September 2010. KIMO, Shetland 105pp. https://www. noordzeeloket.nl/images/Economic\% 20impacts\%20of\%20marine\% 20litter 1290.pdf

MSFD-TSGML 2011. Marine Litter - Technical recommendations for the implementation of MSFD requirements. J oint Research Centre - Institute for Environment and Sustainability Report EU 25009 EN. Publications Office of the EU, Luxembourg, 91pp http://dx.doi.org/10.2788/91406

MSFD-TSGML 2013. Guidance on monitoring of marine litter in European Seas - a guidance document within the Common Implementation Strategy for the Marine Strategy Framework Directive. EUR26113 EN. J RC Scientific and Policy Reports JRC83985. 128pp http://dx.doi.org/10.2788/99475

Munari, C., Infantini, V., Scoponi, M., Rastelli, E., Corinaldesi, C. \& Mistri, M. 2017. Microplastics in the sediments of Terra Nova Bay (Ross Sea, Antarctica). Marine Pollution Bulletin xxx: xxx-xxx. http://dx.doi.org/10.1016/i.marpolbul.2017.06.039

Nevins, H., Donnelly, E., Hester, M. \& Hyrenbach, D. 2011. Evidence for Increasing Plastic Ingestion in Northern Fulmars (Fulmarus glacialis rodgersii) in the Pacific. Fifth International Marine Debris Conference, Honolulu Hawaii 20-25 Mar 2011. Oral Presentation Extended Abstracts 4.b.3. 140144.

Newman, S., Watkins, E., Farmer, A., Ten Brink, P. \& Schweitzer, J.-P. 2015. The economics of marine litter. pp 367-394 Chpt. 14 In: Bergmann, M., Gutow, L., and Klages, M. (Eds). Marine Anthropogenic Litter. Springer, Berlin, http://link.springer.com/book/10.1007\%2F978-3-319-16510$\underline{3}$

North Sea Ministerial Conference 2002. Bergen Declaration. Ministerial declaration of the Fifth International Conference on the Protection of the North Sea. Bergen, Norway, 20-21 March 2002. NSMC Secretariat, Bergen. 50pp. http://www.regjeringen.no/upload/kilde/md/rap/2002/0002/ddd/pdfv/156076-engelsk.pdf

Obbard, R.W., Sadri, S., Wong, Y.Q., Khitun, A.A., Baker, I. \& Thompson, R.C. 2014. Global warming releases microplastic legacy frozen in Arctic Sea ice.. Earth's Future 2:315-320. http://dx.doi.org/10.1002/2014EF000240

OECD-MTC (Organisation for Economic Co-operation and Development - Maritime Transport Committee) 2003. Cost savings stemming from non-compliance with international environmental regulations in the maritime sector. MEPC 49/I NF.7. 14 March 2003. 53pp.

Olsen, K. 2005. Havhesten - en flygende söppelbötte. Var Fuglefauna 28: 28-32.

OSPAR 2005. North Sea Pilot Project on Ecological Quality Objectives: Background Document on the Ecological Quality Objective on Oiled Guillemots. OSPAR Commission Biodiversity Series Publication Number: 2005/252, OSPAR, London 33pp. https://www.ospar.org/documents?d=7011 
OSPAR 2008. Background Document for the EcoQO on plastic particles in stomachs of seabirds. OSPAR Commission, Biodiversity Series. ISBN 978-1-905859-94-8 Publication Number: 355/2008. https://www. ospar.org/documents?v=7109

OSPAR 2009. EcoQO Handbook - Handbook for the application of Ecological Quality Objectives in the North Sea. Second Edition - 2009. OSPAR Biodiversity Series Publication 307/2009. OSPAR Commission London, 65pp. https://www.ospar.org/documents? $=7127$

OSPAR 2010a. Quality Status Report 2010. OSPAR Commission, London. 175pp. http://qsr2010.ospar.org/en/

OSPAR 2010b. The OSPAR system of Ecological Quality Objectives for the North Sea: a contribution to OSPAR's Quality Status Report 2010. OSPAR Publication 404/2009. OSPAR Commission London, en Rijkswaterstaat VenW, Rijswijk. 16pp. (Update 2010). https://qsr2010.ospar.org/media/assessments/EcoQO/EcoQO_P01-16_complete.pdf

OSPAR 2014. Marine Litter Regional Action Plan. London, 18p http://www.ospar.org/documents?v=34422

OSPAR 2015a. Guidelines for Monitoring of plastic particles in stomachs of fulmars in the North Sea area. OSPAR Commission Agreement 2015-03e (Source: EIHA 15/5/12 Add.1). 26pp. http://www. ospar.org/convention/agreements?q=fulmar.

OSPAR 2015b. Explanatory note for the data reporting format for the OSPAR common indicator on plastic particles in fulmars' stomachs. OSPAR Commission Agreement 2015-09ef 2pp. http://www. ospar.org/convention/agreements?q=fulmar.

OSPAR (2017) OSPAR Intermediate Assessment 2017. Plastic Particles in Fulmar Stomachs in the North Sea. OSPAR Assessment Portal OAP online document: https://oap.ospar.org/en/osparassessments/intermediate-assessment-2017/pressures-human-activities-v2/marine-litter/plasticparticles-fulmar-stomachs-north-sea/ Printable Abstract: https://oapcloudfront.ospar.org/media/filer_public/f4/34/f434a292-3fad-466c-9e89-c2ff09dc9e9d/fulmar.pdf

Peda, C., Caccamo, L., Fossi, M.C., Cai, F., Andaloro, F., Genovese, L., Perdichizzi, A., Romeo, T. \& Maricchiolo, G. 2016. Intestinal alterations in European sea bass Dicentrarchus labrax (Linnaeus, 1758) exposed to microplastics: Preliminary results. Environmental pollution 212: 251-256. http://dx.doi.org/10.1016/j.envpol.2016.01.083.

PlasticsEurope 2016. Plastics - the Facts 2016. An analysis of European plastics production, demand and waste data. PlasticsEurope Association of Plastics Manufacturers. Report. Brussels, 38pp. http://www.plasticseurope.org/cust/documentrequest.aspx?DoclD=67651

Port of Rotterdam 2017. Throughput Port of Rotterdam 2015 and 2016 (addition to time series). https://www. portofrotterdam.com/en/the-port/port-facts-and-figures/throughput

Provencher, J.F., Gaston, A.J . \& Mallory, M.L. 2009. Evidence for increased ingestion of plastics by northern fulmars (Fulmarus glacialis) in the Canadian Arctic. Marine Pollution Bulletin 58: 1092 1095. https://doi.org/10.1016/i.marpolbul.2009.04.002

Rakestraw, A. 2012. Open oceans and marine debris: solutions for the ineffective enforcement of MARPOL Annex V. Hastings International and Comparative Law Review 35:383-409. http://heinonline.org/HOL/LandingPage?handle=hein.journals/hasint35\&div $=17 \&$ id $=\& p a g e=$

Ribeiro, F., Garcia, A.R., Pereira, B.P., Fonseca, M., Mestre, M.C., Fonseca, T.G., Ilharco, L. M. \& J oão Bebianno, M.J. 2017. Microplastics effects in Scrobicularia plana. Marine Pollution Bulletin 122: 379-391. https://doi.org/10.1016/j.marpolbul.2017.06.078

Robards, M.D., Piatt, J.F. \& Wohl, K.D. 1995. Increasing frequency of plastic particles ingested by seabirds in the subarctic North Pacific. Marine Pollution Bulletin 30: 151-157.

Rochman, C.M., Hoh, E., Kurobe, T. \& Teh, S.J. 2013. Ingested plastic transfers hazardous chemicals to fish and induces hepatic stress. Scientific Reports 3, 3263. 7pp http://dx.doi.org/10.1038/srep03263.

Rochman, C.M., Kurobe, T., Flores, I. \& Teh, S.J. 2014a. Early warning signs of endocrine disruption in adult fish from the ingestion of polyethylene with and without sorbed chemical pollutants from the marine environment. Science of the Total Environment 493: 656-661 http://dx.doi.org/10.1016/i.scitotenv.2014.06.051.

Rochman, C.M., Lewison, R.L., Eriksen, M., Allen. H., Cook, A.-M. \& Teh, S.J. 2014b. Polybrominated diphenyl ethers (PBDEs) in fish tissue may be an indicator of plastic contamination in marine habitats. Science of The Total Environment, Volumes 476-477: 622-633 http://dx.doi.org/10.1016/j.scitotenv.2014.01.058

Rochman, C.M., Browne, M.A., Underwood, A.J., Van Franeker, J.A., Thompson, R.C. \& AmaralZettler, L. 2016. The ecological impacts of marine debris: unraveling the demonstrated evidence from what is perceived. Ecology 97: 302-312. http://www.esajournals.org/doi/pdf/10.1890/142070.1.

Ryan, P.G. 2008. Seabirds indicate changes in the composition of plastic litter in the Atlantic and south-western Indian Oceans. Marine Pollution Bulletin 56: 1406-1409. https://doi.org/10.1016/j. marpolbul.2008.05.004

Ryan, P.G., Moore, C.J., Van Franeker, J.A. \& Moloney, C.L. 2009. Monitoring the abundance of plastic debris in the marine environment. Philosophical Transactions of the Royal Society B 364: 19992012. http://dx. doi.org/10.1098/rstb.2008.0207. 
Save the North Sea 2004. Reduce marine litter: 'Save the North Sea' project results. Keep Sweden Tidy Foundation, Stockholm, 17pp. http://www.hsr.se/sites/default/files/content_media/save the north_sea_low.pdf

Schulz, M., Neumann, D., Fleet, D. \& Matthies, M. 2013. A multi-criteria evaluation system for marine litter pollution based on statistical analyses of OSPAR beach litter monitoring time series. Marine Environmental Research 92: 61-70 http://dx.doi.org/10.1016/j.marenvres.2013.08.013

Schulz, M. Van Loon, W, Fleet, D.M., Baggelaar, P. \& Van der Meulen, E. 2017. OSPAR standard method and software for statistical analysis of beach litter data. Marine Pollution Bulletin 122: 166-175. http://dx.doi.org/10.1016/j.marpolbul.2017.06.045

Stichting De Noordzee 2003. Coastwatch Onderzoek 2002. Stichting de Noordzee, Utrecht. 17pp + addenda. (http://www. coastwatch.nl/)

Tanaka, K., Takada, H., Yamashita, R., Mizukawa, K., Fukuwaka, M. \& Watanuki, Y. 2013. Accumulation of plastic- derived chemicals in tissues of seabirds ingesting marine plastics. Marine Pollution Bulletin 69: 219-222. http://dx.doi.org/10.1016/j.marpolbul.2012.12.010

Tekman, M.B., Krumpen, T. \& Bergmann, M 2017. Marine litter on deep Arctic seafloor continues to increase and spreads to the north at the HAUSGARTEN observatory.. Deep Sea Research Part I: 120: 88-99. http://doi.org/10.1016/j.dsr.2016.12.011

Terepocki, A.K., Brush, A.T., Kleine, L.U., Shugart, G.W. \& Hodum, P. 2017. Size and dynamics of microplastic in gastrointestinal tracts of Northern Fulmars (Fulmarus glacialis) and Sooty Shearwaters (Ardenna grisea). Marine Pollution Bulletin 116: 143-150. https://doi.org/10.1016/j. marpolbul.2016.12.064

Teuten, E.L., Rowland, S.J., Galloway, T.S. \& Thompson, R.C. 2007. Potential for Plastics to Transport Hydrophobic Contaminants. Environmental Science and Technology 41: 7759-7764 http://dx.doi.org/10.1021/es071737s

Teuten, E. L., Saquing, J.M., Knappe, D.R.U., Barlaz, M.A., Jonsson, S., Björn, A., Rowland, S.J., Thompson, R.C., Galloway, T.S., Yamashita, R., Ochi, D., Watanuki, Y., Moore, C., Viet, P.H., Tana, T.S., Prudente, M., Boonyatumanond, R., Zakaria, M.P., Akkhavong, K., Ogata, Y., Hirai, H., I wasa, S., Mizukawa, K., Hagino, U., Imamura, A., Saha, M. \& Takada, H. 2009. Transport and release of chemicals from plastics to the environment and to wildlife. Philosophical Transactions of the Royal Society B 364: 2027-2045 http://dx.doi.org/10.1098/rstb.2008.0284

Thompson, R.C., Moore, C.J., vom Saal, F.S. \& Swan, S.H. (Eds.) 2009. Plastics, the environment and human health. Philosophical Transactions of the Royal Society B 364 ( $\mathrm{nr} 1526$ Theme Issue) pages 1969-2166. http://rstb.royalsocietypublishing.org/content/364/1526

Thompson, R.C., Olsen, Y., Mitchell, R.P., Davis, A., Rowland, S.J., John, A.W.G., McGonigle. D. \& Russell, A.E. 2004. Lost at sea: Where is all the plastic?. Science 304 (5672): 838-838. http://dx.doi.org/10.1126/science.1094559

Trevail, A.M., Gabrielsen, G.W., Kühn, S. \& Van Franeker, J.A. 2015. Elevated levels of ingested plastic in a high Arctic seabird, the northern fulmar (Fulmarus glacialis). Polar Biology 38: 975981. (open access) http://dx.doi.org/10.1007/s00300-015-1657-4

Trouwborst, A. 2011. Managing marine litter: exploring the evolving role of international and European law in confronting a persistent environmental problem. Merkourios 27-73: 4-18. https://utrechtjournal.org/articles/abstract/10.5334/ujiel.an/

UNEP 2011. UNEP Year Book 2011: Emerging issues in our global environment. United Nations Environment Programme, Nairobi, 79pp. http://www.unep.org/yearbook/2011

UNEP 2016. Marine plastic debris and microplastics - Global lessons and research to inspire action and guide policy change. United Nations Environment Programme, Nairobi. 252pp. https://wedocs.unep.org/rest/bitstreams/11700/retrieve

Van Cauwenberghe, L. \& Janssen, C.R. 2014. Microplastics in bivalves cultured for human consumption. Environmental Pollution 193: 65-70 http://dx.doi.org/10.1016/j.envpol.2014.06.010

Van Franeker, J.A. 1985. Plastic ingestion in the North Atlantic Fulmar. Marine Pollution Bulletin 16: 367-369. https://doi.org/10.1016/0025-326X(85)90090-6

Van Franeker, J.A. \& Bell, P.J. 1988. Plastic ingestion by petrels breeding in Antarctica. Marine Pollution Bulletin 19: 672-674. https://doi.org/10.1016/0025-326X(88)90388-8

Van Franeker, J.A. \& Meijboom, A. 2002. Litter NSV - Marine litter monitoring by Northern Fulmars: a pilot study. ALTERRA-Rapport 401. Alterra, Wageningen, 72pp. http://edepot.wur.nl/45695

Van Franeker, J.A. \& Meijboom, A. 2003. Marine Litter Monitoring by Northern Fulmars: progress report 2002. ALTERRA-rapport 622. Alterra, Wageningen, $49 \mathrm{pp}$. http://library.wur.nl/WebQuery/wurpubs/fulltext/43713

Van Franeker, J.A. 2004a. The Fulmar-Litter-EcoQO in relation to EU Directive 2000/59/EC on Port Reception Facilities. Rapportage in opdracht van Directoraat Generaal Goederenvervoer, Ministerie van Verkeer en Waterstaat. Contract DGG-27020138. DGG-VenW, Den Haag. 47pp.

Van Franeker, J.A. 2004b. Save the North Sea - Fulmar Study Manual 1: Collection and dissection procedures. Alterra Rapport 672. Alterra, Wageningen. 38pp. http://edepot.wur.nl/40451

Van Franeker, J.A. 2004c. Fulmar wreck in the southern North Sea: preliminary findings. British Birds 97: 247-250. 
Van Franeker, J.A., Meijboom, A. \& De J ong, M.L. 2004. Marine litter monitoring by Northern Fulmars in the Netherlands 1982-2003. Alterra Rapport 1093. Alterra, Wageningen. 48pp. http://library.wur.nl/WebQuery/wurpubs/fulltext/39233

Van Franeker, J.A. 2005. Schoon strand Texel 2005: onderzoeksresultaten van de schoonmaakactie van het Texelse strand op 20 april 2005. Alterra speciale uitgave 2005/09. Alterra, Texel. 23pp. http://edepot.wur.nl/19515

Van Franeker, J.A., Heubeck, M., Fairclough, K., Turner, D.M., Grantham, M., Stienen, E.W.M., Guse, N., Pedersen, J., Olsen, K.O., Andersson, P.J. \& Olsen, B. 2005. 'Save the North Sea' Fulmar Study 2002-2004: a regional pilot project for the Fulmar-Litter-EcoQO in the OSPAR area. Alterra-rapport 1162. Alterra, Wageningen, 70pp. http://edepot.wur.nl/35175

Van Franeker, J.A. \& Meijboom, A. 2006. Fulmar Litter EcoQO Monitoring in the Netherlands 19822004 in relation to EU Directive 2000/59/EC on Port Reception Facilities. Report for the Ministry of Transport, Public Works and Water Management (VenW), contract nr DGTL/ZH/2.53.2.5012. Alterra, Texel. 41pp.

Van Franeker, J.A. \& Meijboom, A. 2007. Fulmar Litter EcoQO Monitoring in the Netherlands 19822005 in relation to EU Directive 2000/59/EC on Port Reception Facilities. Wageningen IMARES Report Nr C019-07. I MARES Texel, 40pp

Van Franeker, J.A. \& the SNS Fulmar Study Group 2008. Fulmar Litter EcoQO monitoring in the North Sea - results to 2006. IMARES Report nr C033/08. Wageningen IMARES, Texel. 53pp.

Van Franeker, J.A., Meijboom, A., De Jong, M. \& Verdaat, H. 2009. Fulmar Litter EcoQO Monitoring in the Netherlands 1979-2007 in relation to EU Directive 2000/59/EC on Port Reception Facilities. Wageningen IMARES Report nr C032/09. Wageningen IMARES, Texel. 39pp.

Van Franeker, J.A. 2009. Fulmar Litter EcoQO Monitoring in the Netherlands 1979-2008 in relation to EU Directive 2000/59/EC on Port Reception Facilities. Interim Report dd 15 Dec 2009, IMARES Wageningen UR, Texel..

Van Franeker, J.A. 2010. Fulmar Litter EcoQO Monitoring in the Netherlands 1979-2008 in relation to EU Directive 2000/59/EC on Port Reception Facilities. Wageningen IMARES Report nr C027/10. Wageningen IMARES, Texel. 40pp.

Van Franeker, J.A. \& the SNS Fulmar Study Group 2011. Fulmar Litter EcoQO monitoring along Dutch and North Sea coasts in relation to EU Directive 2000/59/EC on Port Reception Facilities: results to 2009. IMARES Report Nr C037/11. IMARES, Texel, 52pp +2app.

Van Franeker, J.A., Blaize, C., Danielsen, J., Fairclough, K., Gollan, J., Guse, N., Hansen, P.L., Heubeck, M., Jensen, J.-K., Le Guillou, G., Olsen, B., Olsen, K.O., Pedersen, J., Stienen, E.W.M. \& Turner, D.M. 2011. Monitoring plastic ingestion by the northern fulmar Fulmarus glacialis in the North Sea. Environmental Pollution 159: 2609-2615. http://dx.doi.org/10.1016/i.envpol.2011.06.008

Van Franeker, J.A. 2012. Plastic ingestion by fulmars at the Faroe Islands (Plastic i færoske mallemukkers fodeindtagelse). pp 82-85 in: Jensen, J.-K., Mallemukken på Færoerne / The Fulmar on the Faroe Islands. Prenta, Torshavn. http://www.wur.nl/upload_mm/e/9/f/c7466bbdd617-4a01-943f-f6e7dfa3c7ba_2012_Faroe.pdf

Van Franeker, J.A. \& the SNS Fulmar Study Group 2013. Fulmar Litter EcoQO monitoring along Dutch and North Sea coasts - Update 2010 and 2011. IMARES Report C076/13. IMARES, Texel. 61pp. http://edepot. wur.nl/258764

Van Franeker, J.A., Kühn, S., Bravo Rebolledo, E.L. \& Meijboom, A. 2014. Fulmar Litter EcoQO monitoring in the Netherlands - Update 2012 and 2013. IMARES Report C122/14. IMARES, Texel, 56pp. http://edepot.wur.nl/315514

Van Franeker, J.A. \& Law, K.L. 2015. Seabirds, gyres and global trends in plastic pollution. Environmental Pollution 203: 89-96. http://dx.doi.org/10.1016/i.envpol.2015.02.034

Van Franeker, J.A. 2015. Fulmar Litter EcoQO monitoring in the Netherlands - Update 2014. IMARES Report C123/15 . IMARES, Texel. 55 pp. http://edepot.wur. nl/365964

Van Franeker, J.A., Kühn, S. \& Bravo Rebolledo, E.L. 2016. Fulmar Litter EcoQO monitoring in the Netherlands - Update 2015. Wageningen Marine Research Report C091/16, RWS Centrale Informatievoorziening BM 16.12. Den Helder, 50pp. http://edepot.wur.nl/393794

Van Sebille, E., England, M.H. \& Froyland, G. 2012. Origin, dynamics and evolution of ocean garbage patches from observed surface drifters. Environmental Research Letters 7: 044040 (6pp) http://dx.doi.org/10.1088/1748-9326/7/4/044040.

Van Sebille, E., Wilcox, C., Lebreton, L., Maximenko, N., Hardesty, B.D., Van Franeker, J.A., Eriksen, M., Siegel, D., Galgani, F. \& Law, K.L. (2015). A global inventory of small floating plastic debris. Environmental Research Letters 10: 124006 (11pp). http://dx.doi.org/10.1088/17489326/10/12/124006

Veiga, J.M., Fleet, D., Kinsey, S., Nilsson, P., Vlachogianni, T., Werner, S., Galgani, F., Thompson, R.C., Dagevos, J., Gago, J., Sobral, P. \& Cronin, R. 2016. Identifying Sources of Marine Litter. MSFD GES TG Marine Litter Thematic Report. JRC Technical Report; EUR 28309. http://publications.jrc.ec. europa.eu/repository/bitstream/J RC104038/lb-na-28309-en-n.pdf

Venables, V.N. \& Ripley, B.D. 2002. Modern applied statistics with S, fourth ed. Springer, New York, 503pp. http://www. bagualu.net/wordpress/wpcontent/uploads/2015/10/Modern_Applied_Statistics_With_S.pdf 
Vlietstra, L.S. \& Parga, J.A. 2002. Long-term changes in the type, but not the amount, of ingested plastic particles in Shorlt-tailed Shearwaters in the southeastern Bering Sea. Marine Pollution Bulletin 44: 945-955. https://doi.org/10.1016/S0025-326X(02)00130-3

Watts, A.J.R.; Urbina, M.A.; Corr, S.; Lewis, C.; \& Galloway, T.S. 2015. Ingestion of plastic microfibers by the crab Carcinus maenas and its effect on food consumption and energy balance.. Environmental Science and Technology 49: 14597-14604. http://dx.doi.org/10.1021/acs. est.5b04026

Werner, S., Budziak, A., Van Franeker, J., Galgani, F., Maes, T., Matiddi, M., Nilsson, P., Oosterbaan, L., Priestland, E., Thompson, R., Veiga, J. \& Vlachogianni, T. 2016. Harm caused by marine litter. MSFD GES TG Marine Litter - Thematic Report.. J RC Technical Report EUR 28317, Publications Office of the European Union, Luxembourg, 89pp. http://dx.doi.org/10.2788/19937

\section{Relevant websites}

www.wur.eu/plastics-fulmars

www.zeevogelgroep.nl click on downloads - Fulmar-Litter-Study

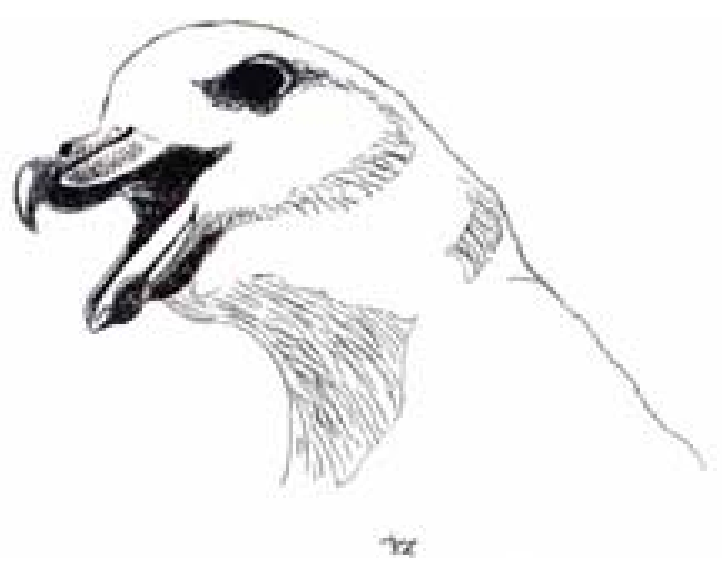




\title{
Quality Assurance
}

Wageningen Marine Research utilises an ISO 9001:2008 certified quality management system (certificate number: 187378-2015-AQ-NLD-RvA). This certificate is valid until 15 September 2018. The organisation has been certified since 27 February 2001. The certification was issued by DNV Certification B.V.

\section{Justification}

\author{
Report Wageningen Marine Research C053/17 \\ RWS Centrale Informatievoorziening BM 17.23 \\ Project number: \\ WMR project 4312100031 Fulmar-EcoQO-NL2015-19
}

The scientific quality of this report has been peer reviewed by a colleague scientist and a member of the Management Team of Wageningen Marine Research
Approved:
Dr. R.H. J ongbloed,
Senior Scientist Wageningen Marine Research
Signature:
Date:

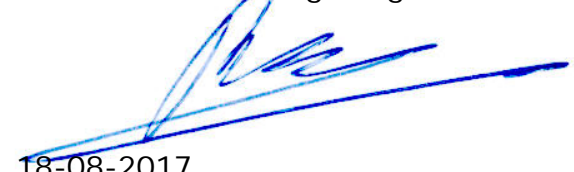

Approved

Dr. J. Asjes

Manager Integration

Signature:

Date: 
Wageningen Marine Research

T +31 (0)317 480900

E: marine-research@wur.nl www.wur.eu/marine-research

Visitors' address

- Ankerpark 271781 AG Den Helder

- Korringaweg 7, 4401 NT Yerseke

- Haringkade 1, 1976 CP IJ muiden
Wageningen Marine Research is the Netherlands research institute established to provide the scientific support that is essential for developing policies and innovation in respect of the marine environment, fishery activities, aquaculture and the maritime sector.

\section{Wageningen University \& Research:}

is specialised in the domain of healthy food and living environment.

\section{The Wageningen Marine Research vision}

'To explore the potential of marine nature to improve the quality of life'

\section{The Wageningen Marine Research mission}

- To conduct research with the aim of acquiring knowledge and offering advice on the sustainable management and use of marine and coastal areas.

- Wageningen Marine Research is an independent, leading scientific research institute

Wageningen Marine Research is part of the international knowledge organisation Wageningen UR (University \& Research centre). Within Wageningen UR, nine specialised research institutes of the Stichting Wageningen Research Foundation have joined forces with Wageningen University to help answer the most important questions in the domain of healthy food and living environment. 